\title{
Macroeconomic Effects of the 2017 Tax Reform
}

ABSTRACT We use a cost-of-capital framework to analyze the long-run steady state and transition path for GDP as a result of the 2017 tax law. We predict that, for the law as written, the long-run increase in corporate productivity will be 2.5 percent, which translates into a 0.4 percent increase in GDP after 10 years - or an increase in the growth rate of 0.04 percentage point per year. If the 2019 provisions of the law are made permanent, these numbers are 4.8 percent for long-run corporate productivity, 1.2 percent for GDP after 10 years, and 0.13 percentage point for the increase in the growth rate. We perform a sensitivity analysis, and conclude that if interest rates rose as a result of fiscal crowding out, the 10th-year GDP increases would be 0.2 percent and 1.0 percent for the two scenarios, respectively. We assess the short-run impact of the 2.3 percentage point reduction in average marginal tax rates for individuals under the law. Existing empirical evidence implies that this change would raise the annual GDP growth rate for $2018-19$ by 0.9 percentage point per year.

n December 2017, Congress enacted the most sweeping set of tax changes in a generation, lowering statutory tax rates for individuals and businesses and altering the tax base-in some cases to remove distortionary tax preferences and in some cases to create new ones. The law generated substantial debate on many issues, notably about its long-term impact

Conflict of Interest Disclosure: The authors did not receive financial support from any firm or person for this paper or from any firm or person with a financial or political interest in this paper. They are currently not officers, directors, or board members of any organization with an interest in this paper. No outside party had the right to review this paper before publication. 
on the capital-labor ratio, GDP per worker, real wages, and-in the transition to the new steady state- economic growth. One of us (Robert) joined a group of economists (Barro and others 2017) to argue that the corporate tax part of the tax reform would have substantially positive long-term effects in all these dimensions. The other (Jason) was a consistent critic of the law.

Broadly speaking, we agree that a simple neoclassical model of the economy can provide useful insights in assessing the macroeconomic consequences of the tax changes. This paper is an attempt to provide a more thorough analysis of the macroeconomic impact of the tax changes based on this model. In addition, we develop estimates of the short-run impact of the tax changes based on previous analyses of convergence toward longrun positions. The bulk of the paper reflects a joint analysis, but we also have different interpretations of the results and their implications for public policy—which we discuss in separate concluding sections.

This paper focuses on the macroeconomic impact of the tax changes. It does not directly address their welfare implications-for example, by allowing for changes in leisure or by working out the full dynamics of consumption and saving. Moreover, we do not address issues of the fairness of who should pay taxes or the impact of the tax legislation on the distribution of after-tax income. As such, this analysis is a contribution to a broader evaluation of the tax law but not a full evaluation itself. We each provide thoughts on these broader issues in our separate concluding sections.

The paper is organized as follows. Section I describes the tax changes passed by Congress in December 2017. Section II details the alternative scenarios about future tax policy that we analyze in the paper. The law itself is incomplete in two important respects. First, it contains a number of provisions that will expire or be phased out. Second, the government's intertemporal budget constraint will eventually need to be satisfied by future changes in government spending or revenues that were not specified in the legislation itself but would themselves have macroeconomic consequences. The first scenario we consider is the tax law that Congress passed, which includes phasing out expensing of equipment investment, phasing in of new and expanded offsets, and a sunset of most of the individual and pass-through provisions. We call this the "law-as-written" scenario. The second approach treats as permanent the features of the tax law that are scheduled to be in effect in 2019. This scenario treats as permanent the full expensing of equipment and research and development (R\&D) investment and the individual and pass-through provisions. It also ignores some delayed offsets in the law. We call this the "provisions-permanent" scenario. In both scenarios, we implicitly assume that any revenue losses due 
to the tax cuts will eventually be paid for through nondistortionary lump sum financing or cuts in government expenditures that have no substantial economic effects.

Section III is a neoclassical analysis of the long-run impact of the 2017 tax changes on the corporate and pass-through sectors. Our main approach involves calibrating effects on the user cost of capital. We then translate the changes in user costs into long-run effects on capital-labor ratios, levels of real GDP, and the real wage. This translation considers five types of capital-equipment, structures, residential rental property, $\mathrm{R} \& \mathrm{D}$ intellectual property, and other forms of intellectual propertyand uses reasonable parameter values within the context of a neoclassical model of production and investment. We analyze the law-as-written and provisions-permanent scenarios and compare them with a baseline of what the pre-2017 law would have implied in the long run. We show how the conclusions depend on assumptions about key parameters that enter into the neoclassical framework, and we evaluate hypothetical alternative tax reforms, including full expensing of all capital. Although this study has a long-run focus, we also project shorter-run growth effectsout to the 10-year horizon emphasized by Congress- based on estimated convergence rates toward long-run or steady-state positions.

Section IV discusses the impact of crowding out, and includes a sensitivity analysis of these effects. Section $\mathrm{V}$ provides a qualitative discussion of factors that are left out of the standard neoclassical analysis. These forces are hard to assess and are of varying signs. However, these effects may be important.

Section VI analyzes the effects of the reductions in individuals' average marginal income tax rates. We assess these effects using existing reducedform empirical studies of the effects of changes in marginal income tax rates. These regression-based estimates imply that these effects are important over a two-year horizon and, in fact, dwarf the estimated growth effects of the business tax changes during this period. However, the business tax changes analyzed in sections III and IV are what matter for longer-term growth projections.

Section VII provides brief comparisons with other estimates. The final section offers a conclusion and implications for future tax and fiscal policy, including the different perspectives of the two authors.

A summary of our main results for the corporate tax changes is given in table 1 . In the long run, the level of GDP rises by 0.9 percent under the lawas-written scenario and by 3.1 percent if all the provisions in effect in 2019 are made permanent. The economy gets about 40 percent of the way to this 
Table 1. Summary of Major Macroeconomic Effects of Business Tax Changes in the 2017 Tax Law

\begin{tabular}{lcc}
\hline Result & $\begin{array}{c}\text { Law as } \\
\text { written }\end{array}$ & $\begin{array}{c}\text { Provisions } \\
\text { permanent }\end{array}$ \\
\hline Long-run results & & \\
Corporate productivity (percent change) & 2.5 & 4.8 \\
Pass-through productivity (percent change) & -0.8 & 3.1 \\
GDP (percent change) & 0.9 & 3.1 \\
10-year results & & \\
GDP level (percent change) & 0.4 & 1.2 \\
Annual GDP growth rate (percentage point change) & 0.04 & 0.13 \\
Financing assumptions, 2018-27 & & \\
Cost assuming JCT scoring and our dynamic feedback & $\$ 1.2$ trillion & $\$ 1.7$ trillion \\
Annual lump sum cost per household & $\$ 900$ & $\$ 1,400$ \\
\hline
\end{tabular}

Source: Authors' calculations.

new long-run steady state after 10 years, which means that annual GDP growth would rise by between 0.04 percentage point and 0.13 percentage point in these two scenarios. The associated dynamic feedback would offset about $\$ 250$ billion of the cost of the tax cuts in the law-as-written case and about $\$ 450$ billion of the tax cuts in the provisions-permanent case. These estimates are predicated on the remainder of the tax cuts being fully paid for with nondistortionary financing, which would correspond to annual lump sum payments of about $\$ 900$ per household in the law-aswritten case and $\$ 1,400$ in the provisions-permanent case. Absent this, a sensitivity analysis shows that if interest rates increase by 14 and 20 basis points, respectively, in these two cases, then the increases in annual GDP growth would be reduced to 0.02 percentage point and 0.10 percentage point, respectively.

When we also factor in the changes for individual income taxes, we estimate that the tax law will add 0.9 to 1.1 percentage points to the GDP growth rate for 2018-19. These results are based on existing reduced-form regressions and focus on the effects of changes in average marginal income tax rates.

Overall, our views on the tax law's effects on economic growth do not completely converge, and there are three sources of differences. First, we have different expectations for future tax and spending policy. For example, the long-term macroeconomic impact of the tax changes is considerably more positive if it is assumed that the equipment expensing provisions that are set to be phased out after 2022 are made permanent and any resultant cost of the bill is paid for with lump sum taxes. Second, we have different 
Table 2. Individual Income Tax Brackets for Married Individuals Filing Jointly, 2018

\begin{tabular}{lcllc}
\hline \multicolumn{2}{c}{ Before 2017 tax law } & & \multicolumn{2}{c}{ After 2017 tax law } \\
\cline { 1 - 2 } \cline { 5 - 5 } Taxable income & Marginal tax rate & & Taxable income & Marginal tax rate \\
\hline$\$ 0$ to $\$ 19,050$ & $10 \%$ & & $\$ 0$ to $\$ 19,050$ & $10 \%$ \\
$\$ 19,050$ to $\$ 77,400$ & $15 \%$ & & $\$ 19,050$ to $\$ 77,400$ & $12 \%$ \\
$\$ 77,400$ to $\$ 156,150$ & $25 \%$ & & $\$ 77,400$ to $\$ 165,000$ & $22 \%$ \\
$\$ 156,150$ to $\$ 237,950$ & $28 \%$ & & $\$ 165,000$ to $\$ 315,000$ & $24 \%$ \\
$\$ 237,950$ to $\$ 424,950$ & $33 \%$ & & $\$ 315,000$ to $\$ 400,000$ & $32 \%$ \\
$\$ 424,950$ to $\$ 480,050$ & $35 \%$ & & $\$ 400,000$ to $\$ 600,000$ & $35 \%$ \\
Over $\$ 480,050$ & $39.6 \%$ & & Over $\$ 600,000$ & $37 \%$ \\
\hline
\end{tabular}

Source: Internal Revenue Service.

views on whether and to what extent higher budget deficits result in crowding out, through either reduced domestic investment or more domestic investment being financed by capital inflows. And third, we agree that the model with which we are working is incomplete and does not capture potentially economically important aspects of the law, but we disagree on how these modifications would affect the conclusions. For example, to the degree that the law resulted in future spending cuts, would such cuts further boost growth by reducing distorting government programs or hurt growth by reducing investments in infrastructure and research?

\section{The Tax Law}

On December 22, 2017, President Donald Trump signed Public Law 115-97, "An Act to Provide for Reconciliation Pursuant to Titles II and V of the Concurrent Resolution on the Budget for Fiscal Year 2018," which was originally called the "Tax Cuts and Jobs Act" before that title had to be dropped due to procedural objections. The 2017 tax law made the most sweeping changes to individual and corporate tax law in decades and also reduced the estate tax. Congress's Joint Committee on Taxation (JCT $2017 \mathrm{~b}$ ) estimated that the law will cost $\$ 1.5$ trillion in federal revenue, or $\$ 1.1$ trillion after accounting for its impact on the economy (see appendix table 1 for a breakdown).

The 2017 tax law altered individual rates and bracket structures, maintaining seven rates as in prior law but reducing several of them-including cutting the top rate from 39.6 percent to 37.0 percent. The full set of these changes for married couples in the first year is shown in table 2.

In addition, the law nearly doubled the standard deduction, eliminated personal exemptions, reduced the individual alternative minimum tax, 
and doubled the child tax credit from $\$ 1,000$ to $\$ 2,000$, providing $\$ 75$ of additional refundability for households currently constrained by the refundable limit. The law also limited some tax benefits, most notably capping the deductibility of state and local taxes at $\$ 10,000$ and lowering the cap on the mortgage interest deduction for new mortgages from $\$ 1,100,000$ to $\$ 750,000$. Finally, the law sets the shared responsibility payment to $\$ 0$ starting in 2019 , which effectively repeals the individual mandate to have health insurance that was originally established by the Affordable Care Act.

The law established a new 20 percent deduction for certain pass-through income. The deduction applies broadly to individual filers making less than $\$ 157,500$ and joint filers making less than $\$ 315,000$. For individual filers making more than $\$ 207,500$ and joint filers making more than $\$ 415,000$, the pass-through deduction is limited by a set of guardrails, including that it does not apply to personal services firms and is limited by a firm's amount of wages, and potentially capital. The tax law also doubled the exemption for the estate tax from $\$ 5.6$ million to $\$ 11.2$ million in 2018 , or from $\$ 11.2$ million to $\$ 22.4$ million for married couples.

All the individual, pass-through, and estate provisions sunset after 2025, with the exception of the shift to the chained consumer price index (CPI) and the de facto repeal of the individual mandate.

On the corporate side, the law cut the statutory corporate tax rate from 35 percent to 21 percent. It also allows businesses to fully expense investments in equipment for five years and then phases down that favorable treatment, returning to previous depreciation schedules starting in 2027. The law also includes a number of domestic offsets that pay for a portion of these costs, including repealing the domestic production deduction, limiting the deductibility of interest to 30 percent of earnings (defined before 2022 as earnings before interest, taxes, depreciation, and amortization, or EBITDA, and thereafter as earnings before interest and taxes, or EBIT), requiring fiveyear amortization of research and experimentation expenditures starting in 2022, and limiting net operating loss carrybacks and carryforwards.

The law also made major changes to international business taxation, including establishing a territorial system and reducing the tax rate on foreign intangibles associated with income derived in the United States. These costs are almost exactly offset within the 10-year budget window with two major new anti-abuse provisions: a minimum tax on global intangible low-taxed income that is 10.5 percent through 2025 and 13.125 percent thereafter, and a base erosion and anti-abuse tax that functions like an alternative minimum tax on inbound investment. In addition, the law 
mandated a one-time payment on existing overseas earnings and allowed free repatriation of these earnings thereafter.

\section{Modeling the Tax Law with Assumptions about Future Policy}

Modeling the tax law requires analyzing not just what Congress passed but also making assumptions about future policy. Our analysis compares tax policies with a baseline that reflects what would have happened absent any legislation in 2017 or later, what is sometimes called a "current law baseline."

We focus on two scenarios. The first is the law as passed by Congresshenceforth, the "law-as-written" scenario. This specification assumes that all the tax cuts will be phased out or expire as scheduled and all the offsets will come into effect as scheduled. This scenario is the one that has been the basis for widely cited cost and macroeconomic estimates by official agencies like the JCT and groups like the Penn Wharton Budget Model, the Tax Policy Center, and the Tax Foundation.

The second scenario takes the law that was passed by Congress and assumes that its major provisions are extended and the delayed offsets never happen-henceforth, the "provisions-permanent" scenario. Most important, this scenario assumes that full expensing of equipment is expected to be and is actually made permanent after 2022, and that the individual, pass-through, and estate provisions scheduled to expire after 2025 are instead made permanent. We also assume that Congress will cancel additional offsets that come into effect in 2022, including requiring the fiveyear amortization of research and experimentation (R\&E) expenditures, tougher limits on interest deductibility, and tougher limits on international income shifting. ${ }^{2}$

Making economic predictions conditional on a given set of policy inputs is difficult; making political predictions about those future policy inputs

1. We do not consider the so-called tax extenders that were not addressed in the legislation, nor the expiring energy provisions and delayed health provisions. Effectively, we are assuming that these provisions would have had the same set of expirations and extensions under the baseline and the policy, and thus they do not significantly affect our analysis.

2. This choice of a "permanent" baseline differs from the permanent baseline concept advanced by the Office of Management and Budget, which assumes that the individual and estate tax provisions scheduled to expire after 2025 are instead made permanent but does not assume or propose to make expensing permanent or cancel the scheduled offsets. 
is considerably more difficult. The argument for focusing on the law as passed by Congress is that it is conceptually unambiguous, corresponds to what Congress actually passed, and is consistent with the prioritizations made by Congress (for example, prioritizing permanent corporate changes over permanent individual changes or phasing down bonus depreciation in a stated attempt to make it less likely that expensing is made permanent). Moreover, it is difficult to make predictions about future tax law. The 1986 tax reform also incorporated many phase-ins and phase-outs, most of which actually happened. In addition, future tax policy will be shaped by developments in the path of the fiscal deficit and changes in the political system.

The argument for focusing on the law assuming that all its provisions are extended is that this best corresponds to "current policy" in the tax code - that is, what is actually in place in the short run (say, 2019) and what would happen economically in the long run if everything in place in 2019 continued. For many provisions in the tax code, assuming the continuation of current policy has been an accurate predictor of future practice. For example, the R\&E tax credit was routinely extended on a temporary basis, with virtually no lapses, for more than three decades before being made permanent in 2015, and the alternative minimum tax was routinely patched and extended on an annual basis until these fixes were made permanent in 2013. Moreover, about 80 percent of the Bush tax cuts were made permanent under a Democratic president with a Democratic Senate in early 2013 (Huang 2013). ${ }^{3}$

In addition, any long-run macroeconomic estimates require that the government's intertemporal budget constraint be satisfied. As such, the law that Congress passed was incomplete and will necessitate the passage of future tax laws (or changes in government spending) to satisfy this budget constraint. Our main analysis assumes that any effects on government revenue will be financed later in a lump sum, nondistortionary manner. This specification amounts to assuming that households will make payments that are not conditional on income or any economic

3. The same logic for applying a "current policy" concept to the tax law implies that a reasonable counterfactual would be to assume that provisions in the tax law that were phasing down or out in 2017 were made permanent-which in this case applies to the 50 percent bonus depreciation for equipment. Another argument for assuming that a counterfactual to the passage of the tax law was the extension of 50 percent bonus depreciation is that 50 percent or more bonus depreciation had been in effect continuously since 2008. Estimates for this scenario are presented in section III and can be used as an alternative baseline if desired. 
choices and thus will have no distortionary effects on the economy. In policy terms, we might have reductions in Social Security or Medicare benefits or other government transfer programs.

\section{The Neoclassical Framework}

Our long-run estimates are based on a comparative statics exercise using a standard neoclassical framework in a Ramsey-style setup with CobbDouglas production functions, infinitely lived agents, and perfect foresight. We model different steady-state tax policies, assuming that they are fully anticipated and do not change. We chose this model because it provides a tractable and transparent framework for analyzing changes in long-run steady states. It is also the workhorse model used by economists who study long-run economic growth and long-run consequences of tax policies.

One assumption in our baseline model is that the expected real rate of return on capital, $r^{k}$, is fixed in the long run even when the business tax structure changes. This result holds for the real interest rate in the steady state of the standard neoclassical growth model because of given values for the rate of time preference, the elasticity of intertemporal substitution, and the rate of exogenous technical progress (Barro and Sala-i-Martin 2004). That is, the long-run supply of capital is horizontal in this model. This theoretical proposition accords with the empirical observation of rough constancy over long periods of the expected real rate of return on corporate equity. We provide some analysis of how the results change when a tax-induced expansion of the capital stock is accompanied by a long-term rise in real interest rates.

Our assumption about unchanged real rates of return in the long run is the same as that made by the Tax Foundation (2017). The assumption differs from the Penn Wharton Budget Model (2017), which uses an overlapping generations model; the Tax Policy Center model (Page and others 2017), which assumes a fixed saving rate in the context of a Solow model; and some of the models used by the JCT. These models all have real interest rates responding in the long run to tax-induced changes in the demand for capital.

Our modeling also assumes that the economy is fully utilizing its capacity, which is appropriate for the long-run comparative statics results that we emphasize. In contrast, two of the three models used by the JCT allow for changes in factor utilization-its macroeconomic equilibrium growth model and its dynamic stochastic general equilibrium model. 
Overall, as discussed in section VII, the results from our law-as-written case are similar to those found by the JCT, the Tax Policy Center, the Penn Wharton Budget Model, and the Tax Foundation. These other organizations did not publish estimates corresponding to our provisions-permanent scenario, which treats as permanent the tax parameters scheduled to apply as of 2019. Notably, this setting assumes that the full expensing of equipment introduced in the 2017 law will apply in the long run (even though the law specified a phase-out schedule beginning after 2022).

\section{III.A. User Costs and Investment}

We focus on user costs, which indicate the expected rate of return that an investor requires to invest in a particular form of capital. A reduction in taxes, for example, means that user costs are reduced, which leads to increased investment until diminishing returns drive the expected rate of return back to indifference with alternative investments. The concept of user costs was used by John Maynard Keynes (1936, chap. 11) and has since been employed in public and corporate finance by many economists, including Robert Hall and Dale Jorgenson (1967), who did not use the explicit term. We base part of our conceptual framework on the theoretical framework of Mervyn King and Don Fullerton (1984). We initially ignore debt financing and therefore think of all financing as coming from owners-that is, from equity.

The after-tax expected cash flow for owners of a corporation in period $t$ is given by

$$
\Psi_{t}=\left(1-\tau_{t}\right)\left(Y_{t}-w_{t} L_{t}\right)-\left(1-\tau_{t} \lambda_{t}-c_{t}\right)\left(K_{t}-K_{t-1}+\delta K_{t-1}\right),
$$

where $Y$ is output, $w$ is the real wage rate, $L$ is labor, $K$ is capital, $\tau$ is the tax rate on profits, $\lambda$ is the effective expensing rate on purchases of capital goods, $c$ is an investment tax credit, and $\delta$ is the true proportionate depreciation rate on capital. As we detail below, the expensing rate, $\lambda$, takes account of literal expensing and depreciation allowances. The tax rate is different across the two sectors we are analyzing: the "corporate sector," by which we mean $\mathrm{C}$ corporations that pay taxes at the corporate rate; and the "pass-through sector," by which we mean S corporations, partnerships, and sole proprietors, which pay taxes at the individual level.

We assume that a corporation makes investment choices to maximize the expected present value of its net cash flows given in equation 1 , where the present value calculation uses as a discount rate the required after-tax expected rate of return on capital, $r^{k}$. In practice, we measure $r^{k}$ 
after corporate taxes but before taxation at the individual level on dividends and deferred capital gains. Therefore, we are assuming that changes in the relevant marginal tax rate at the individual level can be neglected. ${ }^{4}$

Our main analysis assumes a high value for $r^{k}$, about 8.2 percent per year, which is the average real rate of return on equity for the United States and also for a group of 11 countries belonging to the Organization for Economic Cooperation and Development (OECD) with long-term data at annual or higher frequency. ${ }^{5}$ This rate has been roughly stable over long periods back as far as 1870 .

The $r^{k}$ of 8.2 percent in real terms is well above the risk-free rate. For example, the long-term average real rate of return on assets akin to shortterm Treasury bills for the 11 OECD countries was 1 percent in real terms, corresponding to an equity premium of about 7 percent. ${ }^{6}$ Economists have advanced alternative explanations of this high equity premium, including the rare-disasters idea of Thomas Rietz (1988) and Barro (2006).

We use $r^{k}=8.2$ percent to discount all expected future corporate cash flows, although different discount rates may apply to different components. For example, Alan Auerbach and Kevin Hassett (1992, p. 144) argue that the real value of future depreciation allowances is nearly known in advance (subject to minor uncertainty associated with inflation) and, therefore, should be discounted at a rate not much above the risk-free rate. However, Larry Summers (1987) surveyed companies and found that they used an average nominal discount rate of 15 to 17 percent per year, compared with a 10 -year Treasury rate at the time of about 8 percent. This procedure may be rational from a rare-disasters perspective-a possible explanation for why $r^{k}$ is so high in the first place-where the critical question is what happens to the real value of depreciation allowances in extremely

4. The rate of return after household taxes at rate $\tau_{h}$ is $r^{k}\left(1-\tau_{h}\right)$, where $\tau_{h}$ reflects marginal tax rates on dividends on capital gains. The rate $\tau_{h}$ tends to be small because taxable dividend payouts can be avoided by retaining earnings and buying back shares and by concentrating holdings of dividend-paying stocks in tax-exempt entities. In any event, $\tau_{h}$ would be roughly constant in our analysis because the 2017 tax law did not change the tax treatment of dividends and capital gains.

5. We use an updated version of the data from Barro and Ursúa (2008, table 5). The countries are Australia, Canada, Denmark, France, Germany, Italy, Japan, Norway, Sweden, the United Kingdom, and the United States. Most of the data on total real, arithmetic, annual returns are based on information from Global Financial Data.

6. Duarte and Rosa (2015, figure 1) infer from an array of empirical models that the U.S. equity premium has no clear long-term trend and is, if anything, above normal in recent years (up to 2014). 
bad states. An inability to recognize losses fully for tax purposes in such states is one consideration. Another is that if assets are sold off, such as in a bankruptcy, the value of depreciation allowances for the buyer could be sharply reduced.

We assume now that the tax rate, expensing rate, and investment tax credit are constant over time: $\tau_{t}=\tau_{t+1}=\tau, \lambda_{t}=\lambda_{t+1}=\lambda$, and $c_{t}=c_{t+1}=c$. If we abstract from adjustment costs for investment and changes in the relative price of investment goods, we get the first-order condition for $K_{t}$ by calculating derivatives of $\Psi_{t}$ and $\Psi_{t+1}$ in equation 1 with respect to $K_{t}$. We then set to 0 the sum of the first expression and the discounted value of the second expression. The result, as the arbitrary length of the period approaches zero, is

$$
M P K_{t}=\Omega=\frac{1-\tau \lambda-c}{1-\tau} \cdot\left(r^{k}+\delta\right),
$$

where $M P K_{t}$ is the marginal product of capital and $\Omega$ is the user cost of capital. ${ }^{7}$ Because we are abstracting from adjustment costs for investment and changes in the relative price of investment goods, the left side of equation $2, M P K_{t}$, is the expected marginal rate of return on investment at time $t$. We assume that the neglect of adjustment costs is satisfactory for analyses of long-run effects on capital-labor ratios, $K / L$.

The user cost of capital, $\Omega$, on the right side of equation 2 includes $r^{k}$ and $\delta$. User costs depend also on features of the corporate tax system, summarized by $\tau, \lambda$, and $c$. In calculating $\lambda$ for the old and new corporate tax systems, we estimate present values (using the nominal discount rate implied by $r^{k}$ and the inflation rate, $\pi$ ) associated with depreciation allowances. The investment tax credit, $c$, corresponds in recent years to the $\mathrm{R} \& \mathrm{E}$ credit associated with $\mathrm{R} \& \mathrm{D}$ investment. We should stress that equation 2 holds for a tax system with permanently fixed values of $\tau, \lambda$, and $c$. More generally, there would be dynamic effects generated by anticipated changes in $\tau, \lambda$, and $c$ over time.

Some properties of the user cost formula when $c=0$ are:

$-\lambda=1$ (full expensing) implies no effect of $\tau$ on $\Omega$.

$-\lambda=0$ gives the formula $(1-\tau) M P K_{t}=r^{k}+\delta$.

$-0<\tau<1$ implies that $\Omega$ falls with $\lambda$.

7. This neoclassical analysis neglects fixed costs, which were stressed by Devereux and Griffith (1998) in their analysis of international investment decisions. However, such costs could also be significant for domestic investment. A useful alternative model might have fixed costs and diminishing returns to scale at the firm level. 
$-0 \leq \lambda<1$ implies that $\Omega$ rises with $\tau$.

$-\lambda>1$ implies that $\Omega$ falls with $\tau$.

- If the tax system allows only for depreciation deductions corresponding to true deprecation at the rate $\delta$, then $\lambda=\delta /\left(r^{k}+\delta\right)$. Correspondingly, the formula becomes $(1-\tau)\left(M P K_{t}-\delta\right)=r^{k}$.

Economists typically agree that permanent full expensing with no investment tax credit makes sense from an efficiency standpoint, because this approach matches deductions from corporate taxable income with cash flows for buying capital goods. This match eliminates the tax on the normal rate of return, which we interpret as the required expected rate of return on capital. ${ }^{8}$ With this system permanently in place, corresponding to $\lambda=1$ and $c=0$ in equation 1 , the tax rate, $\tau$, does not influence the user cost, $\Omega$. In effect, taxes are rebated through expensing at the time of investment at the rate $\tau$. Then the government gets back this rebate over time by taxing future returns on capital at the rate $\tau$. The expected present value of these future flows, when discounted at the rate $r^{k}$, coincides with the initial rebate. Hence, the expected present value of taxes collected is zero, although the realized value would be positive or negative if returns are better or worse than expected-implying that the tax system serves an insurance function. ${ }^{9}$ However, if the government uses a discount rate less than $r^{k}$, it would raise revenue in a present value sense.

The analysis can be extended more broadly to allow for changes over time in $\lambda, \tau$, and $c$. These changes would be subject to uncertainty and may feature feedback from the state of the economy. Anticipations of this feedback can affect the extent of economic fluctuations. ${ }^{10}$ In analyzing the 2017 tax law, our main analysis treats the changes in $\lambda$, $\tau$, and $c$ as unanticipated and permanent.

8. In practice, there are a number of qualifications to this statement, especially for a tax system that does not fully and immediately refund losses and thus acts as a tax on riskpotentially discouraging entrepreneurship. Moreover, changes to the expensing rate or the tax rate can act as capital levies or windfalls, depending on how they are designed.

9. At the margin, the impact of a permanent increase in the capital stock by one unit at the current date on the expected present value of taxes is (if $c=0$ ):

$$
\frac{1}{r^{k}} \cdot \frac{\tau(1-\lambda)}{1-\tau} \cdot\left(r^{k}+\delta\right)
$$

If $0<\tau<1$, this expression is positive if $\lambda<1$, zero if $\lambda=1$, and negative if $\lambda>1$.

10. Lucas (1976, sec. 5.2) uses cyclical variations in the investment tax credit as an example. If the credit is expanded (reduced) with a lag in response to economic contractions (expansions), then anticipations of the changing credit can lead to an increased amplitude of the business cycle. 


\section{III.B. Debt Financing}

We now expand the analysis to allow for bond and debt financing. We know from Franco Modigliani and Merton Miller (1958) that if there were no corporate tax advantages for bonds, then, under reasonable conditions, the issuance of bonds would not matter for the overall value of the corporation and for investment choices. The core idea is that, if owners can also issue or hold bonds that pay the nominal interest rate, $i$ (that is, borrow and lend at the same interest rate and on the same terms as the corporation), then leverage choices made at the firm level do not matter.

When there are tax advantages at the corporate level from bond financing and no transaction costs associated with default and bankruptcy, all financing would optimally occur through bonds or debt, and none through equity. The usual view (Kraus and Litzenberger 1973; Myers 1984; Leland 1994) is that the optimal debt/equity mix trades off the tax advantages against the costs implied by the positive effect of leverage on a corporation's probability of default and bankruptcy. ${ }^{11}$ In our applied analysis, we use a simple model that captures this core trade-off.

We introduce debt financing in a simple way by adding to the after-tax corporate cash flow, $\psi_{t}$, in equation 1 the two critical terms: the tax deductibility of interest payments on debt and the transaction costs associated with default and bankruptcy. The new terms for period $t$ are

$$
\tau_{t} \cdot i_{t-1} \cdot \frac{B_{t-1}}{P_{t}}-\Phi\left(\frac{B_{t}}{P_{t} K_{t}}\right) \cdot K_{t},
$$

where $B_{t}$ is the nominal quantity of the corporation's bonds, $P_{t}$ is the price level, and $i_{t}$ is the nominal interest rate on corporate bonds. ${ }^{12}$ We adopt the timing convention that interest payments made in period $t$ depend on $i_{t-1}$ and $B_{t-1}$. The first term in equation 3 reflects the tax deductibility of these interest payments at the corporate level. ${ }^{13}$

11. Bondholders may also play a monitoring role with respect to corporate management.

12. We can include in $\psi_{t}$ in equation 1 the flows associated with net bond issuance and interest payments, $\left(B_{t}-B_{t-1}\right) / P_{t}-\left(i_{t-1} B_{t-1}\right) / P_{t}$. However, when we consider the firstorder condition associated with $B_{t}$, the effects from these additional terms is nil if we discount the new terms for year $t+1$ by the real interest rate on bonds, $\left(1+i_{t}\right) /\left(1+\pi_{t}\right)$, where $\pi_{t}=\left(P_{t+1} / P_{t}\right)-1$ is the inflation rate. This discounting is appropriate when, as in Modigliani and Miller (1958), the firm's owners can borrow and lend at the same interest rate, $i_{t}$, and on the same terms as the corporation. This result works even when default and bankruptcy can occur because $i_{t}$ will incorporate this probability.

13. In the subsequent analysis, we allow for the limitations on deductibility of bond interest that were included in the new tax law. 
The term $\Phi\left(B_{t} / P_{t} K_{t}\right)$ in equation 3 represents the cost associated with potential corporate default and bankruptcy, whose probability is assumed to be an increasing function of the debt-asset ratio, $B_{t} / P_{t} K_{t}$. We assume $\Phi^{\prime}>0$ and $\Phi^{\prime \prime}>0$. These costs can involve transaction costs associated with default and bankruptcy. This expression multiplies the total assets at risk, $K_{t}$, in equation 3 . We treat the overall term, $\Phi\left(B_{t} / P_{t} K_{t}\right) \cdot K_{t}$, as effectively a flow cost that subtracts from expected corporate cash flow in period $t$.

The first-order conditions for $B_{t}$ (applying to $\Psi_{t}$ and $\Psi_{t+1}$ in the form of equations 1 and 3 ) lead, as the length of the period goes to zero, to

$$
\Phi^{\prime}\left(\frac{B_{t}}{P_{t} K_{t}}\right)=\tau_{t+1} i_{t} .
$$

The condition says that the marginal cost associated with potential default (per unit of assets) equals the tax savings per unit financed by bonds.

The presence of debt finance modifies the first-order conditions associated with investment. The new effects arise because $K_{t}$ influences the term $\Phi\left(B_{t} / P_{t} K_{t}\right) \cdot K_{t}$ for a given real debt, $B_{t} / P_{t}$. The revised condition-an extension of equation 3-can be written when $\tau, \lambda, c$, and $r^{k}$ are constant over time as

$$
\begin{aligned}
M P K_{t}=\Omega= & \left(\frac{1-\tau \lambda-c}{1-\tau}\right) \cdot\left(r^{k}+\delta\right) \\
& -\left(\frac{1}{1-\tau}\right) \cdot \Phi\left(\frac{B_{t}}{P_{t} K_{t}}\right) \cdot(\theta-1),
\end{aligned}
$$

where $\theta$ is the elasticity of $\Phi$ with respect to the debt-asset ratio, $B_{t} / P_{t} K_{t}$. If $\theta$ is constant (with $\theta>1$ ), we can use equation 5 to rewrite equation 6 as

$$
\begin{aligned}
M P K_{t}=\Omega= & \left(\frac{1-\tau \lambda-c}{1-\tau}\right) \cdot\left(r^{k}+\delta\right) \\
& -\left(\frac{\theta-1}{\theta}\right) \cdot\left(\frac{\tau}{1-\tau}\right) \cdot\left(\frac{B_{t}}{P_{t} K_{t}}\right) \cdot i{ }^{14}
\end{aligned}
$$

14. If we write $\Phi=a\left(B_{t} / P_{t} K_{t}\right)^{\theta}$, then the optimal debt-asset ratio is $B_{t} / P_{t} K_{t}=(\tau i / a \theta)^{1 /(\theta-1)}$. If $\theta=2$, the right side simplifies to $\tau i / 2 a$. 
Note that the last term on the right side of equation 7 is decreasing in $\tau$ and $i$; that is, a higher nominal interest rate, $i$, implies a lower cost of capital. ${ }^{15}$ More specifically, if default probability depends as an approximation on the square of the debt-asset ratio (so that the marginal effect is proportional to the ratio), then $\theta=2$ and the final term in equation 7 simplifies to $-1 / 2 \cdot[\tau /(1-\tau)] \cdot\left(B_{t} / P_{t} K_{t}\right)$. We use this specification in our calibration exercises - although the results change little if we assume larger values of $\theta$.

Our approach to bond financing differs from the standard cost-of-capital formula used in tax analysis (Office of Tax Analysis 2014; CBO 2017b). Our alternative puts less weight on debt financing and raises the user cost when the real interest rate on bonds is well below the expected real rate of return on capital.

\section{III.C. Production Function}

Our main analysis assumes a Cobb-Douglas production function, where expected output, $Y_{t}$, relates to capital, $K_{t}$, and labor, $L_{t}$, in accordance with

$$
Y_{t}=A K_{t}^{\alpha} L_{t}^{1-\alpha}
$$

where $0<\alpha<1$. We begin with one type of capital and broaden subsequently to distinguish among equipment, structures, residential rental property, R\&D, and other intellectual property. ${ }^{16}$ With that extension, the term $K_{t}^{\alpha}$ is replaced in equation 8 by $\prod_{i} K_{i t}^{\alpha_{i}}$, where each subscript $i$ corresponds to a type of capital, and $\Sigma_{i} \alpha_{i}=\alpha$.

Returning to equation 8 , if the marginal products of capital and labor, $M P K$ and $M P L$, are equated to the respective real factor prices, then $\alpha$ equals the gross capital share of income. The marginal product of capital is then given by

$$
M P K_{t}=\alpha A\left(K_{t} / L_{t}\right)^{-(1-\alpha)} .
$$

15. The negative effect of $i$ on user cost when corporate interest payments are tax deductible was noted by Modigliani and Miller (1958, p. 296).

16. We ignore land and inventories, effectively distributing them proportionately to the other forms of capital. 
This specification implies that the long-run elasticity of $K / L$ with respect to $\Omega$ (given on the right side of equation 7 ) is $-1 /(1-\alpha)$, which exceeds 1 in magnitude. ${ }^{17}$

As mentioned above, our analysis treats $r^{k}$ as given; that is, the supply of capital is horizontal (see note 4). In other models, such as the finite horizon framework of Olivier Blanchard (1985), the long-run supply of capital slopes upward, so that an increase in $K / L$ (generated, for example, by a cut in $\tau$ or rise in $\lambda$ ) is associated with a rise in the real interest rate. ${ }^{18}$ However, this effect is quantitatively small in the Blanchard model. Further, an opposing force on the real interest rate arises if-as seems reasonable - the time preference rate falls or the elasticity of intertemporal substitution rises when $K / L$ increases. That is, individuals may become more patient or more willing to substitute intertemporally when they get richer.

We assume a capital share $\alpha=0.38$ to match the most recent value from an updated version of the data set described by John Fernald (2014). This specification assumes that the capital share will neither revert to its pre2000 value of about one-third nor continue to rise as it did from 2000 to 2012. When we extend to multiple types of capital, we use individual $\alpha_{i} \mathrm{~s}$ that add to $\alpha=0.38 .{ }^{19}$ The full set of economic parameters we use is shown in table 3 .

17. As is well known, the Cobb-Douglas specification implies a unit elasticity of substitution between capital and labor; that is, $\sigma=1$. We can use instead a constant elasticity of substitution production function, with $\sigma \geq 0$. In this case, changes in $K / L$ associate with changes in shares of income going to capital and labor. Karabarbounis and Neiman (2014) estimate $\sigma \approx 1.2$ in order to explain a rising trend of gross corporate capital income shares in many countries from the observed reductions in real prices of capital. For general $\sigma$, the elasticity of $K / L$ with respect to $\Omega$ is given by

$$
\frac{d(K / L)}{K / L}=\frac{-\sigma}{\left(1-s_{k}\right)} \cdot \frac{d \Omega}{\Omega},
$$

where $s_{k}$ is the gross capital share of income (equal to $\alpha$ in the Cobb-Douglas case). Therefore, if $\sigma$ is 1.2 or 0.8 , our subsequent results on $K / L$ (which assume $\sigma=1$ ) would be modified by \pm 20 percent.

18. With respect to assessing effects from finite horizons, this model is essentially a tractable version of the overlapping generations framework.

19. We calculate capital shares of income (table 3 ) based on information from the Bureau of Labor Statistics-specifically, the Multifactor Productivity Capital Tables, which are available at https://www.bls.gov/mfp/mprdload.htm, and B-Tax, which is available at https://github.com/open-source-economics/B-Tax. 
Table 3. Assumptions for Economic Parameters in the Baseline Analysis

\begin{tabular}{|c|c|c|}
\hline Parameter & \multicolumn{2}{|c|}{ Baseline } \\
\hline After-tax expected real rate of return on capital, $r^{k}$ & \multicolumn{2}{|c|}{$8.2 \%$} \\
\hline Inflation expectations, $\pi$ & \multicolumn{2}{|c|}{$2.3 \%$} \\
\hline Nominal interest rate on corporate bonds, $i$ & \multicolumn{2}{|c|}{$4.0 \%$} \\
\hline Debt share of financing, $B / P K$ & \multicolumn{2}{|c|}{$32 \%$} \\
\hline \multicolumn{3}{|l|}{ Share of value added } \\
\hline C corporations & \multicolumn{2}{|c|}{$39 \%$} \\
\hline Pass-throughs & \multicolumn{2}{|c|}{$36 \%$} \\
\hline Government, households, and nonprofits & \multicolumn{2}{|c|}{$25 \%$} \\
\hline \multicolumn{3}{|l|}{ Payroll per worker, 2015} \\
\hline $\mathrm{C}$ corporations & \multicolumn{2}{|c|}{$\$ 60,000$} \\
\hline Pass-throughs & \multicolumn{2}{|c|}{$\$ 41,000$} \\
\hline \multicolumn{3}{|l|}{ Economic depreciation rate, $\delta$} \\
\hline Equipment & \multicolumn{2}{|c|}{$8.8 \%$} \\
\hline Structures & \multicolumn{2}{|c|}{$2.0 \%$} \\
\hline Rental residential property & \multicolumn{2}{|c|}{$2.7 \%$} \\
\hline $\mathrm{R} \& \mathrm{D}$ intellectual property & \multicolumn{2}{|c|}{$12.2 \%$} \\
\hline \multirow[t]{2}{*}{ Other intellectual property } & \multicolumn{2}{|c|}{$19.6 \%$} \\
\hline & C corporations & Pass-throughs \\
\hline \multicolumn{3}{|l|}{ Share of income } \\
\hline Equipment & $13.8 \%$ & $12.2 \%$ \\
\hline Structures & $12.3 \%$ & $13.1 \%$ \\
\hline Rental residential property & $0.7 \%$ & $6.9 \%$ \\
\hline $\mathrm{R} \& \mathrm{D}$ intellectual property & $4.5 \%$ & $2.3 \%$ \\
\hline Other intellectual property & $6.6 \%$ & $3.4 \%$ \\
\hline Overall capital share, $\alpha$ & $38.0 \%$ & $38.0 \%$ \\
\hline
\end{tabular}

Sources: U.S. Bureau of Labor Statistics; U.S. Bureau of Economic Analysis; U.S. Census Bureau, County Business Patterns; B-Tax; Pearce (2015); authors' calculations.

\section{III.D. Effects of the 2017 Tax Law on User Costs}

We begin the empirical exercise by calibrating the effects of the 2017 tax changes on the user cost of capital, $\Omega$, for the corporate sector on the right side of equation 7 . This user cost involves the tax rate, $\tau$; the effective expensing rate, $\lambda$; the investment tax credit on R\&D outlays, $c$; and the treatment of interest deductions. Our calibration requires one set of tax parameters for the baseline and two for the different concepts of the law-as-written case and the provisions-permanent case. These parameters are shown in table 4.

For the baseline specification, we use parameters consistent with the tax law as it existed in 2017. The federal statutory tax rate was 35 percent, but about one-third of corporate income received a 9 percent domestic production deduction and was thus taxed at 31.85 percent. Therefore, we 
Table 4. Modeled Tax Policy Parameters

\begin{tabular}{lccc}
\hline Parameter & Baseline $^{\mathrm{a}, \mathrm{d}, \mathrm{e}}$ & $\begin{array}{c}\text { Law as } \\
\text { written }^{\mathrm{b}, \mathrm{d}, \mathrm{e}}\end{array}$ & $\begin{array}{c}\text { Provisions } \\
\text { permanent }^{\mathrm{c}, \mathrm{e}}\end{array}$ \\
\hline Corporate tax rate & $38.0 \%$ & $27.0 \%$ & $26.0 \%$ \\
Corporate R\&E credit rate & $5.0 \%$ & $6.4 \%$ & $6.1 \%$ \\
Pass-through tax rate & $35.2 \%$ & $35.5 \%$ & $31.1 \%$ \\
Effective limitation on debt & $0 \%$ & $15 \%$ & $5 \%$ \\
Expensing of equipment & $\mathrm{No}$ & No & $100 \%$ \\
Expensing of R\&D intellectual property & $100 \%$ & No & $100 \%$ \\
\hline
\end{tabular}

Source: Authors' calculations.

a. Baseline refers to the law in place before the enactment of the 2017 law. Bonus depreciation is assumed to be zero because this allowance was set to expire after 2019.

b. Law as written reflects long-run changes as specified in the 2017 law. R\&D intellectual property is assumed to have 5-year straight-line depreciation.

c. Provisions permanent treats the changes in effect for 2019 in the 2017 tax law as permanent.

d. Equipment is assumed to have double declining balance depreciation over 5 or 7 years.

e. Structures are assumed to have 20- or 39-year straight-line depreciation. Residential rental property is assumed to have 27.5-year straight-line depreciation. The R\&E credit is assumed to be zero for passthroughs. Other intellectual property is assumed to have double declining balance depreciation over 5 years.

use a federal rate of 34 percent and add to this 4 percent for state corporate profits taxes (net of the associated deduction in federal liability) to get a baseline tax rate of 38 percent. We assume normal depreciation schedules for the five types of capital, because the bonus depreciation in effect in 2017 was scheduled to expire after 2019. Our modeling of the R\&E credit, $c$, in table 4 follows the Office of Tax Analysis (2016).

For the law-as-written scenario (applicable as of 2027), we use a statutory federal tax rate of 21 percent but adjust it to reflect limitations on net operating losses and some smaller offsets that are not lump sum in nature. ${ }^{20}$ We end up with a tax rate inclusive of state corporate profit taxes of 27 percent - that is, a cut by 11 percentage points from the baseline. We also model the shift to five-year amortization of R\&D expenses (scheduled to start in 2022) and the associated interactions with the R\&E credit. Finally, we assume that 85 percent of investment is unconstrained by the limit on interest deductions.

20. Specifically, we assume that half the cost of these offsets is counted as an adjustment to the tax rate-which works out to about 1.5 percentage points in the law-as-written scenario and about 0.25 percentage point in the provisions-permanent scenario. This procedure is an imperfect way of modeling these provisions. Limitations on net operating losses, for example, might be more properly modeled as an increase in the discount rate on depreciation allowances because it increases the riskiness of this delayed tax benefit. 
Table 5. Estimated Effects on C Corporations from the 2017 Tax Law

\begin{tabular}{lccc}
\hline Effect & Baseline & $\begin{array}{c}\text { Law as } \\
\text { written }\end{array}$ & $\begin{array}{c}\text { Provisions } \\
\text { permanent }\end{array}$ \\
\hline Tax rate on corporate profits, $\tau$ & $38 \%$ & $27 \%$ & $26 \%$ \\
Effective expensing rate, $\lambda^{\mathrm{b}}$ & & & \\
$\quad$ Equipment & 0.812 & 0.812 & 1.000 \\
$\quad$ Structures & 0.338 & 0.338 & 0.338 \\
Rental residential property & 0.336 & 0.336 & 0.336 \\
R\&D intellectual property & 1.000 & 0.785 & 1.000 \\
Other intellectual property & 0.842 & 0.842 & 0.842 \\
User cost of capital, $\Omega^{\mathrm{c}}$ & & & \\
Equipment & 0.186 & $0.180(-3 \%)$ & $0.168(-10 \%)$ \\
Structures & 0.139 & $0.125(-10 \%)$ & $0.124(-11 \%)$ \\
$\quad$ Rental residential property & 0.149 & $0.134(-10 \%)$ & $0.132(-11 \%)$ \\
R\&D intellectual property & 0.184 & $0.200(+9 \%)$ & $0.185(+1 \%)$ \\
Other intellectual property & 0.301 & $0.292(-3 \%)$ & $0.291(-3 \%)$ \\
Average & & $-4.1 \%$ & $-7.8 \%$ \\
Percent change in the capital-labor ratio, $K / L$ & & & \\
Equipment & & $5.7 \%$ & $14.4 \%$ \\
Structures & & $12.9 \%$ & $16.2 \%$ \\
Rental residential property & $13.0 \%$ & $16.3 \%$ \\
R\&D intellectual property & & $-6.6 \%$ & $4.0 \%$ \\
Other intellectual property & & $5.4 \%$ & $8.0 \%$ \\
Average & & $6.7 \%$ & $12.7 \%$ \\
Percent change in output per worker, $Y / L$ & & $2.5 \%$ & $4.8 \%$ \\
\hline S & &
\end{tabular}

Source: Authors' calculations.

a. See tables 3 and 4 for the parameters.

b. The effective expensing rate is calculated as a present value.

c. The values in parentheses are the percent deviation from the baseline.

$\mathrm{d}$. This is the average percent change for each type of capital weighted by the capital income shares.

The provisions-permanent scenario, applicable as of 2019, differs in assuming that expensing of investment in equipment and $R \& D$ is permanent. In addition, the offsets noted above are smaller, resulting in a tax rate inclusive of state corporate profits taxes of 26 percent. That is, the rate cut in this scenario is 12 percentage points. Finally, because of the weaker limitations on interest deductions, we assume that 95 percent of investment is unconstrained by the limit on interest deductions.

Table 5 shows that the 2017 tax reform raises the effective expensing rate, $\lambda$, for equipment from 0.812 to 1.000 in the provisions-permanent scenario but leaves it unchanged in the law-as-written case. The implied reduction in user cost, $\Omega$, in equation 7 is from 0.186 to 0.180 in the lawas-written case (because of the cut in $\tau$ ), or by 3 percent. In the provisionspermanent setting, the user cost falls to 0.168 , or by 10 percent. Note that, 
with $\lambda=1$, the cut in $\tau$ matters only in a minor way (and in a direction to raise user costs) because of the bond interest deductions. ${ }^{21}$

For structures, $\lambda$ is unchanged in both scenarios, at 0.338 . Correspondingly, the user cost, $\Omega$, falls from 0.139 to 0.125 (10 percent) in the lawas-written case and to 0.124 (11 percent) under the provisions-permanent case. Because $\lambda$ is unchanged, these effects entirely reflect the reductions in $\tau$. Surprisingly - despite the move toward full expensing of equipment in the provisions-permanent case - the proportionate reduction in $\Omega$ is greater for structures. The reason is that equipment is already heavily expensed in the old tax system, with $\lambda=0.812$. Results for residential rental capital, a minor component, are similar to those for nonresidential structures.

For R\&D intellectual property, the full expensing of investment in the baseline is maintained under the provisions-permanent case but is replaced in the law-as-written case by five-year straight-line depreciation. The calculations of user costs take account of the R\&E credit, which rises from 5.0 percent to 6.4 percent in the law-as-written case. The expensing rate, $\lambda$, falls because full expensing is dropped, but stays at 1.000 under the provisions-permanent case. The user cost, $\Omega$, rises by 9 percent in the lawas-written case, mostly because of the fall in $\lambda$. The user cost rises by 1 percent in the provisions-permanent case because the cut in $\tau$ lowers the value of the bond interest deduction.

For other intellectual property, $\lambda$ is unchanged in both scenarios at 0.842 . The user cost, $\Omega$, falls by 3 percent in both scenarios.

\section{III.E. From User Costs to Capital-Labor Ratios}

Converting the changes in user costs, $\Omega$, into long-run changes in capital-labor ratios, $K / L$, requires an estimate of the relevant elasticitythat is, the proportionate sensitivity of $K / L$ to $\Omega$. With a Cobb-Douglas production function and a single type of capital, equations 1 and 3 imply that this elasticity is $-1 /(1-\alpha)$, where $\alpha$ is the gross capital share of

21. The cut in $\tau$ from 38 percent to 26 percent provides a substantial benefit for the aftertax returns on old equipment. Our prediction is that this reduction in $\tau$ would not have much effect on investment in new equipment (because $\lambda=1$ ). Instead, this "windfall" cash would be expected to go to retained earnings, dividend payments, share repurchases, and, perhaps, bonuses for workers. In one respect, this tax windfall could be viewed as undesirable because it loses tax revenue and has no direct allocative effects. However, this perspective would suggest that a surprise increase in $\tau$-a capital levy with regard to old capitalwould be desirable. In fact, a key element in the government's credibility is some form of commitment not to engage "regularly" in these types of capital levies-because, once they are anticipated, these levies can substantially curtail investment. From this perspective, the occasional realization of tax windfalls might help to strengthen the government's credibility. 
income (see note 17). Because we use $\alpha=0.38$, the magnitude of this elasticity is $1.6 .^{22}$

As mentioned above, we extend to multiple types of capital by assuming that each type, $i$, enters into an expanded Cobb-Douglas production function with exponent $\alpha_{i}$. For illustrative purposes, suppose there were two types, with exponents $\alpha_{1}$ for equipment and $\alpha_{2}$ for structures. ${ }^{23}$ Given the first-order conditions for choices of $K_{1}$ (equipment) and $K_{2}$ (structures), we can show that the proportionate response of $K_{1} / L$ to changes in the two user costs, $\Omega_{1}$ and $\Omega_{2}$, is given by

$$
\frac{\Delta\left(K_{1} / L\right)}{K_{1} / L}=-\frac{1}{\left(1-\alpha_{1}-\alpha_{2}\right)} \cdot\left[\left(1-\alpha_{2}\right) \cdot \frac{\Delta \Omega_{1}}{\Omega_{1}}+\alpha_{2} \cdot \frac{\Delta \Omega_{2}}{\Omega_{2}}\right] .
$$

That is, on the right side, the term outside the brackets is analogous to that from the case with one type of capital, and the term inside the brackets is a weighted average of the proportionate changes in the two user costs.

An analogous expression gives the proportionate change in $K_{2} / L$ :

$$
\frac{\Delta\left(K_{2} / L\right)}{K_{2} / L}=-\frac{1}{\left(1-\alpha_{1}-\alpha_{2}\right)} \cdot\left[\left(1-\alpha_{1}\right) \cdot \frac{\Delta \Omega_{2}}{\Omega_{2}}+\alpha_{1} \cdot \frac{\Delta \Omega_{1}}{\Omega_{1}}\right] .
$$

Equations 10 and 11 imply that the resulting proportionate change in output per worker, $Y / L$, is given by

$$
\frac{\Delta(Y / L)}{Y / L}=-\frac{1}{\left(1-\alpha_{1}-\alpha_{2}\right)} \cdot\left[\alpha_{1} \cdot \frac{\Delta \Omega_{1}}{\Omega_{1}}+\alpha_{2} \cdot \frac{\Delta \Omega_{2}}{\Omega_{2}}\right] .
$$

Thus, if there is only one form of capital, so that $\alpha_{1}=\alpha$ and $\alpha_{2}=0$, the expression on the right side in front of the brackets is the usual elasticity,

22. This number is at the high end of directly estimated elasticities for investment, as surveyed by Hassett and Hubbard (2002) and the Council of Economic Advisers (2017). However, these estimates apply to investment, not directly to long-run capital-labor ratios.

23. As discussed in note 17 , we could instead have a production function with a constant elasticity of supply, in this case featuring an elasticity of substitution $\sigma$ between labor and a Cobb-Douglas aggregate of capital. Alternatively, we could bring in elasticities of substitution differing from 1 among the types of capital. We are unaware of studies of these elasticities among types of capital. 
and this elasticity is multiplied by $\alpha$ to get the proportionate response of $Y / L$ to the proportionate change in $\Omega$.

We can readily extend equations 10 through 12 to our case with five types of capital - where type 3 corresponds to residential rental property, type 4 to $R \& D$ intellectual property, and type 5 to other intellectual property. In this case, what matters for the change in $Y / L$ in an extension of equation 12 is a weighted average of the proportionate changes in the $\Omega_{i}$, where the weights are the $\alpha_{i}$ s (and then the whole object is divided by $\alpha$ to get an average).

\section{III.F. Effects on Capital-Labor Ratios and Output per Worker}

Table 5 shows that, in the law-as-written scenario, the user cost for equipment falls by 3 percent, user costs for structures and residential rental property fall by 10 percent, the user cost for $R \& D$ rises by 9 percent, and the user cost for other intellectual property falls by 3 percent. ${ }^{24}$ On average, user costs fall by 4 percent. We can then calculate from an extension of equation 10 the changes in the various capital-labor ratios. The result is that $K / L$ rises by 6 percent for equipment, rises by 13 percent for structures and residential rental property, falls by 7 percent for R\&D intellectual property, and rises by 5 percent for other intellectual property. On average, $K / L$ rises by 7 percent. The resulting rise in long-run corporate output per worker, $Y / L$, or corporate productivity, is given from an extension of equation 12 as 2.5 percent.

Correspondingly, for the provisions-permanent scenario, we get larger proportionate increases in capital-labor ratios $-K / L$ rises by 14 percent for equipment, 16 percent for structures and residential rental property, 4 percent for R\&D intellectual property, ${ }^{25}$ and 8 percent for other intellectual property. On average, $K / L$ rises by 13 percent. The resulting rise in longrun corporate $Y / L$ is 4.8 percent.

The results show that the predicted effect on long-run output per worker in the corporate sector, $Y / L$, is about twice as large in the provisionspermanent case (4.8 percent) as in the law-as-written environment

24. As discussed above, all these estimates are relative to a current law baseline. Measured relative to the 50 percent bonus depreciation that was in the law for 2017 , there would be a 2 percent increase in the user cost for equipment because the shift to normal depreciation in the law-as-written case outweighs the lower statutory tax rate.

25. This capital-labor ratio rises despite the small increase in the associated user cost because of the cross effects from the other forms of capital on the marginal product of capital for R\&D capital. 
Table 6. Results with Alternative Parameter Values ${ }^{a}$

\begin{tabular}{lcc}
\hline Effect & Law as written & $\begin{array}{c}\text { Provisions } \\
\text { permanent }\end{array}$ \\
\hline Capital share, $\alpha=1 / 3$ & & \\
$\quad$ Change in user cost of capital, $\Omega$ & $-4.1 \%$ & $-7.8 \%$ \\
Change in capital-labor ratio, $K / L$ & $6.2 \%$ & $11.8 \%$ \\
$\quad$ Change in output per worker, $Y / L$ & $2.1 \%$ & $3.9 \%$ \\
Capital share, $\alpha=0.4$ & & \\
Change in user cost of capital, $\Omega$ & $-4.1 \%$ & $-7.8 \%$ \\
Change in capital-labor ratio, $K / L$ & $6.9 \%$ & $13.1 \%$ \\
Change in output per worker, $Y / L$ & $2.8 \%$ & $5.2 \%$ \\
After-tax expected real rate of return on capital, $r^{k}=6 \%$ & & \\
Change in user cost of capital, $\Omega$ & $-3.5 \%$ & $-6.7 \%$ \\
Change in capital-labor ratio, $K / L$ & $5.6 \%$ & $10.7 \%$ \\
Change in output per worker, $Y / L$ & $2.1 \%$ & $4.1 \%$ \\
\hline
\end{tabular}

Source: Authors' calculations.

a. Except where noted, the specifications are the same as in table 5.

(2.5 percent). The main reason for the difference is the inclusion of full expensing of investment on equipment and $R \& D$ in the provisionspermanent scenario.

\section{III.G. Sensitivity to Parameter Values}

Table 6 shows how the main results in table 5 change when we alter key underlying parameters. We first consider capital shares, $\alpha$, of $1 / 3$ (the value commonly assumed in the literature, which corresponds to the actual capital share before 2000) or 0.4, instead of 0.38 . Then we consider an expected real rate of return on capital, $r^{k}$, of 6 percent (corresponding to an estimated historical average for returns on unlevered equity), rather than 8.2 percent. Table 6 shows results only for average changes in user costs, $\Omega$, capitallabor ratios, $K / L$, and output per worker, $Y / L$.

Differences in the capital share coefficient, $\alpha$, influence how given changes in user costs, $\Omega$, map into variations in $K / L$ and $Y / L$. Specifically, a higher $\alpha$ implies a higher elasticity of response. Thus, with $\alpha=0.38$ in table $5, K / L$ rises on average by 6.7 percent under the law-as-written case. The corresponding changes in table 6 are 6.2 percent when $\alpha=1 / 3$ and 6.9 percent when $\alpha=0.4$. Relatedly, instead of a rise in $Y / L$ by 2.5 percent in table 5 , we get changes by 2.1 percent and 2.8 percent, respectively, in table 6 . We get analogous differences in results for the provisionspermanent case. In particular, instead of the rise in $Y / L$ by 4.8 percent 
in table 5, we get increases of 3.9 percent (for $\alpha=1 / 3$ ) and 5.2 percent (for $\alpha=0.4$ ) in table 6 .

The reduction in $r^{k}$ to 6 percent lowers the effective expensing rate, $\lambda$, when $\lambda<1$. Thus, in the law-as-written case, instead of the average fall in $\Omega$ by 4.1 percent in table 5 , we get the decline by 3.5 percent in table 6 . Correspondingly, the average rise in $K / L$ is by 5.6 percent, rather than 6.7 percent, and the rise in $Y / L$ is by 2.1 percent, rather than 2.5 percent. Analogous results apply to the provisions-permanent setting.

\section{III.H. Hypothetical Alternative Tax Systems}

Table 7 considers three alternative tax systems, some elements of which were considered during the congressional deliberation over the 2017 tax law or at other times. In the column labeled "permanent bonus depreciation," the new tax law is the same as the old one (including $\tau=38$ percent and full expensing for R\&D intellectual property), except that 50 percent bonus depreciation applies permanently to equipment. The idea of this scenario is that it amounts to retaining the corporate tax provisions that were in place in 2017 (and most of the period since 2008), specifically 50 percent bonus depreciation for equipment. When compared with the two scenarios given in table 5, the user cost for equipment is lower than that in the law-as-written scenario but higher than that in the provisions-permanent scenario. The user cost for structures and residential rental property are much higher than those for the law-as-written and provisions-permanent cases. The user cost for $R \& D$ intellectual property is lower than that in the law-as-written scenario because expensing of $R \& D$ is retained in the hypothetical case. Finally, the user cost for other intellectual property is well above that for the law-as-written and provisions-permanent scenarios because $\tau$ is not reduced. Overall, when compared with table 5 , we predict smaller increases in the various $K / L$, and the proportionate increase in long-run corporate $Y / L$ is by 1.2 percent, half the 2.5 percent rise in the law-as-written scenario and about one quarter of the 4.8 percent in the provisions-permanent scenario.

The column labeled "full expensing" in table 7 applies $\lambda=1$ permanently to all forms of capital and assumes a tax rate of $\tau=32$ percent. (This tax rate, which matters little for the results when the $\lambda$ s equal 1 , corresponds to a federal rate of 28 percent plus the net effect of state income taxes.) When compared with the scenarios in table 5, the differences involve larger user cost reductions, particularly for structures. Correspondingly, the increases in $K / L$ are much larger, especially for structures. Overall, the resulting 
Table 7. Responses under Hypothetical Tax Systems ${ }^{\mathrm{a}}$

\begin{tabular}{lccc}
\hline Effect & $\begin{array}{c}\text { Permanent } \\
\text { bonus } \\
\text { depreciation }\end{array}$ & $\begin{array}{c}\text { Full } \\
\text { expensing }^{\mathrm{c}}\end{array}$ & $\begin{array}{c}\text { Pass-through } \\
\text { provisions }^{\text {permanent }}\end{array}$ \\
\hline Tax rate on corporate profits, $\tau$ & $38 \%$ & $32 \%$ & $27 \%$ \\
Effective expensing rate, $\lambda$ & & & \\
$\quad$ Equipment & 0.906 & 1.000 & 0.812 \\
Structures & 0.338 & 1.000 & 0.338 \\
Rental residential property & 0.336 & 1.000 & 0.336 \\
R\&D intellectual property & 1.000 & 1.000 & 0.785 \\
Other intellectual property & 0.842 & 1.000 & 0.842 \\
User cost of capital, $\Omega$ & & & \\
Equipment & $0.176(-5 \%)$ & $0.170(-8 \%)$ & $0.180(-3 \%)$ \\
Structures & $0.139(0 \%)$ & $0.102(-27 \%)$ & $0.125(-10 \%)$ \\
Rental residential property & $0.149(0 \%)$ & $0.109(-27 \%)$ & $0.134(-10 \%)$ \\
R\&D intellectual property & $0.184(0 \%)$ & $0.189(+3 \%)$ & $0.200(+9 \%)$ \\
Other intellectual property & $0.301(0 \%)$ & $0.278(-8 \%)$ & $0.292(-3 \%)$ \\
Average & $-1.9 \%$ & $-13.2 \%$ & $-4.1 \%$ \\
Percent change in capital-labor ratio, $K / L$ & & & \\
Equipment & $6.4 \%$ & $16.5 \%$ & $5.7 \%$ \\
Structures & $1.2 \%$ & $35.0 \%$ & $12.9 \%$ \\
Rental residential property & $1.2 \%$ & $35.2 \%$ & $13.0 \%$ \\
R\&D intellectual property & $1.2 \%$ & $5.2 \%$ & $-6.6 \%$ \\
Other intellectual property & $1.2 \%$ & $15.7 \%$ & $5.4 \%$ \\
Average & $3.1 \%$ & $21.4 \%$ & $6.7 \%$ \\
Percent change in output per worker, $Y / L$ & $1.2 \%$ & $8.1 \%$ & $2.5 \%$ \\
\hline Sourc:A & & &
\end{tabular}

\footnotetext{
Source: Authors' calculations.

a. See the notes to table 5 .

b. Bonus depreciation for equipment is 50 percent, but all other parameters are the same as in the baseline scenario.

c. The effective expensing rate is 1 for all capital. The $\mathrm{R} \& \mathrm{E}$ credit is 5 percent. There are no deductions for bond interest payments. The corporate tax rate is 32 percent.

d. The pass-through tax rate is 31.1 percent, but all other parameters are the same as in the law-as-written scenario.
}

proportionate increase in long-run corporate $Y / L$ is by 8.1 percent in the full expensing scenario in table 7 -more than the rises in table 5 of 4.8 percent in the provisions-permanent scenario and 2.5 percent in the law-as-written case. The full-expensing scenario may even have raised more money than the law Congress passed, especially outside of the 10-year budget window.

The third scenario is "pass-through provisions permanent," which is the same as the law-as-written case for the corporate provisions but assumes that the reductions in individual rates and the pass-through provisions that expire at the end of 2025 are made permanent. This scenario corresponds to the current policy baseline assumed by the Office of Management and Budget (2018b) and would be consistent with statements made by some 
members of Congress that they expect to see expensing phased out as scheduled under the law but to extend all the individual and pass-through tax provisions that expire abruptly in 2025 . The corporate side of this scenario is identical to the law-as-written scenario, so the estimates in table 7 are the same as in table 5. These two scenarios diverge when we incorporate the pass-through sector below.

\section{III.I. Effects on Pass-Through Businesses}

So far, our estimates apply to C-corporate businesses, which pay taxes through the corporation income tax. C corporations, however, represent only 49 percent of total business employment, 71 percent of business wages, and 36 percent of business net income. ${ }^{26}$ Overall, $\mathrm{C}$ corporations represent 52 percent of gross value added in the business sector.

Table 8 applies our previous approach to estimate effects of the tax changes on pass-through businesses (by which we mean $\mathrm{S}$ corporations, partnerships, and sole proprietorships). For pass-throughs, we use the same depreciation rules as for $\mathrm{C}$ corporations (except that we assume, as is typically the case, that they do not receive the R\&E credit). For tax rates, $\tau$, we assume for the baseline that the average marginal income tax rate for owners of non-C-corporate businesses is 35.2 percent. ${ }^{27}$ In the lawas-written scenario, this tax rate rises slightly, to 35.5 percent, reflecting the elimination of the domestic production deduction and bracket creep associated with shifting to the chained CPI. In the provisions-permanent scenario, the tax rate is 31.1 percent, which reflects a combination of the reduction of individual tax rates and the allowable part of the 20 percent pass-through deduction, partially offset by the higher marginal tax rates associated with capping the state income tax deduction. ${ }^{28}$

In the law-as-written case, the minor rise in $\tau$ and the elimination of expensing for $\mathrm{R} \& \mathrm{D}$ combine to generate small increases in the various

26. The employment and wage statistics are based on the U.S. Census Bureau's County Business Patterns data for 2015, adjusted to include railroad workers and the full set of sole proprietors and government workers based on the Current Employment Statistics and Current Population Survey. The shares of net income are based on Pearce (2015) and are for 2012. We combine the wages and profits data in proportion to these categories in the Bureau of Economic Analysis's National Income and Product Accounts table 1.13, for national income, in order to get the sectoral shares.

27. We thank the Tax Foundation for providing the base rates. We modified their numbers to incorporate self-employment taxes and the repeal of the domestic production deduction.

28. We use the 2019 value for the tax rate in the provisions-permanent case, effectively assuming that the chained CPI is turned off in that year. Without this assumption, the tax rate would gradually drift up over time. 
Table 8. Estimated Effects on Pass-Through Businesses from the 2017 Tax Law ${ }^{\mathrm{a}}$

\begin{tabular}{lccc} 
Effect & Baseline & $\begin{array}{c}\text { Law as } \\
\text { written }\end{array}$ & $\begin{array}{c}\text { Provisions } \\
\text { permanent }\end{array}$ \\
\hline Tax rate on pass-throughs, $\tau$ & $35.2 \%$ & $35.5 \%$ & $31.1 \%$ \\
Effective expensing rate, $\lambda$ & & & \\
$\quad$ Equipment & 0.812 & 0.812 & 1.000 \\
Structures & 0.338 & 0.338 & 0.338 \\
Rental residential property & 0.336 & 0.336 & 0.336 \\
R\&D intellectual property & 1.000 & 0.785 & 1.000 \\
Other intellectual property & 0.842 & 0.842 & 0.842 \\
User cost of capital, $\Omega$ & & & \\
Equipment & 0.184 & $0.185(0 \%)$ & $0.167(-9 \%)$ \\
Structures & 0.135 & $0.136(+1 \%)$ & $0.130(-4 \%)$ \\
Rental residential property & 0.145 & $0.146(+1 \%)$ & $0.139(-4 \%)$ \\
R\&D intellectual property & 0.201 & $0.225(+12 \%)$ & $0.201(0 \%)$ \\
Other intellectual property & 0.298 & $0.299(0 \%)$ & $0.295(-1 \%)$ \\
Average & & $1.3 \%$ & $-5.1 \%$ \\
Percent change in capital-labor ratio, $K / L$ & & & \\
Equipment & & $-1.2 \%$ & $12.2 \%$ \\
Structures & & $-1.5 \%$ & $7.2 \%$ \\
Rental residential property & $-1.5 \%$ & $7.2 \%$ \\
R\&D intellectual property & & $-13.1 \%$ & $2.8 \%$ \\
Other intellectual property & $-1.0 \%$ & $4.2 \%$ \\
Average & & $-2.0 \%$ & $8.3 \%$ \\
Percent change in output per worker, $Y / L$ & & $-0.8 \%$ & $3.1 \%$ \\
\hline Sor & & &
\end{tabular}

Source: Authors' calculations.

a. See the notes to table 5 . The R\&E credit is assumed to be zero in all cases.

user costs, $\Omega$, thereby causing reductions in the various $K / L s$, especially for R\&D intellectual property. Correspondingly, long-run pass-through $Y / L$ falls by 0.8 percent. In contrast, for the provisions-permanent scenario, the declines in $\Omega$ (except for $R \& D$ ) lead to increases in the various $K / L s$. The corresponding rise in pass-through $Y / L$ is by 3.1 percent.

The bottom line is that, in the law-as-written case, the predicted proportionate change in long-run $Y / L$ in the pass-through sector is -0.8 percent, compared with +2.5 percent for $\mathrm{C}$-corporate business. In the provisions-permanent scenario, the proportionate rise in long-run $Y / L$ for pass-through businesses is 3.1 percent, not far below the rise by 4.8 percent for $\mathrm{C}$-corporate businesses.

\section{III.J. From Business Sectors to Economy-Wide Estimates}

We model the economy as having three sectors: a corporate sector initially with 39 percent of value added, a pass-through sector with 36 percent 
of value added, and a nonbusiness sector (government, households, and nonprofit institutions) with 25 percent of value added (see table 3 ). ${ }^{29}$ Our analysis in tables 5 and 8 predicts how the tax law affects the various $K / L$ s and, thereby, $Y / L$ in the long run in the corporate and passthrough sectors. We assume no long-run change in $Y / L$ in the nonbusiness sector.

If we ignore shifting of labor and businesses across sectors-particularly from pass-throughs to $\mathrm{C}$ corporations - then the economy-wide change in $Y / L$ is the sum of the share-weighted changes in $Y / L$ by sector. Standard macroeconomic analyses of tax changes make this assumption.

Shifting between the corporate and pass-through sectors, however, could have an impact on our estimates. The modifications depend on the magnitude of the shifting and its impact on productivity. We discuss these two issues in turn.

From the perspective of labor, a key factor is that the changes in $Y / L$ by sector would be accompanied by changes in wages. (In our specification, the wage equals the marginal product of labor, which moves along with the average product in our Cobb-Douglas specification.) Hence, in our cases, the tax changes would raise wages paid by $\mathrm{C}$ corporations compared with those paid by pass-throughs. Labor would, therefore, be predicted to migrate toward $\mathrm{C}$ corporations. In our setting, $\mathrm{C}$ corporations would pair the added labor with additional capital, which is assumed to be available at constant cost in the long run. ${ }^{30}$ It is also likely that the tax changes will cause businesses to migrate in terms of legal form from the pass-through to the corporate sector.

The first question is how large this shift would be. Recent history suggests it could be substantial. The share of net business income going to C corporations fell by 39 percentage points from 1980 to 2000 . Three sets of factors have played a role in this change. The first is the evolution of

29. The division between business and nonbusiness is from the Bureau of Economic Analysis's National Income and Product Accounts table 1.3.5, "gross value added." The division within the business sector was described earlier in the text.

30. The numbers given in table 3 indicate that payroll per worker in the C-corporate sector in 2015 was about 46 percent higher than that in the pass-through sector, although this comparison does not factor in differences in human capital by sector. More generally, our simple model has to be extended to explain why not all labor would work in the corporate sector. Some workers could have a nonpecuniary preference for one sector over the other (or for working at businesses that are typically in one sector or the other). And C corporations would produce types of goods and services that differ from those produced by pass-through businesses. 
the economy away from manufacturing and toward services, given that manufacturing is dominated by $\mathrm{C}$ corporations, whereas servicesespecially health—are dominated by pass-throughs (CBO 2014). More generally, the C-corporate form is more attractive for businesses with larger scale (partly because of the option of public trading of shares) and higher risk (because of limited liability). ${ }^{31}$ The second factor is a set of legal changes, including loosening shareholder rules for $\mathrm{S}$ corporations and the creation of limited liability companies in many U.S. states. These changes mean that limited liability is less of a consideration that favors the C-corporate form. Finally, in the words of Matthew Smith and others (2017, p. 9), "The Tax Reform Act of 1986 reduced the top ordinary personal income tax rate below the top corporate income tax rate for the first time in the postwar era, unleashing a dramatic rise in business activity conducted in 'pass-through' business form." Disentangling the effects is difficult; for example, the pass-through share grew from 1990 to 2000, despite the raising of individual marginal tax rates, and thus taxes on pass-throughs, in 1990 and 1993.

An indication of the magnitude of the potential shifting due to tax changes comes from Jeffrey Mackie-Mason and Roger Gordon (1997), Austan Goolsbee (1998), and Richard Prisinzano and James Pearce (2018), who regress measures of the corporate share on the tax differential between $\mathrm{C}$ corporations and pass-throughs. Based on the changes in the tax rate differential between $\mathrm{C}$ corporations and pass-throughs (11 percentage points in the law-as-written scenario and 8 percentage points in the provisionspermanent scenario), Goolsbee's estimate implies a GDP shift of 0.2 to 3.4 percentage points in the law-as-written scenario and a shift of 0.2 to 2.4 percentage points in the provisions-permanent case. Prisinzano and Pearce's central estimate is the same as the upper bound of Goolsbee's estimate.

Because our modeling is focused on long-run comparative statics, we double the upper bound and assume a GDP increase of 6.8 percentage points in the corporate sector share in the law-as-written case and a 4.7 percentage point increase in the provisions-permanent case, or 19 and 13 percent of the pass-through sector shifting, respectively.

31. Corporations also facilitate a legal identity for a business that extends readily beyond the lifetimes of its owners; this durability is more difficult to ensure for sole proprietorships and some partnerships. Kuran (2004) stresses this idea in arguing that the lack of legal recognition of corporate structure was a key impediment to economic development in Muslim countries, particularly after the Industrial Revolution made economies of scale in production more important. 
Table 9. Estimated Percent Change in Economy-Wide Output per Worker ${ }^{\mathrm{a}}$

\begin{tabular}{lrr}
\hline Sector & $\begin{array}{c}\text { Law as } \\
\text { written }\end{array}$ & $\begin{array}{c}\text { Provisions } \\
\text { permanent }\end{array}$ \\
\hline C corporations & $2.5 \%$ & $4.8 \%$ \\
Pass-throughs & $-0.8 \%$ & $3.1 \%$ \\
Government, households, and nonprofits & $0.0 \%$ & $0.0 \%$ \\
Overall & $0.9 \%$ & $3.1 \%$ \\
Hypothetical 10 percent level shift in productivity for switchers ${ }^{\mathrm{c}}$ & & \\
Overall & $1.6 \%$ & $3.6 \%$ \\
\hline
\end{tabular}

Source: Authors' calculations.

a. The initial sectoral shares in economy-wide value added are from table 3 . The changes in output per worker for the $\mathrm{C}$-corporate and pass-through sectors are from tables 5 and 8 . The estimated final sectoral shares reflect shifting from pass-through to C-corporate status, as discussed in the text.

b. The percent change in overall output per worker is the sum of the changes by sector weighted by the final shares.

c. This row assumes that the shifters from pass-through to C-corporate status experience a 10 percent rise in output per worker for given capital per worker.

A second issue is modeling any changes in productivity associated with the shift from the pass-through sector to the corporate sector. One source of higher productivity in the long run is changes in capital-labor ratios generated by reductions in the user cost of capital because of the changes in the tax system. We make the upper-bound assumption that pass-throughs that shift get the same proportionate reduction in the user cost as do corporations. ${ }^{32}$

The results for long-run GDP per worker are given in table 9. These calculations reflect a weighted average of the proportionate changes in output per worker in each sector, weighted by their final shares-assuming the shift from corporate to pass-through sectors as described above. The results are that long-run GDP per worker increases by 0.9 percent in the law-aswritten case and 3.1 percent in the provisions-permanent case. ${ }^{33}$

As a sensitivity analysis, we also consider level differences in $Y / L$ between $\mathrm{C}$ corporations and pass-throughs-that is, higher output per worker in the corporate sector for given capital per worker. This difference

32. To understand why this is an upper bound, assume hypothetically that corporations have an effective tax rate of 25 percent and pass-throughs have an effective tax rate of 20 percent. In this case, cutting the effective corporate tax rate to 15 percent would result in a tax change for pass-throughs that was half as large as it was for corporations.

33. These estimates are relative to a "current law baseline" that assumes that the bonus depreciation in effect from 2008 through 2017 was phased out. Relative to a "current policy baseline" that assumes permanent bonus depreciation, the long-run increases in the level of GDP would be 0.1 and 2.3 percent, respectively. This alternative baseline has implicit in it the same assumption that underlies the provisions-permanent case we analyze. 
could reflect net productivity benefits from the C-corporate form of legal organization. If this difference applies at the margin to the shifting firms (and is not just a compositional effect related to which companies choose to be $\mathrm{C}$ corporations), then there is an additional boost to economy-wide $Y / L$ from the change in business form. If the productivity advantage for the $\mathrm{C}$-corporate form is 10 percent, we find that long-run GDP per worker rises by 1.6 percent in the law-as-written case and by 3.6 percent in the provisions-permanent case.

This alternative perspective also implies that the partly tax-induced movement away from C-corporate status since 1986 would have contributed to lower economy-wide productivity. More generally, there might be good reason to support the proposal from President Bush's Advisory Panel for Tax Reform that would require pass-through businesses effectively to become $\mathrm{C}$ corporations. Also, it would suggest that cutting individual income tax rates or pass-through tax rates could reduce long-run productivity by causing shifting to the less efficient pass-through sector.

Because there is a lot of uncertainty in these conclusions and also potential for helping to explain movements in economy-wide productivity, we think that the impact of changing organizational form of business on productivity is an important area for macroeconomic research.

In this paper, we present estimates for GDP only. National incomewhich subtracts depreciation and net payments to the rest of the worldhas long been standard in much of the literature on dynamic scoring (Altig and others 2001; Carroll and others 2006)..$^{34}$ The advantage of using national income is that it is somewhat closer to a welfare measure because it subtracts depreciation and adds the net factor income from abroad. Such an adjustment generates lower percentage growth than we are showing for GDP. For depreciation, a rise in $K / L$ implies that depreciation increases as a share of GDP. In addition, as we borrow more from foreigners to finance the higher $K$, the magnitude of the net factor income from abroad (a small positive number in recent U.S. history) is likely to fall as a ratio to GDP or even turn negative (Huntley 2014).

\section{III.K. Ten-Year Changes and Convergence Rates}

Our assessment of the dynamic response of real per capita GDP comes from estimated convergence rates, which determine how rapidly the economy approaches its long-run or steady-state position. Barro and Xavier

34. The CBO consistently presents gross national product for all its dynamic analyses, which adjusts partway to a national income concept. 
Table 10. Estimated Effects over a 10-Year Horizon

\begin{tabular}{lcc}
\hline Effect & $\begin{array}{c}\text { Law as } \\
\text { written }\end{array}$ & $\begin{array}{c}\text { Provisions } \\
\text { permanent }\end{array}$ \\
\hline Change in GDP: Long run (percent) & 0.9 & 3.1 \\
Change in GDP: 10 years out (percent) $^{\mathrm{b}}$ & 0.4 & 1.2 \\
Change in 10-year annual growth rate (percentage points) $^{\text {pan }}$ & 0.04 & 0.13 \\
\hline
\end{tabular}

Source: Authors' calculations.

a. The change in GDP over the long run comes from table 9, with the employment-population ratio unchanged.

b. The change in GDP after 10 years comes from applying a convergence rate of 5 percent per year to the long-run results.

Sala-i-Martin (1992) estimated a convergence rate of about 2 percent per year; more recent estimates by Barro (2015) are closer to 3 percent.

A convergence rate of 3 percent per year implies a half-life of 23 years. This slow process is consistent with the underlying neoclassical growth model only if diminishing productivity of capital sets in slowly. This condition requires a broad view of capital to include human along with physical capital, so that the capital share of income is high, about 75 to 80 percent. This environment seems appropriate if one thinks about convergence associated with broad development of institutions, accumulation of human capital (including education and health), and so on.

However, the 2017 tax law directly affects the incentives to accumulate physical capital. One would expect a higher convergence rate here, akin to that in a recovery from a war that mostly destroys physical capital. In the neoclassical growth model, if one assumes a physical capital share of about 40 percent, the implied convergence rate is about 5 percent a year.

Under this convergence rate, the economy would move 40 percent of the way to its long-run level after 10 years, an assumption that is about the midpoint that has been assumed or found in previous dynamic analyses. For example, Balázs Égert and Peter Gal (2017) and Robert Carroll and others (2006) model a corporate tax cut as getting the economy 30 and 65 percent, respectively, of the way to its steady state by year 10 .

If we apply a convergence rate of 5 percent a year to the long-run rises in economy-wide $Y / L$ reported for the various cases listed in table 9, we get the 10-year level and growth rate effects shown in table 10. This table assumes an unchanged employment-population ratio because of roughly offsetting substitution and income effects on labor supply.

The result is that GDP would rise over 10 years by 0.4 percent in the law-as-written case and by 1.2 percent in the provisions-permanent case. 
Table 11. Macroeconomic Effects of Alternative Policies ${ }^{a}$

\begin{tabular}{|c|c|c|c|}
\hline Effect & $\begin{array}{l}\text { Permanent bonus } \\
\text { depreciation }^{\mathrm{b}}\end{array}$ & $\begin{array}{l}\text { Full } \\
\text { expensing }^{\mathrm{c}}\end{array}$ & $\begin{array}{c}\text { Pass-through } \\
\text { provisions }^{\mathrm{d}} \\
\text { permanent }^{\mathrm{d}}\end{array}$ \\
\hline Change in GDP: Long run (percent) & 0.8 & 6.6 & 1.4 \\
\hline Change in GDP: 10 years out (percent) & 0.3 & 2.7 & 0.6 \\
\hline $\begin{array}{l}\text { Change in } 10 \text {-year annual growth rate } \\
\text { (percentage points) }\end{array}$ & 0.03 & 0.27 & 0.06 \\
\hline
\end{tabular}

Source: Authors' calculations.

a. See the notes to tables 7 and 10 .

b. Shifting from pass-through to the corporate sector is assumed to be zero.

c. Shifting from pass-through to the corporate sector is assumed to be 3.6 percentage points.

d. Shifting from pass-through to the corporate sector is assumed to be 4.1 percentage points.

These results imply that the annual GDP growth rate over the 10-year horizon rises by 0.04 percentage point in the law-as-written case and 0.13 percentage point in the provisions-permanent case.

Finally, table 11 uses the same methods described here to show GDP levels and growth rates for the policy scenarios described above. One interesting result in this table is that the scenario that made bonus depreciation permanent without making any other changes raises the long-run level of GDP by 0.8 percent, nearly the same as the 0.9 percent increase under the law as written. The reason these estimates are much closer than the corporate productivity differential shown in tables 5 and 7 is that this scenario raises productivity in the pass-through sector by 0.9 percent because the bonus depreciation for equipment would apply to the pass-through sector, whereas the law as written would reduce productivity in the pass-through sector by 0.8 percent, largely by ending expensing of R\&D. Permanent bonus depreciation would result in a little over one quarter of the increase in long-run GDP as the provisionspermanent scenario. Based on the JCT's conventional scoring, which does not reflect any dynamic feedback from growth, this scenario would have cost $\$ 250$ billion over 10 years, which is about one-sixth the conventional cost of the law as written and one-ninth the cost of the law with provisions permanent.

The expensing scenario shown in table 11 follows the same pattern as it did for corporate productivity, as discussed in the context of table 7 , with permanent expensing, no interest deductions, and a 28 percent federal rate (for a $\tau=32$ percent after taking into account state taxes) adding 0.3 percentage point to the annual growth rate over the next decade. This scenario would likely raise revenue relative to current law over the long run, and 
possibly over the budget window as well, due to the higher rates and ending of interest deductions.

Finally, if the individual and pass-through provisions are made permanent, that would result in the 10th-year level of GDP being up 0.6 percent, or an additional 0.2 percent relative to the law as written. This would cost about $\$ 200$ billion annually in fiscal years 2026 and 2027, or about 0.7 percent of GDP.

\section{Financing and Crowding Out}

All the estimates given above assume that the government is satisfying its intertemporal budget constraint in a manner that has no economic effects beyond what we modeled. Specifically, this approach is consistent with lump sum financing - where every household pays a fixed amount or, alternatively, pays an amount that is not conditional on its economic choices. The macroeconomic estimates are joint estimates of the specific policy and the assumed course of future fiscal policy.

\section{IV.A. The Magnitude of Financing}

The growth effects estimated above can be used to produce estimates of the additional revenue that would be raised through dynamic scoring that would offset part of the conventional estimate of the tax cut. An approximate version of this can be generated by assuming that the initial level of GDP is 1 percent above the baseline and then moves in a log-linear fashion to our 10th-year estimate, combined with the assumption that taxes as a percentage of GDP match the conventional revenue score over the 10-year window, which averages 17 percent of GDP. In the law-as-written case, the dynamic feedback is about $\$ 250$ billion, while in the provisions-permanent case, it is about $\$ 450$ billion. ${ }^{35}$

Our model does not allow us to estimate the revenue impact of the myriad provisions in the tax law. A number of estimates are available for the cost of the law, assuming no macroeconomic feedback. The JCT (2017a) estimated that the law will cost $\$ 1.5$ trillion in federal revenue over the 10-year budget window. Our estimate is that if the JCT's estimate were adjusted to reflect making the 2019 provisions of the law permanent, the cost would be $\$ 2.2$ trillion (see the appendix for details of the difference).

35. These estimates of dynamic feedback are similar to what would be generated using the sensitivity analysis published by the Office of Management and Budget (2018a) and the CBO (2017a), both of which are based on explicitly modeling the ways in which higher GDP would affect tax revenue. 
Other estimates of the cost have been similar or higher. The Tax Foundation (2017) estimated the static cost of the law as actually passed at $\$ 1.5$ trillion, and the Tax Policy Center (Page and others 2017) estimated it at $\$ 1.4$ trillion. The Trump administration (Mulvaney 2018) estimated the reduction in revenues at "roughly $\$ 1.8$ trillion," ascribing the higher number to a different assumption about the repeal of the individual mandate. The Penn Wharton Budget Model (2017) estimated a \$2.2 trillion reduction in revenue without macroeconomic feedback, largely because its developers believe that more income could circumvent the "guardrails" to benefit from favorable pass-through treatment. Finally, a group of tax law professors (Kamin and others 2017) have argued that the costs could be higher than expected as behavior adjusts to take advantage of the new law, for example, alterations in state and local tax policy to protect the deductibility of taxes.

Combining the JCT's estimate with the macroeconomic feedback generated by our model yields a revenue reduction for a dynamic score of the tax cut of $\$ 1.2$ trillion ( 0.5 percent of GDP) over 10 years for the law as passed and $\$ 1.7$ trillion (0.7 percent of GDP) for the law with provisions permanent. If the tax cuts were financed with equal lump sum payments, the law as passed would require about $\$ 900$ per household per year, while the law with provisions permanent would require about $\$ 1,400$ per household per year, with these payments starting in 2018. To the degree the financing was delayed, it would need to be larger.

Note that these estimates only consider revenue, implicitly assuming that the higher level of GDP does not affect the level of spending. In reality, the higher level of GDP would automatically trigger higher levels of spending-for example, initial Social Security benefits grow with economy-wide wages, much of the cost of Medicare rises with economy-wide productivity growth, and the discretionary baseline is linked to "current services" inflation, which goes up with the level of productivity. As a result, a reduction in revenue as a share of GDP will not reduce spending as a share of GDP by much; and thus, regardless of how much it raises the level of output, it will still result in a long-run increase in the primary deficit in dollar terms and as a share of GDP (Barro 2012).

\section{IV.B. The Possibility of Crowding Out through Higher Interest Rates}

If financing were delayed, the fiscal deficit and debt would rise in the interim. To use the JCT's estimates as adjusted for our estimates of macroeconomic feedback as indicative, the unified deficit would rise by about 
0.6 percent of GDP over the next decade under the law-as-written scenario and by 0.8 percent of GDP under the provisions-permanent scenarioleaving the debt-to-GDP ratio after 10 years 4.7 and 6.0 percentage points higher, respectively.

One view, termed "Ricardian equivalence," is that these additional deficits would have no macroeconomic effects because forward-looking households would raise their personal savings in anticipation of the larger lump sum repayments they would be required to make in the future (Barro 1974).

An alternative view is that, if personal saving did not fully adjust and capital was not supplied perfectly elastically internationally, the result of increased investment demand and reduced savings would be a higher real interest rate. Thomas Laubach (2009) estimates that this interest rate effect is 25 basis points for a 1 percentage point increase in the unified deficit as a share of GDP, and 30 to 40 basis points for a 10 percentage point increase in the debt-to-GDP ratio. This result is similar to William Gale and Peter Orszag's (2004) estimate of an increase of 25 to 35 basis points in interest rates for an increase of 1 percent of GDP in the unified deficit; and is slightly smaller than Eric Engen and Glenn Hubbard's (2005) estimate that a 10 percentage point increase in the debt-to-GDP ratio would raise interest rates by 20 to 30 basis points.

To motivate our sensitivity analysis of the possible impact of crowding out through higher interest rates, we apply Laubach's estimate to the rough, indicative increase in the unified deficit that we estimated by combining the JCT's score with our macroeconomic estimates. The result is an increase in interest rates of 14 basis points in the law-as-written scenario and 20 basis points in the provisions-permanent scenario.

\section{IV.C. Modeling Crowding Out}

In the analysis thus far, we assumed that the various tax changes had no long-run impact on rates of return-the expected real return on capital, $r^{k}$, and the nominal interest rate on bonds, $i$ - or on the inflation rate, $\pi$. As mentioned above, the constancy of real rates of return holds in some models. Other researchers think that enlarged stocks of real public debtinfluenced by the alternative tax plans through their effects on the path of fiscal deficits-could raise real rates of return. The plans may also affect the inflation rate, especially through interactions with monetary policy.

Table 12 provides an assessment of the crowding-out effects associated with increases in long-run rates of return. In the law-as-written scenario, we assume that $r^{k}$ and $i$ each rise by 0.14 percentage point compared with the baseline values. In the provisions-permanent scenario, we assume 
Table 12. Estimated Effect from Crowding Out ${ }^{\mathrm{a}}$

\begin{tabular}{|c|c|c|c|c|}
\hline \multirow[b]{2}{*}{ Effect } & \multicolumn{2}{|c|}{ C corporations } & \multicolumn{2}{|c|}{ Pass-through businesses } \\
\hline & $\begin{array}{l}\text { Law as } \\
\text { written }^{\mathrm{b}}\end{array}$ & $\begin{array}{l}\text { Provisions } \\
\text { permanent }^{\circ}\end{array}$ & $\begin{array}{l}\text { Law as } \\
\text { written }^{\mathrm{b}}\end{array}$ & $\begin{array}{l}\text { Provisions } \\
\text { permanent }^{\mathrm{C}}\end{array}$ \\
\hline \multicolumn{5}{|l|}{ User cost of capital, $\Omega$} \\
\hline Equipment & $0.181(-2 \%)$ & $0.170(-9 \%)$ & $0.186(+1 \%)$ & $0.169(-8 \%)$ \\
\hline Structures & $0.127(-9 \%)$ & $0.126(-10 \%)$ & $0.138(+2 \%)$ & $0.132(-2 \%)$ \\
\hline Rental residential property & $0.136(-9 \%)$ & $0.135(-10 \%)$ & $0.148(+2 \%)$ & $0.142(-2 \%)$ \\
\hline R\&D intellectual property & $0.202(+10 \%)$ & $0.187(+2 \%)$ & $0.227(+13 \%)$ & $0.203(+1 \%)$ \\
\hline Other intellectual property & $0.294(-2 \%)$ & $0.294(-2 \%)$ & $0.301(+1 \%)$ & $0.297(0 \%)$ \\
\hline Average & $-3.2 \%$ & $-6.6 \%$ & $2.4 \%$ & $-3.6 \%$ \\
\hline \multicolumn{5}{|l|}{$\begin{array}{l}\text { Percent change in capital- } \\
\text { labor ratio, } K / L\end{array}$} \\
\hline Equipment & $4.3 \%$ & $12.6 \%$ & $-2.8 \%$ & $10.2 \%$ \\
\hline Structures & $11.1 \%$ & $13.6 \%$ & $-3.7 \%$ & $4.3 \%$ \\
\hline Rental residential property & $11.2 \%$ & $13.8 \%$ & $-3.6 \%$ & $4.4 \%$ \\
\hline R\&D intellectual property & $-8.0 \%$ & $2.3 \%$ & $-14.6 \%$ & $0.9 \%$ \\
\hline Other intellectual property & $4.3 \%$ & $6.5 \%$ & $-2.3 \%$ & $2.6 \%$ \\
\hline Average & $5.2 \%$ & $10.7 \%$ & $-3.9 \%$ & $5.9 \%$ \\
\hline $\begin{array}{l}\text { Percent change in output per } \\
\text { worker, } Y / L\end{array}$ & $2.0 \%$ & $4.1 \%$ & $-1.5 \%$ & $2.2 \%$ \\
\hline
\end{tabular}

Source: Authors' calculations.

a. See the notes to table 5 .

b. The return on capital and the interest rate on bonds are assumed to rise by 0.14 percentage point.

c. The return on capital and the interest rate on bonds are assumed to rise by 0.20 percentage point.

instead that $r^{k}$ and $i$ each rise by 0.20 percentage point. The increases in $r^{k}$ raise user costs, $\Omega$, though there is an offsetting effect because the benefit from the interest deduction is heightened.

For $\mathrm{C}$ corporations, the crowding-out effects assumed in table 12 lead to smaller increases in the various $K / L$ s than those shown in table 5 . Through these channels, the proportionate rise in $Y / L$ is less than otherwise. For the law-as-written case, the rise in $Y / L$ is 2.0 percent in table 12 , compared with 2.5 percent in table 5 . For the provisions-permanent case, the rise in $Y / L$ is 4.1 percent in table 12 , compared with 4.8 percent in table 5 .

Similarly, for pass-through businesses, the crowding-out effects lead to lower proportionate increases in the various $K / L$ s and, thereby, to lower proportionate changes in $Y / L$. For the law-as-written case, the proportionate change in $Y / L$ in table 12 is -1.5 percent, compared with -0.8 percent in table 8 . For the provisions-permanent case, the proportionate increase in $Y / L$ in table 12 is 2.2 percent, compared with 3.1 percent in table 8 . Thus, overall, the assumed amounts of crowding out have significant negative 
Table 13. The Cost of the 2017 Tax Law with Conventional and Dynamic Scoring, 2018-27

\begin{tabular}{lcc} 
Effect & $\begin{array}{c}\text { Law as } \\
\text { written }\end{array}$ & $\begin{array}{c}\text { Provisions } \\
\text { permanent }\end{array}$ \\
\hline JCT conventional score (billions of dollars) & $\$ 1,500$ & $\$ 2,200$ \\
Dynamic feedback (billions of dollars) & $-\$ 250$ & $-\$ 450$ \\
Net cost (billions of dollars) & $\$ 1,200$ & $\$ 1,700$ \\
Annual cost per household & $\$ 900$ & $\$ 1,400$ \\
Increase in $r^{k}$ and $i$ in crowding-out scenario (basis points) & 14 & 20 \\
GDP after 10 years without crowding out (percent) & 0.4 & 1.2 \\
$\begin{array}{l}\text { GDP after 10 years with crowding out (percent) } \\
\text { Change in annual growth rate with crowding out } \\
\quad \text { percentage points) }\end{array}$ & 0.2 & 1.0 \\
\hline
\end{tabular}

Source: Authors' calculations.

effects on the predicted long-run changes in corporate and pass-through output per worker.

We can incorporate the estimates inclusive of crowding-out effects into the analysis of economy-wide output in table 9. The result for the law-aswritten case is that the proportionate rise in overall $Y / L$ is 0.5 percent with no level difference in productivity between the two business sectors and 1.2 percent when there is a 10 percent level difference in productivity. For the provisions-permanent case, the results for overall $Y / L$ become 2.5 and 3.0 percent, respectively. The effects of crowding out on our estimates of the level and growth rate of GDP are shown in table 13.

\section{What Is Missing from the Long-Run Neoclassical Analysis?}

Robert thinks that nothing much of consequence is missing from the longrun neoclassical analysis, although there are many ways in which the framework could be extended. Jason thinks that the neoclassical model captures many of the important and well-understood effects of the tax changes but misses several effects that could be economically important.

\section{V.A. The Potentially Special Role of Research and Development}

The model may miss the potentially special role of research and development in endogenous growth. R\&D may have substantial spillovers that play a role in the level and possibly growth rate of output. In the law 
as written, $R \& D$ falls by 7 percent in the long-run steady state, while in the law with provisions permanent it only increases by a small amount. These changes in R\&D could potentially have consequences beyond what we calculate by entering $R \& D$ capital into a Cobb-Douglas production function.

\section{V.B. International Consideration}

A potential wild card in the analysis is international considerations, including shifting real and reported income. As in the analysis by the Tax Foundation (2017), our analysis effectively assumes that the international provisions of the legislation have no macroeconomic impactthat investment is determined by marginal tax rates in the United States and not by relative tax rates with other countries or average tax rates. Nevertheless, there is evidence that these channels operate as well (Devereux and Griffith 1998).

The sign of the international effects, however, is not clear. At first pass, the legislation lowers the average tax rate on domestic investment and also lowers the tax rate on overseas investment by shifting to a territorial system that would no longer tax profits of foreign subsidiaries of U.S. corporations. As a result, the impact of tax changes even on the large, lumpy location decisions emphasized by other researchers (Mathur and Kallen 2017) is ambiguous in the face of these competing incentives. And this ambiguity is compounded to the degree that the U.S. legislation induces tax rate reductions in other countries, undoing some of the transitory advantages created for U.S.-based firms.

The international effects are further complicated by two significant new base erosion provisions, both of which are likely to have heterogeneous effects on different types of businesses and different activities within businesses. The first provision is a new global intangible low-tax income (GILTI). This provision would immediately tax low-taxed foreign income at a reduced rate- 10.5 percent initially, rising to 13.125 percent starting in 2026. Low-taxed foreign income is defined as total global returns in excess of 10 percent of the tangible capital located overseas. GILTI creates two different incentives. It raises the tax on overseas production, discouraging companies from shifting income, and potentially activity, overseas. Conversely, it creates more of an incentive to locate tangible capital overseas in order to generate a higher threshold before returns on intangible capital become subject to GILTI. This is especially true because GILTI is assessed on a global basis, so additional factories located in Germany, for instance, can be used to offset royalty income booked in the 
Cayman Islands. The net effect of these two features on economic activity is unclear, although the provision overall likely raises revenue and reduces income shifting.

The other major new international base broadener is the base-erosion anti-abuse tax (BEAT), which functions as a minimum tax on foreign direct investment into the United States, with a minimum tax rate of 10 percent on a base that is adjusted in a variety of complicated ways. This provision could potentially deter foreign direct investment into the United States, specifically encouraging foreign-headquartered multinationals not to set up tangible investments in the United States. Conversely, it helps prevent the erosion of the U.S. tax base.

The impact of all these changes on reported income is less ambiguous and is likely to be positive as reported income is shifted back to the United States. This change would, however, not be associated with actual economic activity-just with effectively correcting a measurement error that led to increased underreporting of actual GDP (Guvenen and others 2017).

\section{V.C. Other Issues Not Addressed by the Neoclassical Model We Use}

The model we use is a comparative statics exercise that compares two steady states with adjustment processes based on estimated convergence rates. This approach misses much of the richness in the short-run dynamics, including effects of expectations and shifting provisions. Modeling all these elements would require a much more complicated and opaque model.

The model we use lacks a rich analysis of dynamic consumer behavior. Instead, we assume that the supply of capital is infinitely elastic in the long run, either because of the Ramsey model's properties of our setup or because of a small open economy assumption.

Finally, as discussed in the financing section, this model is as much an estimate of the financing assumed for the tax cuts as of the tax cuts themselves. We have assumed lump sum changes in transfers and taxes. If, instead, the government budget constraint is closed by reduced government spending, this change might raise or lower economic growth.

\section{The Individual Income Tax in the Short Run}

The final form of the 2017 legislation on individual income taxes is complex, but we focus here on the change in the labor income-weighted average marginal income tax rate. The Tax Policy Center calculated a reduction in this average marginal tax rate of 3.2 percentage points for 2018 relative 
to the baseline. ${ }^{36}$ However, this estimate does not factor in the reduced federal deductibility of state and local taxes. Our estimate is that an allowance for the reduced federal deductibility of state income taxes means that the cut in the average marginal income tax rate for 2018 would be about 2.3 percentage points. This number is similar to the CBO's (2018) estimate that the legislation will reduce effective marginal tax rates on labor income by 2.2 percentage points in 2018, 2019, and 2020. This reduction in marginal tax rates is smaller than that in the 1986 Reagan tax cut (4.5 points from 1986 to 1988) and the 1964 Kennedy-Johnson tax cut (3.6 points from 1963 to 1965), and about the same as in the 2003 Bush tax cut (2.1 points from 2003 to 2004) (Barro and Redlick 2011, table I).

We can estimate the impact of the changes in individual marginal income tax rates using existing reduced-form analyses of U.S. macroeconomic data. This method has the advantage of being grounded in empirical data but also has the disadvantage of not reflecting much of the specifics of the tax changes or potential differences in the context today versus the past.

A number of papers have used regression-based methods to assess the impact of tax cuts, including those by Christina Romer and David Romer (2010), Barro and Charles Redlick (2011), Karel Mertens and Morten Ravn (2013), Mertens and José Montiel Olea (2018), and Owen Zidar (forthcoming). We emphasize the papers by Barro and Redlick (2011) and Mertens and Montiel Olea (2018) because they focus on marginal tax rates, rather than average tax rates. We do not consider the issues about the impact of distributional changes in the tax cuts raised by Mertens and Montiel Olea (2018) and Zidar (forthcoming).

For Barro and Redlick (2011), the counterpart of $\tau$ is the labor incomeweighted average marginal income tax rate, factoring in federal income taxes, Social Security taxes, and state income taxes. Barro and Redlick find

36. Barro and Redlick (2011, table I) estimate the largest cuts in labor income-weighted average marginal tax rates (including federal and state income taxes and Social Security taxes) were 4.5 percentage points for 1947-48 and 1986-88, 3.6 percentage points for 1963-65, 2.5 percentage points for $1953-54$ and $1982-84$, and 2.1 percentage points for 2002-03. The largest increases were 15.4 percentage points for 1939-42, 12.9 percentage points for 1972-81, 4.7 percentage points for 1915-18, and 4.2 percentage points for 1967-69. (The Clinton tax increase for 1992-94 was 1.6 percentage points.) The large increases were associated particularly with wars and also pick up the increase in Social Security and Medicare payroll taxes. The sharp cut in the average marginal tax rate for 1948 is hard to evaluate because this change featured the national introduction of joint filing. Although the incomeweighted average marginal tax rate fell sharply, the rate would have risen for many lowerearning spouses, who likely have high labor supply elasticities. For this reason, Barro and Redlick (2011, table I) focused on results that excluded 1949. 
empirically that a cut in $\tau$ by 1 percentage point raises the level of per capita GDP by 0.5 percent over the next two years (their table II, columns 1 and 4 ). Therefore, with $\tau$ down by 2.3 percentage points in 2018, per capita GDP should rise by 1.15 percent by 2019 , implying a boost in the average growth rate of 0.6 percentage point per year for 2018-19. This estimated effect on the growth rate is temporary, lasting for only two years.

Mertens and Montiel Olea (2018) use a structural vector autoregression framework that includes instrumental variables. The instruments were constructed from a narrative approach, following Romer and Romer (2010), who isolated changes in marginal income tax rates that were arguably exogenous with respect to changes in the macroeconomy or in government spending. Mertens and Montiel Olea's analysis (their table III) treats eight federal individual tax reforms as featuring exogenous tax rate changes: 1948, 1964, 1978, 1981, 1986, 1990, 1993, and 2003. In their analysis, only the changes in marginal tax rates through the following year were considered (for example, the 1986 reform entered only for its effects through 1987). Their concept of $\tau$ is the labor income-weighted average marginal income tax rate, including federal income taxes and Social Security taxes, but not state income taxes.

Mertens and Montiel Olea's estimated model (their figure V) implies that a cut in $\tau$ by 1 percentage point (corresponding to a rise in $1-\tau$ by about 1.5 percent) leads to an expansion of the level of real GDP by about 1 percent in 1 to 2 years. This estimated effect is about twice that found by Barro and Redlick. A likely reason for the difference is that Mertens and Montiel Olea more convincingly isolated exogenous tax rate changes, whereas Barro and Redlick pick up some changes that tend to be countercyclical-that is, tax rate cuts tending to happen when the economy is weak.

Mertens and Montiel Olea's results imply that a cut in $\tau$ by 2.3 percentage points in 2018 would raise the level of real GDP by 2.3 percent by $2019 .{ }^{37}$ Hence, the effect on the average GDP growth rate for 2018-19 is about 1.2 percentage points per year, also about twice that predicted by Barro and Redlick.

37. Mertens (2018, table II, panel C) carries out a similar exercise and predicts a rise in real GDP by 2.3 percent by 2019. His analysis assumes that the 2017 law lowers the average marginal income tax rate by 2.75 percentage points, larger than the 2.3 points that we assumed. Mertens (2018, table II, panel A) also summarizes results based on changes in average tax rates. This analysis applies the estimated changes in federal tax revenue from the 2017 law to the models estimated by Romer and Romer (2010) and others. The average predicted rise in real GDP by 2019 is then 1.6 percent. 
A strength and weakness of the structural vector autoregression methodology employed by Mertens and Montiel Olea is that it includes the tax rate variable as part of the system. Therefore, the estimation delivers forecasts of the degree of permanence of tax rate changes based on what has been true historically, given the information contained in the variables included in the dynamic system. Mertens and Montiel Olea find that, empirically, the changes in average marginal income tax rates from the individual income tax themselves tend to be temporary. That is, this tax rate tends to revert over time back to its initial level. ${ }^{38}$ The estimated effects of tax rate changes on real GDP can then be viewed as applying to durations of tax rate changes that applied typically in the past. That is, the estimated effects represent responses to tax rate changes that would be rationally viewed as partly temporary.

A reasonable way to assess the effects of the changes in individual taxation in the 2017 law is to average the predictions from Barro and Redlick (2011) and Mertens and Montiel Olea (2018). Doing so results in a predicted increase in the GDP growth rate for 2018-19 of 0.9 percentage point per year. The predicted growth effects beyond 2019 are close to zero.

The predicted short-run growth effects of the individual tax changes dwarf the estimated effects of the business tax changes shown in table 10 . These results imply an increase in GDP growth rates in the range of 0.04 to 0.13 percentage point per year over a 10 -year horizon, depending on whether one uses the law-as-written or provisions-permanent approach. Thus, the overall predicted effect on the GDP growth rate for 2018-19 based on the regression methodology is in the range of 0.9 to 1.1 percentage points per year.

There are important issues in interpreting and applying these short-run results to these particular tax cuts in these particular economic circumstances. Both Barro and Redlick (2011) and Mertens and Montiel Olea (2018) attempt to pick up supply-side effects through regressions on marginal tax rates. Nevertheless, it is possible that at least some of these effects could be standard demand-side Keynesian effects. Such rapid changes in output raise the possibility that the Federal Reserve would seek to offset some of the increment to growth-either because it was causing inflation

38. As an example, the 1986 Reagan tax rate cuts were partially reversed by future tax law changes and bracket creep. This political behavior means that the effects of tax rate changes on the level of GDP per capita would also be temporary. However, empirically, Mertens and Montiel Olea (2018) find that the average marginal income tax rate tends to revert back more quickly than real GDP to its initial level (their figure V). 
Table 14. Summary of Macroeconomic Analyses of the 2017 Tax Law

\begin{tabular}{|c|c|c|c|c|}
\hline \multirow[b]{2}{*}{ Source } & \multicolumn{3}{|c|}{ Increase in output (percent) } & \multirow{2}{*}{$\begin{array}{c}\begin{array}{c}\text { Increase in annual } \\
\text { growth rate }\end{array} \\
\text { (percentage points) } \\
2017-27\end{array}$} \\
\hline & 2018 & 2027 & Long run & \\
\hline Joint Committee on Taxation & $0.8^{\mathrm{a}}$ & 0.1 to 0.2 & $\approx 0.0$ & 0.01 to 0.02 \\
\hline Tax Policy Center & 0.8 & 0.0 & 0.0 & 0.00 \\
\hline Penn Wharton Budget Model & 0.6 to 1.0 & 0.6 to 1.1 & 0.7 to 1.6 & 0.06 to 0.12 \\
\hline Tax Foundation & 0.4 & 2.8 & 1.7 & 0.29 \\
\hline Congressional Budget Office & 0.3 & 0.6 & n.a. & 0.06 \\
\hline Moody's Analytics & 0.4 & 0.4 & n.a. & 0.04 \\
\hline International Monetary Fund & 0.3 & -0.1 & n.a. & -0.01 \\
\hline Macroeconomic Advisers & 0.1 & 0.2 & n.a. & 0.02 \\
\hline Goldman Sachs & 0.3 & 0.7 & n.a. & 0.07 \\
\hline
\end{tabular}

Sources: JCT (2017b); Page and others (2017); Penn Wharton Budget Model (2017); Tax Foundation (2017); CBO (2018).

a. The JCT does not provide a 2018 number, but says that the tax cut will be 0.8 to 0.9 percent for most of the window.

or because they did not fully appreciate the supply shift—in which case, the numbers would be lower. Moreover, the current context of a low unemployment rate may also be relevant in understanding the macroeconomic impact of the tax cuts.

The business tax changes are the main source of higher predicted economic growth in the long run. Beyond 2019, the predicted growth effect of the individual tax changes is close to zero, whereas that of the business tax changes is 0.0 to 0.1 percentage point a year for 2020-27. Thus, the overall predicted impact on the GDP growth rate for 2020-27 is also 0.0 to 0.1 percentage point a year.

\section{Comparisons with Other Estimates}

Our results for the law-as-written case are similar to several other macroeconomic analyses of the 2017 tax law that are summarized in table 14. Analyses of the provisions-permanent case have not been published, so we cannot compare these results.

The JCT (2017b) estimated that the law would add an average of 0.7 percent to GDP over the 10-year budget window, with about 0.8 percent in additional output up front, 0.1 to 0.2 percent higher output at the end of the budget window, and an even smaller change or a negative change after 30 years. This estimate reflects a weighted average of three models: a 
macroeconomic equilibrium growth model, an overlapping generations model, and a dynamic stochastic general equilibrium model. The Tax Policy Center (Page and others 2017) also estimated an initial 0.8 percent boost to output and a 0.0 percent change in output in 2027 and 2037. The Penn Wharton Budget Model (2017) used an overlapping generations model to estimate a 0.6 to 1.1 percent increase in output at the end of the first decade and a 0.7 to 1.6 percent increase in output by 2040 . Finally, the Tax Foundation (2017) used a comparative statics, steady-state model to estimate that output would increase by 0.4 percent in 2018 and by 1.7 percent in the long run. These estimates are all shown in table 14. In addition to these estimates, a number of authors have published estimates of elements of the law, such as cutting the corporate rate without offsets.

\section{Conclusions}

Future tax changes are inevitable, given all the expirations in the law today and the likelihood that the gap between projected revenue and projected spending will be closed, at least in part, with additional revenue. Both authors of this paper think that macroeconomic modeling can make a useful contribution to understanding future revenue changes. Such modeling is one ingredient in a broader welfare analysis and is also essential for understanding the fiscal impact of legislation.

Both authors also believe the modeling contains some important lessons-for example, expensing investment while eliminating the deductibility of interest would reduce the effective corporate marginal tax rate on investment to zero, thereby boosting capital accumulation and growth.

Both authors also agree with Milton Friedman that the only way to cut taxes is to cut spending. However, the authors disagree on the proper level of spending. But to the degree that the political system has set such a level, tax cuts today simply shift taxes to the future without actually reducing them in a present value sense. Moreover, tax cuts that represent deviations from tax smoothing are more distortionary than smooth taxes (Barro 1979).

The authors also differ in a number of respects, in their interpretation of the results, their preferred models, and their ultimate evaluations of the wisdom of the 2017 tax law and the best next steps for tax reform. This paper is not the place to fully discuss all these issues, but the following gives each author's perspective on the aspects of these issues that are most directly related to the modeling in this paper-highlighting the divergences that remain after the attempts at convergence we have made in this paper. 


\section{VIII.A. Jason Furman's View}

The bulk of this paper focuses on one model, a Ramsey model. This model has real strengths: It is transparent, internally consistent, and maps into some of the most important questions in tax reforms. Within the context of this model, I believe the estimates in this paper are reasonable. If I had written it by myself using the same model, I would have chosen some other parameters for the central case-like a lower capital share, to reflect the fact that part of the increase in the capital share may reflect an increase in pure profits; higher present values of depreciation allowances, to reflect the fact that depreciation allowances have many safe, bond-like characteristics; and a more standard cost-of-capital formula that places more weight on debt-financed investment. ${ }^{39}$ Moreover, I personally prefer the estimates that incorporate crowding out in section IV, which I believe better capture the consequences of the tax law. But even with those different parameters, the overall takeaways would be largely the same.

However, the Ramsey model has important limitations, so I believe that for public policy purposes, its results are useful and informative but it should only be one among many models (such as overlapping generations and dynamic stochastic general equilibrium), and its results should be interpreted with care. The biggest issue with applying the Ramsey framework to tax changes, especially those that have no explicit financing, is that they do not fully record from where all the capital comes. Some likely comes from abroad — and would need to be repaid — something that could be captured in national income results but not in GDP results. To the degree that the supply of capital is not infinitely elastic, some of the capital will come from other sectors in the economy-like residential real estate. Finally, and important from the perspective of welfare, some of it will come from reduced consumption up front to finance greater consumption later. The Ramsey model misses some of these issues and, by focusing on comparative long-run steady states, looks more at the end result that happens in the long-term future than the costs and benefits along the way.

Moreover, the model we are using has the feature that the lower the tax rates are, the higher the growth rate will be. In fact, negative tax rates

39. For example, using our economic and tax policy parameters in Devereux and Griffith's (1998) cost-of-capital formula, as implemented by Mathur and Kallen (2017) (available at https://www.aei.org/wp-content/uploads/2017/12/taxes_investment_growth. $\mathrm{xlsx}$ ), the reduction in the average user cost of capital for the corporate sector would be 1 percent in the law-as-written case and 6 percent in the provisions-permanent case, as compared with 4 and 8 percent, respectively, which we find in our results. 
produce even higher GDP than zero tax rates. It is certainly true that replacing distortionary taxation with lump sum taxation likely would lead to efficiency improvements, but this misses the point of the tax system, which is to raise revenue for desired levels of spending. As such, this model may be better suited to comparing reforms with similar revenue paths than comparing reforms with very different revenue levels.

Even with these issues, I believe that the results of this model generally support my skepticism about the desirability of the 2017 tax law (beyond the critical issues of distribution, effects on the health system, and other issues that are important to me but beyond the scope of this paper). The law that Congress actually passed would, according to our analysis, raise the level of GDP by 0.4 percent in 2027 while cutting the R\&D component of investment. If Congress had just made the 50 percent bonus depreciation for equipment permanent, that would have raised the level of GDP by 0.3 percent in 2027. Moreover, making the bonus depreciation permanent would have cost one-sixth as much, so if one looks at the estimates reflecting crowding out, then bonus depreciation would have been even better, at 0.3 percent of GDP, as compared with 0.2 percent of GDP for the law that Congress passed. ${ }^{40}$

Moreover, any evaluation should not be based on GDP but on welfare. In particular, the ideal procedure would be to do a dynamic distributional analysis (Elmendorf and others 2008; Furman 2016). Such an analysis would incorporate the direct effects of the tax changes on households, the cost of lump sum financing, the welfare effects of reduced consumption and increased leisure (if relevant), and also the growth effects described in this paper. I have not done this full analysis, but I suspect I would find that the 2017 law as written was not welfare-improving for the median household and was dominated by just making permanent the bonus depreciation that had been in the law from 2008 through 2017.

Finally, the most important question is what to do next. The Ramsey model finds that making permanent all the provisions in effect in 2019 would add modestly to growth, raising the annual growth rate by 0.1 percentage point over the next decade, at an additional lump sum cost of $\$ 450$ per year per household. For the reasons discussed above, I think this is unlikely to be substantially welfare-improving for the median household. In addition, this paper contains an important finding that it is possible

40. Under the administration's version of the tax law being made permanent, which assumes the individual and estate provisions are made permanent but expensing is phased out, the change in GDP under the law is slightly less than what would have happened if bonus depreciation had been made permanent. 
to substantially improve on growth while raising revenue through a tax reform that improves the tax base and raises tax rates. In particular, a combination of expensing all capital investment, disallowing all interest deductions, and raising the tax rate would add 0.3 percentage point to the annual growth rate over the next decade while increasing revenue.

Ultimately, however, for me the most important priority is that we need more revenue, and as I learned in graduate school, when I read Barro (1979), the sooner we do that the better-so we can avoid larger abrupt increases in taxes in the future. And Robert and I agree that perhaps this could ultimately include spending reforms and maybe even a value-added tax.

\section{VIII.B. Robert Barro's View}

The 2017 tax reform is an important step in improving the efficiency of the U.S. tax system. On the corporate side, the main changes are the full expensing of equipment and the cut in the corporate tax rate. These changes imply, if the provisions of the tax cut as of 2019 are made permanent, that user costs on corporate capital will fall by 8 percent on average and that capital-labor ratios will rise in the long run by 13 percent on average. The expansion in equipment by 14 percent reflects mainly the full expensing, and the rise in structures by 16 percent reflects mostly the cut in the tax rate. Overall, the predicted rise in long-run output per worker in the corporate sector is 5 percent, and the rise in corporate wages should also be 5 percent. Over a 10-year interval, the added GDP growth rate should be 0.1 to 0.2 percentage point a year.

The cut in the average marginal income tax rate on individuals by 2.3 percentage points should be expansionary in the short run, leading to extra GDP growth by 0.9 percentage point per year through 2019 . Hence, the cuts on the individual side dominate the predicted addition to economic growth in the short run. However, in the longer term, the key element for growth comes from the corporate changes.

Naturally, the 2017 tax law is not perfect. A better plan would have introduced full expensing for all forms of capital spending on a permanent basis. In this scenario, the cut in the corporate tax rate would have been a minor issue. Moreover, tax reform is best viewed as part of a broader reform package-reminiscent, perhaps, of the Simpson-Bowles commission. Such a package would particularly feature entitlement reforms and maybe even a value-added tax.

The main long-run analysis comes from calibration of a neoclassical model. I thought initially that it would be straightforward to carry out this 
analysis of the long-run effects of corporate tax changes on capital intensity, labor productivity, and wages. However, even when staying within the neoclassical framework, a number of interesting issues emerged that warrant further research.

One question is the appropriate discount rate for corporate cash flows. A high expected rate of return on capital-something in the neighborhood of the observed long-run 6 to 8 percent after-tax real rate of return on equity-seems appropriate. Safe real interest rates, of about 1 percent a year, cannot be the main story. However, there are interesting issues concerning the use of different discount rates for different components of corporate cash flow, such as depreciation allowances, real sales revenue, and payments to labor.

We brought out the interplay between differential taxation of corporate versus pass-through business forms and the choices among these alternative legal arrangements. We need to consider further the overall equilibrium, which determines allocations of labor and capital across business types and may feature different wages paid by corporations and passthrough enterprises. We also want to assess how these legal choices influence overall productivity.

We considered five forms of business capital, but our main analysis did not go beyond the Cobb-Douglas form of interactions among these types and between capital and labor.

Finally, we should deal seriously with the dynamics of tax changes. Such an analysis would emphasize how investment relates to anticipations about future tax policy.

\section{APPENDIX}

\section{JCT-Based Revenue Estimates}

Appendix table 1 summarizes the cost of the provisions of the 2017 tax law according to the JCT's conventional score, which assumes no macroeconomic feedback from the law but does reflect an extensive set of microeconomic behavioral changes, such as shifting of home loans and charitable giving. The table also shows estimates of the cost of making all the 2019 provisions permanent-including extending expiring provisions and canceling delayed offsets. The numbers are shown both for the traditional 10 -year budget window and for 2027. Given the substantial timing shifts, especially on the corporate side, the 2027 numbers are a better guide to the steady state under the new law. 
Appendix Table 1. Conventional Revenue Score of the 2017 Tax Law

\begin{tabular}{|c|c|c|c|c|}
\hline \multirow[b]{2}{*}{ Score } & \multicolumn{2}{|c|}{2017 law as written } & \multicolumn{2}{|c|}{2019 law permanent } \\
\hline & 2027 & $2018-27$ & 2027 & $2018-27$ \\
\hline \multicolumn{5}{|l|}{ Individual provisions } \\
\hline \multicolumn{5}{|l|}{ Gross cuts } \\
\hline Statutory rates & $\$ 0$ & $-\$ 1,214$ & $-\$ 186$ & $-\$ 1,525$ \\
\hline Standard deduction & $\$ 0$ & $-\$ 720$ & $-\$ 106$ & $-\$ 899$ \\
\hline Child credit & $\$ 1$ & $-\$ 544$ & $-\$ 76$ & $-\$ 694$ \\
\hline Alternative minimum tax & $\$ 0$ & $-\$ 637$ & $-\$ 108$ & $-\$ 777$ \\
\hline Estate tax & $-\$ 3$ & $-\$ 83$ & $-\$ 13$ & $-\$ 94$ \\
\hline Subtotal, individual cuts & $-\$ 3$ & $-\$ 3,198$ & $-\$ 488$ & $-\$ 3,989$ \\
\hline \multicolumn{5}{|l|}{ Gross increases } \\
\hline Personal exemption & $\$ 0$ & $\$ 1,212$ & $\$ 182$ & $\$ 1,517$ \\
\hline Itemized deductions & $\$ 0$ & $\$ 676$ & $\$ 112$ & $\$ 835$ \\
\hline Shared responsibility payment & $\$ 53$ & $\$ 314$ & $\$ 53$ & $\$ 314$ \\
\hline Chained CPI & $\$ 32$ & $\$ 134$ & $\$ 32$ & $\$ 134$ \\
\hline Other & $\$ 2$ & $\$ 2$ & $\$ 2$ & $\$ 2$ \\
\hline Subtotal, individual increases & $\$ 86$ & $\$ 2,337$ & $\$ 380$ & $\$ 2,801$ \\
\hline Total, individual & $\$ 84$ & $-\$ 863$ & $-\$ 108$ & $-\$ 1,188$ \\
\hline Pass-through provisions & $-\$ 1$ & $-\$ 265$ & $-\$ 42$ & $-\$ 344$ \\
\hline \multicolumn{5}{|l|}{ Corporate provisions } \\
\hline \multicolumn{5}{|l|}{ Gross cuts } \\
\hline Rate & $-\$ 156$ & $-\$ 1,349$ & $-\$ 156$ & $-\$ 1,349$ \\
\hline Expensing & $\$ 14$ & $-\$ 86$ & $-\$ 5$ & $-\$ 150$ \\
\hline Territorial system & $-\$ 26$ & $-\$ 224$ & $-\$ 26$ & $-\$ 224$ \\
\hline Other & $-\$ 3$ & $-\$ 127$ & $-\$ 9$ & $-\$ 161$ \\
\hline Subtotal, corporate cuts & $-\$ 172$ & $-\$ 1,785$ & $-\$ 196$ & $-\$ 1,883$ \\
\hline \multicolumn{5}{|l|}{ Gross increases } \\
\hline Manufacturing deduction & $\$ 12$ & $\$ 98$ & $\$ 12$ & $\$ 98$ \\
\hline Interest limitation & $\$ 37$ & $\$ 253$ & $\$ 21$ & $\$ 179$ \\
\hline Net operating losses limitation & $\$ 11$ & $\$ 201$ & $\$ 11$ & $\$ 201$ \\
\hline Amortization of $R \& D$ expenditures & $\$ 6$ & $\$ 120$ & $\$ 0$ & $\$ 0$ \\
\hline Global intangibles & $\$ 5$ & $\$ 49$ & $-\$ 22$ & $\$ 9$ \\
\hline Inbound investments & $\$ 27$ & $\$ 150$ & $\$ 17$ & $\$ 134$ \\
\hline Other & $\$ 23$ & $\$ 585$ & $\$ 23$ & $\$ 585$ \\
\hline Subtotal, corporate increases & $\$ 121$ & $\$ 1,456$ & $\$ 62$ & $\$ 1,206$ \\
\hline Total, corporate & $-\$ 50$ & $-\$ 330$ & $-\$ 134$ & $-\$ 677$ \\
\hline Grand total & $\$ 33$ & $-\$ 1,456$ & $-\$ 284$ & $-\$ 2,209$ \\
\hline
\end{tabular}

Sources: JCT (2017a); authors' calculations.

a. Units are billions of dollars. 
ACKNOWLED G M ENTS We thank our editor, James Stock, and our discussants, Kent Smetters and Karel Mertens, for helpful comments, and Wilson Powell III for outstanding research assistance. We thank the following people for helpful conversations, inputs, and comments: Alex Arnon, Mihir Desai, Emmanuel Farhi, John Fernald, Bill Gale, Scott Greenberg, Robert Hall, David Kamin, Cody Kallen, Stephanie Kestelman, Timur Kuran, Greg Leiserson, James Mackie III, Greg Mankiw, John McClelland, Casey Mulligan, Benjamin Page, Joseph Rosenberg, Stefanie Stantcheva, Larry Summers, Owen Zidar, and Eric Zwick. 


\section{References}

Altig, David, Alan J. Auerbach, Laurence J. Kotlikoff, Kent A. Smetters, and Jan Walliser. 2001. "Simulating Fundamental Tax Reform in the United States." American Economic Review 91, no. 3: 574-95.

Auerbach, Alan J., and Kevin Hassett. 1992. "Tax Policy and Business Fixed Investment in the United States." Journal of Public Economics 47, no. 2: 141-70.

Barro, Josh. 2012. "The Problem with Dynamic Scoring.” Forbes, April 14.

Barro, Robert J. 1974. “Are Government Bonds Net Wealth?” Journal of Political Economy 82, no. 6: 1095-117.

1979. "On the Determination of the Public Debt." Journal of Political Economy 87, no. 5: 940-71.

_. 2006. "Rare Disasters and Asset Markets in the Twentieth Century." Quarterly Journal of Economics 121, no. 3: 823-66.

- 2015. "Convergence and Modernisation." Economic Journal 125, no. 585 : 911-42.

Barro, Robert J., Michael J. Boskin, John Cogan, Douglas Holtz-Eakin, Glenn Hubbard, Lawrence B. Lindsey, Harvey S. Rosen, George P. Shultz, and John B. Taylor. 2017. "How Tax Reform Will Lift the Economy." Wall Street Journal, November 26.

Barro, Robert J., and Charles J. Redlick. 2011. "Macroeconomic Effects from Government Purchases and Taxes." Quarterly Journal of Economics 126, no. 1: 51-102.

Barro, Robert J., and Xavier Sala-i-Martin. 1992. "Convergence.” Journal of Political Economy 100, no. 2: 223-51.

- 2004. "Growth Models with Consumer Optimization (the Ramsey Model).” In Economic Growth, 2nd ed. MIT Press.

Barro, Robert J., and José F. Ursúa. 2008. "Macroeconomic Crises since 1970." Brookings Papers on Economic Activity, Spring: 255-335.

Blanchard, Olivier J. 1985. "Debt, Deficits, and Finite Horizons." Journal of Political Economy 93, no. 2: 223-47.

Carroll, Robert, John Diamond, Craig Johnson, and James Mackie III. 2006. "A Summary of the Dynamic Analysis of the Tax Reform Options Prepared for the President's Advisory Panel on Federal Tax Reform." Washington: U.S. Department of the Treasury, Office of Tax Analysis. https://www.treasury.gov/ resource-center/tax-policy/Documents/Report-Summary-Dynamic-Analysis2006.pdf

CBO (Congressional Budget Office). 2014. "Taxing Capital Income: Effective Marginal Tax Rates under 2014 Law and Selected Policy Options.” Washington. https://www.cbo.gov/publication/49817

_. 2017a. "The Budget and Economic Outlook: 2017 to 2027." Washington. https://www.cbo.gov/publication/52370 
. 2017b. "International Comparisons of Corporate Income Tax Rates." Washington. https://www.cbo.gov/publication/52419

. 2018. "The Budget and Economic Outlook: 2018 to 2028." Washington. https://www.cbo.gov/publication/53651

Council of Economic Advisers. 2017. "The Growth Effects of Corporate Tax Reform and Implications for Wages." Washington: White House.

Devereux, Michael P., and Rachel Griffith. 1998. "Taxes and the Location of Production: Evidence from a Panel of US Multinationals." Journal of Public Economics 68, no. 3: 335-67.

Duarte, Fernando, and Carlo Rosa. 2015. "The Equity Risk Premium: A Review of Models." Staff Report no. 714. Federal Reserve Bank of New York.

Égert, Balázs, and Peter Gal. 2017. "The Quantification of Structural Reforms in OECD Countries: A New Framework." OECD Journal: Economic Studies 2016: 91-108.

Elmendorf, Douglas W., Jason Furman, William G. Gale, and Benjamin H. Harris. 2008. "Distributional Effects of the 2001 and 2003 Tax Cuts: How Do Financing and Behavioral Responses Matter?" National Tax Journal 61, no. 3: 365-80.

Engen, Eric M., and R. Glenn Hubbard. 2005. "Federal Government Debt and Interest Rates." NBER Macroeconomics Annual 19: 83-160.

Fernald, John G. 2014. "A Quarterly, Utilization-Adjusted Series on Total Factor Productivity." Working Paper no. 2012-19. Federal Reserve Bank of San Francisco.

Furman, Jason. 2016. "Dynamic Analysis, Welfare, and Implications for Tax Reform." Remarks given at the Tax Policy and the Economy Conference, National Bureau of Economic Research, Washington, September 22.

Gale, William G., and Peter R. Orszag. 2004. "Budget Deficits, National Saving, and Interest Rates." Brookings Papers on Economic Activity, no. 2: 101-210.

Goolsbee, Austan. 1998. "Taxes, Organizational Form, and the Deadweight Loss of the Corporate Income Tax." Journal of Public Economics 69, no. 1: $143-52$.

Guvenen, Faith, Raymond J. Mataloni Jr., Dylan G. Rassier, and Kim J. Ruhl. 2017. "Offshore Profit Shifting and Domestic Productivity Measurement." Working Paper no. 23324. Cambridge, Mass.: National Bureau of Economic Research.

Hall, Robert E., and Dale W. Jorgenson. 1967. "Tax Policy and Investment Behavior." American Economic Review 57, no. 3: 391-414.

Hassett, Kevin A., and R. Glenn Hubbard. 2002. "Tax Policy and Business Investment." In Handbook of Public Economics, Vol. 3, edited by Alan J. Auerbach and Martin Feldstein. Amsterdam: North-Holland.

Huang, Chye-Ching. 2013. "Budget Deal Makes Permanent 82 Percent of President Bush's Tax Cuts." Washington: Center on Budget and Policy Priorities.

Huntley, Jonathan. 2014. "The Long-Run Effects of Federal Budget Deficits on National Saving and Private Domestic Investment." Working Paper no. 2014-02. Washington: Congressional Budget Office. 
JCT (Joint Committee on Taxation). 2017a. "Estimated Budget Effects of the Conference Agreement for H.R. 1, the 'Tax Cuts and Jobs Act."' Report no. JCX67-17. Washington. https://www.jct.gov/publications.html?func=fileinfo\&id=5053

. 2017b. "Macroeconomic Analysis of the Conference Agreement for H.R. 1, the "Tax Cuts and Jobs Act."' Report no. JCX-69-17. Washington. https://www.jct.gov/publications.html?func=fileinfo\&id=5055

Kamin, David, David Gamage, Ari D. Glogower, Rebecca M. Kysar, Darien Shanske, Reuven S. Avi-Yonah, Lily L. Batchelder, J. Clifton Fleming, Daniel Jacob Hemel, Mitchell Kane, David S. Miller, Daniel Shaviro, and Manoj Viswanathan. 2017. "The Games They Will Play: Tax Games, Roadblocks, and Glitches Under the New Legislation." Working paper. https:// ssrn.com/abstract=3084187

Karabarbounis, Loukas, and Brent Neiman. 2014. "The Global Decline of the Labor Share." Quarterly Journal of Economics 129, no. 1: 61-103.

Keynes, John Maynard. 1936. The General Theory of Employment, Interest and Money. London: Macmillan.

King, Mervyn A., and Don Fullerton. 1984. "The Theoretical Framework." In The Taxation of Income from Capital: A Comparative Study of the United States, the United Kingdom, Sweden, and West Germany, edited by Mervyn A. King and Don Fullerton. University of Chicago Press.

Kraus, Alan, and Robert H. Litzenberger. 1973. "A State-Preference Model of Optimal Financial Leverage.” Journal of Finance 28, no. 4: 911-22.

Kuran, Timur. 2004. "Why the Middle East Is Economically Underdeveloped: Historical Mechanisms of Institutional Stagnation." Journal of Economic Perspectives 18, no. 3: 71-90.

Laubach, Thomas. 2009. "New Evidence on the Interest Rate Effects of Budget Deficits and Debt." Journal of the European Economic Association 7, no. 4: 858-85.

Leland, Hayne E. 1994. "Corporate Debt Value, Bond Covenants, and Optimal Capital Structure.” Journal of Finance 49, no. 4: 1213-52.

Lucas, Robert E., Jr. 1976. "Econometric Policy Evaluation: A Critique." CarnegieRochester Conference Series on Public Policy 1, no. 1: 19-46.

Mackie-Mason, Jeffrey K., and Roger H. Gordon. 1997. "How Much Do Taxes Discourage Incorporation?" Journal of Finance 52, no. 2: 477-505.

Mathur, Aparna, and Cody Kallen. 2017. "Business Tax Reform, Investment and GDP: Potential Impacts of the Tax Cuts and Jobs Act." Daily Tax Report, December 11. https://www.aei.org/wp-content/uploads/2017/12/12.11.17-MathurBusiness-Tax-Reform.pdf

Mertens, Karel. 2018. "The Near Term Growth Impact of the Tax Cut and Jobs Act." Working paper. https://karelmertenscom.files.wordpress.com/2018/02/ tcja_impact.pdf

Mertens, Karel, and José Luis Montiel Olea. 2018. "Marginal Tax Rates and Income: New Time Series Evidence.” Quarterly Journal of Economics 133, no. 4 . 
Mertens, Karel, and Morten O. Ravn. 2013. "The Dynamic Effects of Personal and Corporate Income Tax Changes in the United States." American Economic Review 103, no. 4: 1212-47.

Modigliani, Franco, and Merton H. Miller. 1958. "The Cost of Capital, Corporation Finance and the Theory of Investment." American Economic Review 48, no. 3: 261-97.

Mulvaney, Mick. 2018. "The President's Fiscal Year 2019 Budget." Testimony before the Committee on the Budget, U.S. House of Representatives, February 14.

Myers, Stewart C. 1984. "The Capital Structure Puzzle.” Journal of Finance 39, no. 3: 575-92.

Office of Management and Budget. 2018a. "Budget of the U.S. Government: Analytical Perspectives, Fiscal Year 2019." Washington: U.S. Government Publishing Office. https://www.gpo.gov/fdsys/pkg/BUDGET-2019-PER/pdf/ BUDGET-2019-PER.pdf

2018b. "Budget of the U.S. Government, Fiscal Year 2019." Washington: U.S. Government Publishing Office. https://www.gpo.gov/fdsys/pkg/BUDGET2019-BUD/pdf/BUDGET-2019-BUD.pdf

Office of Tax Analysis. 2014. "Effective Tax Rate Model." Washington: U.S. Department of the Treasury. https://www.treasury.gov/resource-center/taxpolicy/tax-analysis/Documents/New-Investment-Rates-Methodology.pdf

2016. "Research and Experimentation (R\&E) Credit." Washington: U.S. Department of the Treasury. https://www.treasury.gov/resource-center/taxpolicy/tax-analysis/Documents/RE-Credit.pdf

Page, Benjamin R., Joseph Rosenberg, James R. Nunns, Jeffrey Rohaly, and Daniel Berger. 2017. "Macroeconomic Analysis of the Tax Cuts and Jobs Act." Washington: Urban-Brookings Tax Policy Center.

Pearce, James. 2015. "Measuring Aggregate Business Income with Tax Data." National Tax Journal 68, no. 4: 1025-46.

Penn Wharton Budget Model. 2017. "The Tax Cuts and Jobs Act, as Reported by Conference Committee (12/15/17): Static and Dynamic Effects on the Budget and the Economy." Philadelphia: University of Pennsylvania, Wharton School.

Prisinzano, Richard, and James Pearce. 2018. "Tax Based Switching of Business Income." Working Paper no. 2018-2. Philadelphia: University of Pennsylvania, Wharton School, Penn Wharton Budget Model.

Rietz, Thomas A. 1988. “The Equity Risk Premium: A Solution.” Journal of Monetary Economics 22, no. 1: 117-31.

Romer, Christina D., and David H. Romer. 2010. "The Macroeconomic Effects of Tax Changes: Estimates Based on a New Measure of Fiscal Shocks." American Economic Review 100, no. 3: 763-801.

Smith, Matthew, Danny Yagan, Owen Zidar, and Eric Zwick. 2017. "Capitalists in the Twenty-First Century." Working paper. https://eml.berkeley.edu/ yagan/ Capitalists.pdf 
Summers, Lawrence H. 1987. "Investment Incentives and the Discounting of Depreciation Allowances." In The Effects of Taxation on Capital Accumulation, edited by Martin Feldstein. University of Chicago Press.

Tax Foundation. 2017. "Preliminary Details and Analysis of the Tax Cuts and Jobs Act." Special Report no. 241. Washington.

Zidar, Owen M. Forthcoming. "Tax Cuts for Whom? Heterogeneous Effects of Income Tax Changes on Growth and Employment." Journal of Political Economy. 


\section{Comments and Discussion}

\section{COMMENT BY}

KAREL MERTENS ${ }^{1}$ The 2017 tax law is the most significant reform of individual and business income taxation in decades, and will be a topic of study for years to come. In their paper, Robert Barro and Jason Furman lay the groundwork with a quantitative analysis of the long-run impact on economic activity through the lens of neoclassical growth theory and a careful calibration of the user cost effects of the law. Their empirical exercise appears straightforward, but it quickly raises difficult questions with important quantitative implications: What is the appropriate discount rate for firms? Will the temporary provisions in the law be extended, and what are agents' expectations? How will the government balance the intertemporal budget, and will there be crowding out? To what extent will production shift from pass-through entities to corporations, and how does this affect productivity? After tackling all these issues, Barro and Furman calculate that GDP will rise by 0.4 percent after 10 years under the law as written, and by 1.2 percent if all the law's provisions are eventually made permanent.

The neoclassical modeling approach is tractable and transparent, and it may well capture most of the relevant tax incentive effects on capital formation. It remains at the core of many of the structural macroeconomic models used for evaluating tax policy reforms. Barro and Furman discuss the key sensitivities to modeling assumptions, and point to several features that are missing from the basic framework, such as the extensive margin effects of the reduction in the corporate tax rate due to the lumpy nature

1. The views expressed in this comment are those of the author and do not necessarily reflect the views of the Federal Reserve Bank of Dallas or the Federal Reserve System. 
of many investment decisions, the possible effects on total factor productivity as a result of the changed incentives for investment in research and development, or the impact on foreign direct investment flows and international tax competition. Given these limitations, there clearly remains considerable uncertainty about the estimates of the long-term effects of the 2017 tax reform.

Although the focus is primarily on the long run, Barro and Furman also calculate the short-term effects of the business tax reform using estimated convergence rates toward the postreform steady state. A full analysis of the short-run dynamics would require additional detailed assumptions about expectations of future tax rates, the monetary policy response, and the like. Guided by the existing reduced-form evidence on the effects of changes in individual marginal rates, Barro and Furman conclude that the short-term effects of the corporate tax cut will be dwarfed by an increase of 0.9 percentage point in annual GDP growth for 2018-19. The personal tax cuts, which are currently set to expire in 2025 , are more important than the corporate cuts for the overall debt impact of the law, and their impact may play a role in determining future political outcomes. In this sense, they may also matter in the longer run.

Barro and Furman rely on empirical studies by Barro and Charles Redlick (2011) and by Mertens and José Montiel Olea (2018) to assess the effects of the personal tax cuts. These studies are part of a broader body of empirical literature estimating the aggregate causal effects of tax changes. Much of this literature has deployed empirical tools originally developed to study monetary policy, but has adapted them in recent years to address the identification challenges associated with tax policy. Some of the findings have been used by policymakers to evaluate recent tax proposals (Council of Economic Advisers 2017). The remainder of this comment provides additional perspective on the possible GDP effects of the 2017 tax law based on the results from this literature. I describe the main reduced-form models, show how they may be used to make projections about the impact of the 2017 tax law, and discuss their interpretation and limitations. For brevity, details are omitted but can be found online (Mertens 2018), together with replication materials. ${ }^{2}$

2. The supplemental materials for this and all other papers in this volume may be found at the Brookings Papers web page, www.brookings.edu/bpea, under "Past BPEA Editions." Also see https://karelmertens.com/research. 
The object of interest is the causal effect $\gamma_{h}$ on GDP observed $h \geq 0$ years after a reform of size $\Delta \tau_{t}$ in period $t$, given by

$$
\Delta y_{t+h}=\gamma_{h} \Delta \tau_{t}+\Delta \bar{y}_{t+h},
$$

where $\Delta y_{t+h}$ is future output growth and $\Delta \bar{y}_{t+h}$ is counterfactual future output growth in the absence of the tax reform. In order to use equation 1 for outof-sample projections, the tax policy interventions $\Delta \tau_{t}$ in this equation are inputs that are measurable in advance. Also required are estimates of the dynamic causal effects $\gamma_{h}$ associated with these inputs. Such estimates are commonly obtained from structural macroeconomic models, but can also be obtained from regression-based models that avoid the need to make detailed assumptions.

Starting with Christina Romer and David Romer (2010), a growing number of studies have exploited historical tax reforms as quasi-experiments to identify the effects of tax changes on aggregate economic activity. ${ }^{3}$ Romer and Romer construct a time series, $\Delta \hat{\tau}_{t}$, containing revenue impact measures for all the major postwar tax reforms in the United States. Estimating $\gamma_{h}$ in equation 1 by regressing $\Delta y_{t+h}$ on $\Delta \hat{\tau}_{t}$ is, however, problematic because tax reforms are not random events. Important determinants of GDP growth, such as government spending and recessionary shocks, also influence tax policy. To avoid problems of simultaneity, Romer and Romer classify each of the tax reforms according to the primary motivation of policymakers, on the basis of a variety of historical sources. Next, they construct a series of exogenous tax reforms $\Delta \hat{\tau}_{t}^{\text {exo }}$, containing only those reforms classified as either ideological or as arising from long-term deficit concerns, while omitting interventions responding to the business cycle or short-term (and typically defense-related) government spending changes. The causal effects of tax reforms can be obtained as the least-squares estimates of $\delta_{h}$ in

$$
\Delta y_{t+h}=\delta_{h} \Delta \hat{\tau}_{t}^{e x o}+u_{t+h},
$$

where $u_{t+h}$ is a residual term. This approach is valid as long as the tax reforms retained in $\Delta \hat{\tau}_{t}^{\text {exo }}$ are indeed uncorrelated with the residual $u_{t+h}$,

3. The same approach has been used to study the effects of tax policy changes in the United Kingdom (Cloyne 2013; Cloyne and Surico 2017; Nguyen, Onnis, and Rossi 2017; Hussain and Liu 2018), Germany (Hayo and Uhl 2014), Canada (Lopes 2016; Hussain and Liu 2017), Spain (Gil and others, forthcoming), or multiple countries (Guajardo, Leigh, and Pescotori 2014; Riera-Crichton, Vegh, and Vuletin 2016). 
Table 1. Estimates of the Effects of the 2017 Tax Law on Real GDP Growth, 2018-20

Cumulative,

Effect on GDP growth (percentage points)

$2018 \quad 2019 \quad 2020$

2018-20

A. Based on tax multiplier estimates

Direct regressions

Romer and Romer (2010)

Favero and Giavazzi (2012)

$\begin{array}{rrr}1.34 & 0.83 & 0.57\end{array}$

2.74

Mertens and Ravn (2012)

$\begin{array}{lll}1.23 & -0.11 & -0.30\end{array}$

0.82

$\begin{array}{llll}1.31 & 1.17 & -1.08 & 1.39\end{array}$

Blanchard and Perotti (2002)

$\begin{array}{llll}0.93 & 0.30 & -0.18 & 1.05\end{array}$

Mertens and Ravn (2014)

$\begin{array}{llll}1.57 & -0.09 & -0.36 & 1.13\end{array}$

Caldara and Kamps (2017)

$\begin{array}{lll}0.86 & 0.06 & -0.15\end{array}$

0.77

$\begin{array}{llll}1.21 & 0.36 & -0.25 & 1.32\end{array}$

Average

B. By individual and corporate tax provisions

Mertens and Ravn (2013)

Individual tax reform

Business tax reform

International tax reform

Total

$\begin{array}{llll}0.87 & -0.25 & -0.12 & 0.51\end{array}$

$\begin{array}{rrrr}2.04 & 0.03 & -0.16 & 1.92\end{array}$

$\begin{array}{llll}-1.00 & -0.02 & 0.08 & -0.94\end{array}$

$\begin{array}{llll}1.79 & -0.21 & -0.19 & 1.39\end{array}$

C. Based on responses to individual marginal tax rates

Barro and Redlick (2011)

Average marginal tax rate

1.38

n.a.

n.a.

Mertens and Montiel Olea (2018)

Average marginal tax rate

$1.29 \quad 1.01 \quad 0.13$

2.44

Average marginal tax rate and average tax rate

1.38

$1.07-0.05$

2.39

D. Based on estimates allowing for income dependence Mertens and Montiel Olea (2018)

$\begin{array}{lllll}\text { Top } 1 \text { percent and bottom } 99 \text { percent average } & 0.54 & 1.06 & 1.45 & 3.04\end{array}$ marginal tax rates

Zidar (forthcoming)

$\begin{array}{lllll}\text { Top } 10 \text { percent and bottom } 90 \text { percent } & -0.77 & 1.70 & 0.62 & 1.55\end{array}$ incomes

Source: Author's calculations.

capturing all other determinants of output growth in $t+h$. In practice, the $\delta_{h} \mathrm{~s}$ can be estimated by separate regressions for every $h$, by a single regression for $h=0$ and additional lags of $\Delta \hat{\tau}_{t}^{e x o}$ as regressors, or by inverting the coefficients of a single regression for $h=0$ and lags of $\Delta y_{t}$ as additional regressors. The regressions may include other control variables, or they may be part of a system of dynamic equations with many other endogenous variables.

The first three rows of panel A in my table 1 present estimates of the GDP impact of the 2017 tax law for different variants of the direct 
regression approach given in equation 2 . The estimates are not based on the original series of Romer and Romer (2010) for $\Delta \hat{\tau}_{t}^{\text {exo }}$, but on an alternative version proposed by Mertens and Morten Ravn (2012) that omits tax changes with long implementation lags to avoid an additional source of bias. ${ }^{4}$ The models use postwar quarterly data, and the series for $\Delta \hat{\tau}_{t}^{\text {exo }}$ are static estimates of total revenue effects as a ratio of GDP in the previous quarters. The scaling by GDP means that the estimates of $\gamma_{h}$ have the familiar interpretation as tax multipliers. Because almost all provisions in the 2017 tax law become effective in the 2018 tax year, the act clearly fits into the category of reforms with short implementation lags included in Mertens and Ravn's (2012) version of $\Delta \hat{\tau}_{t}^{\text {exo }}$. The motivation for the 2017 law also seems predominantly ideological, such that it appears reasonable to make use of the estimated effects derived from the exogenous tax reforms of Romer and Romer (2010).

The projections in rows 1 through 3 of panel $\mathrm{A}$ in my table 1 are calculated by applying the estimated tax multipliers for each of the three models to a reduction in total tax revenues in the first quarter of 2018 equal to -1.1 percent of GDP, which is based on scoring by the Joint Committee on Taxation. The results in the first row are from the distributed lag specification given by Romer and Romer (2010). The results in the second row are from a multivariate vector autoregressive model that includes $\Delta \hat{\tau}_{t}^{e x o}$ as an exogenous regressor to each equation, following Carlo Favero and Francesco Giavazzi (2012). Finally, the third row shows results for the same vector autoregressive model but adds a distributed lag of $\Delta \hat{\tau}_{t}^{\text {exo }}$, following Mertens and Ravn (2012).

Each of the three direct regression approaches yields very similar projections for output growth in 2018, which is predicted to rise by about 1.3 percentage points. The models differ significantly, however, in dynamics after the first year. The Romer and Romer (2010) model shows a continued positive impact on GDP growth rates through 2019 and 2020, and a total cumulative increase of 2.74 percentage points by 2020 . The Favero and Giavazzi (2012) model, by contrast, shows a moderate reversal of GDP levels beyond 2018, and a much more modest cumulative threeyear growth impact of 0.82 percentage point. Finally, the Mertens and Ravn (2012) model yields a positive effect on GDP growth that persists in 2019,

4. Tax reforms often legislate tax changes that only become effective with a delay. Mertens and Ravn (2012) provide evidence for anticipation effects on economic activity of preannounced tax changes, which generally lead to a violation of the exogeneity requirements. 
a sharp reversal in 2020, and a cumulative three-year increase in GDP of 1.39 percentage points.

The other common approaches in the literature can be explained by considering a simple joint system for taxes and output:

$$
\begin{gathered}
\Delta y_{t+h}=\zeta_{h} \Delta T_{t}+e_{t+h}, \\
\Delta T_{t}=\theta \Delta y_{t}+\Delta \tau_{t} .
\end{gathered}
$$

Equation 3 relates future output growth to changes in observable measures of the burden of taxation $\Delta T_{t}$, such as tax revenues (Blanchard and Perotti 2002), average tax rates (Mertens and Ravn 2013), or average marginal tax rates (Barro and Redlick 2011). Equation 4 makes explicit that these tax measures are endogenous and vary not only because of occasional tax reforms but also because of changes in economic activity $\Delta y_{t}$. This is obvious when $T$ is tax revenues, but it is also true when using average or average marginal tax rates, for example, because of tax progressivity. Another reason that $T$ is endogenous is that tax policy interventions are also systematically related to $\Delta y_{t}$-for instance, by some policy rule. In this case, $\Delta y_{t}$ in equation 4 can be viewed as the unobserved residual in such a rule that is uncorrelated with $e_{t+h}$ for $h= \pm 0,1, \ldots$, and with the policy reaction coefficient absorbed in $\theta$. When $\theta=0$, least-squares estimates of $\zeta_{h}$ in equation 3 are not interpretable as the causal effect of tax changes because of simultaneity.

The literature has addressed this identification problem in three alternative ways. Olivier Blanchard and Roberto Perotti (2002) use an outside estimate of $\theta$ to back out $\Delta \tau_{t}$ as the residual in equation 3, and then use this residual as an instrument to estimate $\zeta_{h}$. Barro and Redlick (2011) and Mertens and Ravn (2014) instead use the Romer and Romer (2010) series $\Delta \hat{\tau}_{t}^{\text {exo }}$ as an instrument to estimate $\zeta_{h}$. Mertens and Ravn (2014) also use the resulting estimate of $\zeta_{h}$ to obtain $e_{t}$ and use it as an instrument to estimate $\theta$. Finally, Dario Caldara and Christophe Kamps (2017) use nontax instruments (for example, oil or monetary shocks) to estimate $\theta$, and then use the implied residuals given in equation 4 as an instrument to estimate $\zeta_{h}$. In practice, most studies embed the relationship between equations 3 and 4 in richer systems with dynamic terms and more endogenous variables than just output and taxes. The main reason is that the required identification assumptions become less stringent, and arguably only plausible, in these richer settings. 
Two complications arise when using parameter estimates from equations 3 and 4 for out-of-sample projections of the impact of tax reforms. Each of these complications becomes clearer after combining both equations to obtain

$$
\Delta y_{t+h}=\left(1-\zeta_{h} \theta\right)^{-1} \zeta_{h} \Delta \tau_{t}+\left(1-\zeta_{h} \theta\right)^{-1} e_{t+h} .
$$

The first difficulty stems from a key difference with the direct regression approach used in equation 2, which is that the indirect approaches treat $\Delta \tau_{t}$ as unobserved. Moreover, richer dynamic models identify $\Delta \tau_{t}$ as a macroeconomic shock-that is, as a surprise deviation in taxes from the prior period forecasts that are unrelated to any other structural source of forecast error, such as monetary policy, productivity, or financial market shocks. The tax shocks are only loosely related to historical tax reforms, which are all at least to some degree anticipated preceding enactment. In addition, sizable tax shocks may also occur when forecasted tax changes are not realized, and the series for $\Delta \hat{\tau}_{t}^{\text {exo }}$ may also more generally contain measurement error. Any of these concerns causes bias in a direct regression of equation 5 after replacing $\Delta \tau_{t}$ with $\Delta \hat{\tau}_{t}^{e x o}$. Although the indirect approaches, at least in principle, avoid these problems, one disadvantage is that the tax shocks measured by the residual in equation 4 are only identified in-sample. This means that, for the purpose of out-of-sample projections, an additional assumption is required regarding the size of the surprise tax shock induced by the 2017 tax reform.

Another, more minor, complication arises because of macroeconomic feedback on taxes. Typically, the focus in empirical work is on estimates of $\zeta_{h}$, which have the interpretation of the causal effects of a tax shock leading to a unit change in the measure of taxes of interest, $\Delta T_{t}$. With macroeconomic feedback $\theta \neq 0$, this differs from the effect of a unit change in $\Delta \tau_{t}{ }^{5}$ However, after establishing the size of the shock induced by the reform, it is the latter that is needed for projecting the GDP impact. Equation 5 shows that this projection requires knowledge of $\left(1-\zeta_{h} \theta\right)^{-1} \zeta_{h}$, and therefore not only of $\zeta_{h}$ but also of $\theta$. The distinction is almost automatically relevant, because if $\theta=0$, there would not be an identification problem to begin with. Empirically, it is the case that $\theta>0$ (higher output leads to higher taxes) and $\zeta_{h}<0$ (higher taxes lead to lower output), such that $\left(1-\zeta_{h} \theta\right)^{-1}<1 .^{6}$

5. The same distinction is also highlighted by Caldara and Kamps (2017).

6. In models with more endogenous variables, the effect usually goes in the same direction. 
In practice, the difference therefore leads to a reduction in the effects relative to those measured by $\zeta_{h}$.

Rows 4 through 6 in panel A of my table 1 report results for each of the three indirect approaches outlined above, as implemented within a structural vector autoregressive model. The estimates shown are for a tax shock that occurs in 2018:Q1 and equals the entire revenue impact of -1.1 percent of GDP. The implicit assumption is therefore that the prospects for the eventual tax reform had no influence on economic activity before 2017:Q4 . This assumption is perhaps questionable, because proposals with the basic contours of the reform were made well in advance. Conversely, the odds of passage in Congress as well as the extent of the cuts in individual taxes remained highly uncertain until very late in the legislative process. ${ }^{7}$ In any case, the projections in rows 4 through 6 can easily be adjusted to reflect alternative assumptions regarding the size of the tax surprise induced by the 2017 tax law.

Panel A in my table 1 shows that the Blanchard and Perotti (2002) and Caldara and Kamps (2017) identification approaches yield relatively similar projections for GDP growth, which is predicted to increase by about 0.9 percentage point in 2018. The projections of the Mertens and Ravn (2014) model, which uses the Romer and Romer (2010) exogenous reforms for identification, indicate GDP growth that is higher by 1.57 percentage points for 2018. All three models show relatively small effects beyond 2018, with a slightly more pronounced reversal in the Mertens and Ravn (2014) model. The projected cumulative effect on 2020 GDP levels ranges from 0.77 to 1.13 percentage points higher. The final row of panel $\mathrm{A}$ in my table 1 provides the simple average of the projections of all six tax multiplier models, which shows a growth impact of 1.21 and 0.36 percentage points in 2018 and 2019, respectively. The average of the projections suggests that in 2020 (and beyond), the 2017 act becomes a modest drag on economic growth.

The tax multiplier models discussed so far only consider the effects of changes in total tax revenues. The usefulness of the resulting projections depends on how similar the 2017 tax reform is in terms of the persistence and composition of the tax changes identified in the sample by the various models. In the postwar period, federal tax changes have typically either included sunsets or offsetting provisions, or else have been reversed by

7. Based on the Romer and Romer (2010) exogenous reforms with short implementation lags, Mertens and Ravn (2012) cannot reject the null hypothesis of no effects on GDP in quarters before enactment, which suggests that anticipation effects during the legislative process are limited. 
bracket creep or subsequent legislation. The revenue-to-GDP ratio, as a result, has remained fairly stable, and the projections in my table 1 implicitly assume a trajectory of future taxes that is correspondingly reverting to average levels. The many sunsets included in the 2017 act suggest that its enactment has generated historical typical expectations for future taxes, at least on the individual side. Important differences in the composition of tax changes relative to other reforms, however, may also matter for determining growth effects. The remainder of the estimates in my table 1 provide projections based on a number of additional models that account for different aspects of reforms.

One dimension in which the 2017 act differs substantially from most other postwar reforms is the magnitude of the business tax cuts. Panel B in my table 1 shows projections that are based on the baseline model of Mertens and Ravn (2013), which separately identifies the effects of changes in the personal and corporate provisions of the tax reforms. The identification approach is similar to that of Mertens and Ravn (2014), but makes use of separate instruments for the individual and corporate provisions of the exogenous tax reforms presented by Romer and Romer (2010). The identification allows for correlation between personal and corporate tax changes, and exploits heterogeneity in composition across U.S. postwar tax reforms to isolate the dynamic causal effects of each type of tax change. The model only indirectly identifies shocks to both average tax rates, and the projections in my table 1 use the numbers from the Joint Committee on Taxation's report to determine the size of the shocks. Specifically, the first (second) row shows the effects of an unexpected shock of -0.8 percent $(-7.4$ percent) in the average personal (corporate) tax rate in 2018:Q1. Assessing the effects of the international reform is particularly difficult, because it has no historical counterpart in the estimation sample. The projections in panel B for the international provisions, which are based on assuming an additional positive corporate tax shock of 3.6 percent in 2018:Q1, should therefore be interpreted with great caution. ${ }^{8}$ The last row in panel B of my table 1 shows the combined effect of all provisions implied by the estimates based on Mertens and Ravn (2014).

The main implication of accounting for the composition of the 2017 law in terms of the individual and corporate provisions is that the projection for 2018 GDP growth is noticeably larger, at an increase of 1.79 percentage points. The predicted three-year cumulative impact of 1.39 percentage

8. Since the expected revenue increases stem from the repatriation of income at lower rates than the prior statutory rate, it may even be considered to be a cut in taxes. 
points, conversely, is roughly similar to the average of projections in the tax multiplier models, which indicates a somewhat more pronounced reversal of GDP growth in 2019 and 2020. The projections suggest a relatively large, but short-lived, effect on growth as a result of the business tax reform. This reflects the fact that the corporate tax shocks discussed by Mertens and Ravn (2013) are identified largely by transitory changes in the after-tax cost of new investment that can create strong incentives for intertemporal substitution. ${ }^{9}$ Whether such incentives are currently at play depends on firms' expectations regarding future corporate tax rates and depreciation allowances. In any case, the results are not directly informative about the long-run impact of the reduction in the corporate tax rate, which is an important limitation relative to Barro and Furman's approach.

Another distinguishing feature of the 2017 law is the substantial cuts in marginal tax rates for individuals, at least in the short run. Panel $\mathrm{C}$ in my table 1 shows projections based on two studies that estimate the growth effects of changes in marginal tax rates, rather than revenues or average tax rates. These numbers are for the individual tax reform only, and do not incorporate the growth effects of the business and international tax reforms. Identification in both cases relies on using the exogenous tax reforms discussed by Romer and Romer (2010) to construct instruments for income-weighted average marginal tax rates (AMTRs). Barro and Redlick (2011) use Romer and Romer's original average tax rate series, whereas Mertens and Montiel Olea (2018) construct new instruments for changes in AMTRs. The estimate for Barro and Redlick's (2011) model in my table 1 is obtained by multiplying an AMTR cut of 2.75 percentage points with an estimated 0.5 percent two-year increase in GDP for every percentage point decrease in the AMTR. ${ }^{10}$ The remaining projections in panel $\mathrm{C}$ are obtained by assuming a shock to the overall AMTR of -2.75 percentage points. This number is calculated using the same methods as Mertens and Montiel Olea, and is higher than the cut of 2.30 percentage points assumed by Barro and Furman.

The first set of projections from Mertens and Montiel Olea uses a model that only identifies the effects of AMTR shocks. The second set of projections is based on a model that separately identifies the effects of

9. See Auerbach (1989) and House and Shapiro (2008) for theory and evidence.

10. Note that Barro and Redlick (2011) do not estimate the equivalent of $\theta$ from equations 3 and 4. Therefore, the estimate reported in my table 1 is in this case not adjusted for scale as discussed, and is instead based directly on the instrumental variables estimate of the slope coefficient $\zeta_{h}$. The results in my table 1 based on Mertens and Montiel Olea (2018) are adjusted to account for macroeconomic feedback effects. 
changes in marginal and average tax rates. The methodology in this case is analogous to that of Mertens and Ravn (2014), with distinct instruments for marginal and average tax rates, while accounting for the fact that both are correlated. Both sets of projections are roughly similar, and suggest a growth impact of about 1.30 percentage points in 2018, and an additional 1 percentage point of GDP growth in 2019. The cumulative three-year increase in real GDP is predicted to be about 2.4 percentage points. An estimate of the total growth impact of the 2017 tax law can in principle be obtained by adding the projections in panel $\mathrm{C}$ to those in the second and third rows of panel $\mathrm{B}$. The main conclusion is that taking into account the substantial cuts in marginal tax rates in the 2017 law suggests a larger impact on GDP growth than suggested by the tax multiplier models in panel A.

Most postwar changes to individual tax rates differ substantially by income level, with typically much larger changes in top statutory rates. The 2017 law differs in that it cuts tax rates more uniformly than is typically the case. Panel D in my table 1 shows results based on two studies that allow the aggregate effects of tax changes to depend on the distribution of tax changes by income level. Mertens and Montiel Olea (2018) separately identify the effects of shocks to average marginal tax rates for the top 1 percent and bottom 99 percent income groups, again by adopting the methodology used by Mertens and Ravn (2014), with distinct instruments for changes in AMTRs for both groups. The projections in the first row are based on a shock to the top 1 percent and bottom 99 percent AMTRs of -2.66 and -2.78 percentage points, respectively. Owen Zidar (forthcoming) instead follows a direct regression approach based on an extension of Romer and Romer's (2010) series that separates the revenue impact of tax changes affecting the top 10 percent and bottom 90 percent of the income distribution. The results in my table 1 use the estimates reported by Zidar and assume a 50/50 split between the top 10 percent and bottom 90 percent, as suggested in a distributional analysis by the Tax Policy Center (2017).

According to the results in panel D of my table 1, the main implication of accounting for the distributional aspects of the 2017 law is that the growth impact is more delayed, and occurs largely in 2019 and 2020 rather than 2018. Zidar's estimates even suggest a negative effect in 2018, although it is based on an estimate that is not statistically significant. By 2020, Mertens and Montiel Olea's model predicts a level of GDP that is higher by 3 percentage points, while Zidar's regressions suggest an increase in GDP by about half that amount. As for panel D, an estimate of 
the total growth impact of the 2017 tax law can be obtained by adding the projections in panel B for the corporate provisions.

The main advantage of the reduced-form approaches is that all the relevant channels through which taxes affect economic activity are in principle reflected in the model parameters, without the need for large numbers of detailed theoretical assumptions. Expectations of future tax rates can be particularly hard to verify, but are likely important in shaping the shortrun effects. Reduced-form models do not require explicit assumptions regarding the dynamics of expected future tax rates, which are instead part of the estimation. Recent methodological advances also make it possible to account for changes in multiple policy instruments. Conversely, the approach is valid only to the extent the reform is unexpected, exogenous, and reasonably similar to the historical variation and dynamics of tax policy that underlie the model estimates. For these reasons, it is better suited to assess the impact of the individual tax component of the 2017 tax law than the impact of the corporate and international tax components.

The main conclusion from the projections from the reduced-form models is that most specifications yield a sizable growth effect for 2018, and more modest effects afterward. The projections complement those available from structural models, and it should be noted that uncertainty in the underlying parameters means that the range of plausible outcomes typically remains wide. That being said, much progress has been made in monetary economics by combining reduced-form evidence and quantitative structural models, and there is no reason to believe that the same strategy cannot similarly advance the study of tax policy. In any case, in the absence of any major macroeconomic shocks, the trajectory of GDP over the next few years will be informative.

\section{REFERENCES FOR THE MERTENS COMMENT}

Auerbach, Alan J. 1989. "Tax Reform and Adjustment Costs: The Impact on Investment and Market Value." International Economic Review 30, no. 4: 939-62.

Barro, Robert J., and Charles J. Redlick. 2011. "Macroeconomic Effects from Government Purchases and Taxes." Quarterly Journal of Economics 126, no. 1: 51-102.

Blanchard, Olivier, and Roberto Perotti. 2002. “An Empirical Characterization of the Dynamic Effects of Changes in Government Spending and Taxes on Output." Quarterly Journal of Economics 117, no. 4: 1329-68.

Caldara, Dario, and Christophe Kamps. 2017. "The Analytics of SVARs: A Unified Framework to Measure Fiscal Multipliers." Review of Economic Studies 84, no. 3: 1015-40. 
Cloyne, James. 2013. "Discretionary Tax Changes and the Macroeconomy: New Narrative Evidence from the United Kingdom." American Economic Review 103, no. 4: 1507-28.

Cloyne, James S., and Paolo Surico. 2017. "Household Debt and the Dynamic Effects of Income Tax Changes." Review of Economic Studies 84, no. 1: 45-81.

Council of Economic Advisers. 2017. "The Growth Effects of Corporate Tax Reform and Implications for Wages." Washington: White House.

Favero, Carlo, and Francesco Giavazzi. 2012. "Measuring Tax Multipliers. The Narrative Method in Fiscal VARs." American Economic Journal: Economic Policy 4, no. 2: 69-94.

Gil, Paula, Francisco Martí, Richard Morris, Javier J. Pérez, and Roberto Ramos. Forthcoming. "The Output Effects of Tax Changes: Narrative Evidence from Spain." SERIEs.

Guajardo, Jaime, Daniel Leigh, and Andrea Pescatori. 2014. "Expansionary Austerity? International Evidence." Journal of the European Economic Association 12, no. 4: 949-68.

Hayo, Bernd, and Matthias Uhl. 2014. "The Macroeconomic Effects of Legislated Tax Changes in Germany." Oxford Economic Papers 66, no. 2: 397-418.

House, Christopher L., and Matthew D. Shapiro. 2008. "Temporary Investment Tax Incentives: Theory with Evidence from Bonus Depreciation." American Economic Review 98, no. 3: 737-68.

Hussain, Syed M., and Lin Liu. 2017. "Macroeconomic Effects of Government Spending Shocks: New Narrative Evidence from Canada." Working paper. https://sites.google.com/site/syedmhussain1984/research

_ 2018. "Comparing the Effects of Discretionary Tax Changes between the US and the UK." B. E. Journal of Macroeconomics 18, no. 1: article 20160041.

Lopes, José. 2016. "The Federal Tax Multiplier in Canada: A Narrative Approach." Job market paper, Cornell University. https://sites.google.com/a/cornell.edu/ josemariolopes/research

Mertens, Karel. 2018. "The Near Term Growth Impact of the Tax Cuts and Jobs Act.” Working Paper no. 1803. Federal Reserve Bank of Dallas.

Mertens, Karel, and José Luis Montiel Olea. 2018. "Marginal Tax Rates and Income: New Time Series Evidence." Quarterly Journal of Economics 133, no. 4.

Mertens, Karel, and Morten Ravn. 2012. "Empirical Evidence on the Aggregate Effects of Anticipated and Unanticipated US Tax Policy Shocks." American Economic Journal: Economic Policy 4, no. 2: 145-81.

- 2013. "The Dynamic Effects of Personal and Corporate Income Tax Changes in the United States.” American Economic Review 103, no. 4: 1212-47.

— 2014. "A Reconciliation of SVAR and Narrative Estimates of Tax Multipliers.” Journal of Monetary Economics 68, suppl.: S1-S19.

Nguyen, Anh D. M., Luisanna Onnis, and Raffaele Rossi. 2017. "The Macroeconomic Effects of Income and Consumption Tax Changes." Sheffield 
Economic Research Paper Series no. 2017008. Sheffield: University of Sheffield, Department of Economics.

Riera-Crichton, Daniel, Carlos A. Vegh, and Guillermo Vuletin. 2016. "Tax Multipliers: Pitfalls in Measurement and Identification." Journal of Monetary Economics 79: 30-48.

Romer, Christina D., and David H. Romer. 2010. "The Macroeconomic Effects of Tax Changes: Estimates Based on a New Measure of Fiscal Shocks." American Economic Review 100, no. 3: 763-801.

Tax Policy Center. 2017. "Distributional Analysis of the Conference Agreement for the Tax Cuts and Jobs Act." Washington.

Zidar, Owen. Forthcoming. "Tax Cuts for Whom? Heterogeneous Effects of Income Tax Changes on Growth and Employment." Journal of Political Economy.

\section{COMMENT BY}

KENT SMETTERS Congratulations to the editors for encouraging two distinguished economists on opposing sides of the recent tax debate to coauthor a paper on the topic. And, of course, especially hearty congratulations to the authors for actually doing it! This paper serves as a role model for future discussions of "hot" topics. Although the authors offer different conclusions, they also agree on a lot, which is also instructive for policymakers.

The Barro-Furman modeling is very elegant. The simplicity of the household side makes it easy for the authors to treat extensions to the firm side with rigor, including the debt/equity choice, multiple types of capital, and pass-through entities. They are careful in their calibration. ${ }^{1}$ The model is transparent, a rarity in Washington policymaking, especially during the recent tax debate.

WHY ARE THE GROWTH EFFECTS SO SMALL? The Barro-Furman model, along with its calibration strategy, strike me as fairly "progrowth" in nature: ${ }^{2}$ The base model is Barro-Ricardian (no debt effects, although later adjusted); the government's budget constraint is balanced using lump sum taxes; though prices are deterministic, the initial interest rate includes a risk premium that is being taxed before the tax cut (and with no tax loss offsets); labor supply is fixed (income effects tend to dominate substitution effects in the long run); the household sector is represented by a single, infinitely lived agent facing infinite long-run savings elasticity; and

1. The authors also avoid a common mistake where the estate tax is mixed into the effective tax rate.

2. The results reported by the Penn Wharton Budget Model for the 2017 tax law also assume a government closure rule that stabilizes the debt-to-GDP ratio in 2040 by reducing "wasteful" government spending. 
Table 1. Effective Corporate Tax Rates for All Industries, 2018-40

\begin{tabular}{lrrrr}
\hline Percentages & 2018 & 2023 & 2027 & 2040 \\
\hline Before the 2017 tax law & 21.18 & 23.53 & 22.95 & 21.93 \\
After the 2017 tax law & 9.16 & 17.33 & 18.88 & 16.06 \\
\hline
\end{tabular}

Source: PWBM (2017b).

a. The model incorporates incentives to reclassify and intertemporally shift book income.

Table 2. Several Major Provisions of the 2017 Tax Law That Have an Impact on Effective Tax Rates

\begin{tabular}{ll}
\hline Start year & Provision \\
\hline 2018 & Corporate tax rate drops to 21 percent \\
& Equipment and software expensing increases \\
& Bonus depreciation is extended and expanded \\
& Net interest deductions are limited \\
& Net operating loss deductions are limited \\
& Domestic production activities deduction is repealed \\
& Amortization is allowed for research and experimentation expenditures \\
& Rules change for net interest deduction limitations \\
2022 & Bonus depreciation extension and expansion phaseout begins \\
2026 & Bonus depreciation extension and expansion phaseout completes
\end{tabular}

Source: PWBM (2017b).

there is no international tax competition (allowing the value of $r^{k}$ in the model to remain fixed after the tax cut).

The most obvious question, therefore, is Why are the growth effects so apparently small on the corporate side? My table 1 summarizes a large part of the answer by reporting the output-weighted average effective tax rate (ETR) across U.S. corporate industries, between 2018 and 2040, both before and after the passage of the 2017 tax law.

Notice that the ETR falls sharply in 2018 after passage of the law but returns most of the way to its projected value from before the law by 2023 , and especially by 2027 . The reason can be found in my table 2, which includes a partial list of the numerous tax provisions-including some of their phaseouts-contained in the 2017 tax law used to generate the ETR values in my table 1 . Several provisions in 2018 substantially reduce the ETR, including bonus depreciation. However, within just five years, bonus depreciation starts phasing out. Moreover, "pay-for" provisions, such as the amortization of research and experimental expenditures, also raise the ETR.

Before the 2017 tax law, many capital investments would have been depreciated over the next decade. But since the law, depreciation is being accelerated through expensing. As a result, much of the short-run 
reduction in ETR values simply reflects a shift in the timing of depreciation allowances rather than a permanent reduction in the ETR, thereby creating only a small win for business in present value.

This timing shift also largely explains why the Joint Committee on Taxation (JCT), the government's leading tax experts and official tax scoring agency, priced the provisions in the "changes to the treatment of investment" category at just $\$ 86$ billion in lost revenue between 2018 and 2027. The Penn Wharton Budget Model (PWBM 2017a) priced it higher, at $\$ 180$ billion, the difference largely reflecting the PWBM's different modeling of income-shifting and reclassification. Still, by either measure, these provisions are cheap in comparison with the cost of, for example, permanent expensing. But permanence would have required a standard bill and 60 votes in the Senate.

The temporary reduction in the ETR also largely explains Barro and Furman's table 14, which appears to indicate a general agreement among different models pertaining to the 2017 tax law's growth effect. Some of the models listed in their table 14 are not publicly documented, so it is challenging to make a detailed comparison. Nonetheless, if the tax cuts were permanent, the Ramsey framework used by Barro and Furman would generally produce much larger long-run increases to GDP relative to reduced-form models or models with a fixed savings rate.

Of course, one reason for the bigger potential gain in the Ramsey model is its infinite long-run savings elasticity. But another reason is simply its ability, as a structural model, to consider novel tax changes. In contrast, nonstructural reduced-form or fixed-savings-rate models are generally calibrated to unrelated historical data and unrelated policy changes, which have been more muted. Put differently, the reason for the apparent model similarity in their table 14 is not because the different models are similar but because the 2017 tax law is not a particularly large reform.

THE ROLE OF DEBT The authors discuss the potential role of debt, with Furman believing that it plays a larger role in limiting growth through mitigating capital formation than does Barro. The authors nicely provide a robustness check, where more debt modestly increases the interest rate. Ultimately, the role of debt in the modeling exercise is an empirical question.

Empirically, estimates by Laurence Kotlikoff and Lawrence Summers $(1981,1988)$ indicate that almost 80 percent of wealth is transferred intergenerationally, with the other 20 percent being motivated by standard life cycle considerations, indicating a potentially large role for Ricardian equivalence. Franco Modigliani (1988) flips these percentages, arguing 
that the life cycle explains most wealth accumulation. The excellent review by William Gale and John Karl Scholz (1994) essentially splits the difference, noting challenges in data availability and definitions. All these estimates are based on aggregate wealth data.

Emanuela Cardia (1997) shows that many tests for Ricardian equivalence using aggregate consumption data have low power. Using micro data, however, Joseph Altonji, Fumio Hayashi, and Kotlikoff (1997) find that only $\$ 0.13$ of each $\$ 1$ redistributed from children to parents is rebated back to children.

John Laitner's (1992) excellent but often-overlooked paper-a model with the potential for earnings differences between generations along with a nonnegativity constraint on bequests-effectively reconciles the micro and macro evidence. In his model, a considerable amount of intergenerational transfers can be made, even though the marginal impact of an additional $\$ 1$ of debt behaves more like a traditional life cycle model, thereby crowding out capital formation.

Robust international capital flows, of course, can also mitigate the negative effects of debt on capital formation. Since 1990, the marginal foreign take-up of debt has averaged about 40 percent (PWBM 2016), which motivates the 40 percent open assumption in the PWBM's overlappinggenerations (OLG) model. However, U.S. debt is the ubiquitous safe asset throughout the world, serving, for example, as a reserve asset for foreign insurers. Foreign take-up of U.S. equity is much lower, consistent with the home bias puzzle (Feldstein and Horioka 1980; Obstfeld and Rogoff 2001).

However, what is probably the "scariest" problem associated with rising debt—foreign investors losing confidence (a bank run)—is not captured in modern, smooth tax models. ${ }^{3}$ Although these types of concerns

3. Both the Barro-Furman model and the PWBM use the "magic of the closure rule" to avoid this problem, by assuming that the government eventually does somethingeither using lump sum taxes (Barro-Furman) or reducing "wasteful" government spending (PWBM) - to generate intertemporal balance. Barro and Furman write that lump sum taxes could translate into policy terms through, for example, "reductions to Social Security or Medicare benefits or other government transfer programs." This statement reflects a Ricardian view where changes in pay-as-you-go spending do not have an impact on household saving. A more general justification, although maybe more conservative in ideology, is to associate their mechanism with reducing "wasteful" government spending that is economically neutral and does not enter the representative household's utility function. Nonstructural models do not require closure because they are not complete, instead relying on reduced-form rules. A very common mistake made by nonstructural models, however, is to confuse deficits with debt; it is the stock of debt that matters for the crowding out of capital formation. Moreover, because debt was on an increasing path even before the 2017 tax law, the marginal impact of new debt can have a nonlinear impact on capital formation in the OLG model, which will not be picked up with a simple empirical rule. 
are generally associated with emerging economies, Carmen Reinhart and Kenneth Rogoff (2015) show that even large, advanced economies are not robust to these problems.

RAMSEY VERSUS SAMUELSON AND DIAMOND The presence of infinite horizons in the Ramsey model with capital accumulation allows for the presence of only a single household (think Nietzsche's Übermensch ${ }^{4}$ ) to rule the economy. ${ }^{5}$ This modeling approach, however, produces several challenges.

First, modeling individual-side (nonbusiness) tax provisions is hard. With uninsurable income heterogeneity, identical average marginal tax rates at the household level can be achieved using a wide array of individual-side tax systems, ranging from completely flat to very progressive. However, the risk-sharing properties (relevant for welfare calculations) and precautionary savings (relevant for macro considerations in a second-best, Mirrleesian economy) differ significantly between these different tax designs (Nishiyama and Smetters 2005).

Second, the Ramsey model is often viewed as a long-run equilibrium model, as noted by the authors. As a result, it is often paired with shorterterm disequilibrium models, with the final model output reported as a linear combination across model results. The experts at the JCT, for example, report blended output from three models, with more weight shifting to the neoclassical model over time. The JCT uses very rounded weights to blend its models, presumably because the blend weights are very hard to estimate. Given the infrequent nature of major policy changesabout once every 30 years for major tax reforms (Auerbach and Smetters 2017) — it would likely require centuries of stationary data to estimate the right blend weights, especially because the blend weights should also be a function of the economy (for example, an output gap) and the actual policy experiment (à la the Lucas critique).

We can see the challenges of model blending in the Barro-Furman analysis when trying to bridge their Ramsey and reduced-form model

4. This Ramsey household should not be confused with the social planner common in, for example, Mirrleesian-style screening models. The Ramsey household acts in its own interest, whereas the social planner aggregates heterogeneous utilities according to some social rule (thereby, acting more akin to Kierkegaard's "knight of faith").

5. With multiple infinite-horizon households, the one with the smallest rate of time preference would accumulate all assets asymptotically. If all households have the same time preference, then the steady-state wealth distribution is no longer asymptotic. Uzawa (1968) attempts to solve this problem by allowing the rate of time preference to increase in wealth (for example, rich dynasties have spoiled children). In contrast, Barro and Furman, if anything, suggest the opposite direction, thereby implicitly rejecting this fix. 
output. If they stacked (summed) their GDP level effects between their Ramsey model and their reduced-form model based on that of Barro and Charles Redlick (2011), then the headline, 10th-year GDP that they report in their table 1 would be nearly four times larger- 1.55 percent instead of 0.4 percent. The implied annual growth rates would also be larger, and their corresponding dynamic revenue losses would be smaller. If they regard their two model results as unstacked, then they predict a larger GDP level effect by 2019 than by 2027, requiring a negative growth rate in the intervening years to connect the dots. These differences become even more dramatic if we consider their reduced-form model based on that of Karel Mertens and José Montiel Olea (2018), which produces even larger short-run gains than the Barro-Redlick model.

Ultimately, Barro and Furman choose to report their GDP levels and dynamic revenue losses on an unstacked basis. To be sure, this choice could be reasonable for the 2017 tax law, given its sunsets-although their reduced-form models do not distinguish between a temporary and permanent tax cut. Still, it is a highly subjective judgment that can, as just noted, produce very different final results. For example, even if one believes in large short-run responses (either due to Keynesian or supply-side effects), it is hard to provide an economic interpretation for why some of the initial level gains would have to be given back in subsequent years after a tax cut, especially for the provisions-permanent scenario with no sunsets. ${ }^{6}$

Third, intra- and intergenerational distributional analysis in the Ramsey model is difficult. For intragenerational analysis, simply grossing up all pretax wages from a static distribution by an identical factor misses important nonhomothetic factors, including capital income being much more concentrated than labor income. Intergenerational distributional analysis-generational accounting (Auerbach, Gokhale, and Kotlikoff 1994), or the closely related fiscal imbalances measure (Gokhale and Smetters 2003) —is made irrelevant by the Ricardian property.

For better or worse, distributional analysis is important in any tax reform debate. As a result, the Ramsey macroeconomic results would again need to be blended with distributional outcomes from a different model. Unfortunately, that "different model" is often very simple. In particular, as in

6. The Barro-Furman and Mertens-Montiel Olea reduced-form modeling only has an impact of two years, and therefore does not distinguish between their law-as-written and provisions-permanent scenarios. For their provisions-permanent scenario, the 10th-year GDP level gain is similar to the Barro-Redlick model value in 2019, although much less than their Mertens-Montiel Olea model. Even for the Barro-Redlick model, negative growth rates would be required before the 10th year in the unstacked scenario. 
the recent tax debate, the media usually reports distributional measures such as "the top 1 percent of income earners get X percent of the tax cut," despite the fact that this type of measure does not correspond to a meaningful change in the Mirrleesian after-tax, after-transfer income distribution.

Fourth, the Ramsey model requires infinite long-run savings elasticity. Besides infinity being a "big number," it is also unclear how to divide steady-state savings between foreign capital flows and the domestic Ramsey agent to, for example, distinguish between gross domestic product and gross national product.

All these problems vanish in the life cycle OLG frameworks of Paul Samuelson (1958) and Peter Diamond (1965). ${ }^{7}$ Although the OLG framework is also an equilibrium model, this point is misunderstood. In my view, all well-specified models are always in (transitional or steady-state) equilibrium. Rather, what people really mean by disequilibrium is whether the model can produce Keynesian effects_-for example, unemployment or output gaps.

However, substantial income heterogeneity can be captured in the OLG model, which can also produce Keynesian effects. Poorer households operate closer to their natural borrowing limit (the present value of their safe income that can be legally borrowed against—for example, not Social Security). Under the standard Inada utility condition, it takes the presence of just one reasonably large enough idiosyncratic shock (for example, unemployment risk) in the ergodic set to ensure little to no borrowing. Poorer households, therefore, endogenously have larger marginal propensities to consume, which can be matched against the empirical data. The OLG model can also be modified with search frictions and sticky nominal wages to capture unemployment and an output gap. The economy's openness can also be dialed as desired (for example, to capture the home bias puzzle), because the OLG model's saving elasticity is not infinite asymptotically.

My figure 1 shows the simulations from the PWBM's dynamic OLG model for the 2017 tax law under different initial interest rate assumptions (discussed below). For these purposes, convex adjustment costs (both domestic and international) are turned off, and other fairly "progrowth" assumptions à la Barro and Furman are made, including a closure rule that stabilizes the debt-to-GDP ratio starting in 2040 by reducing "wasteful" government spending.

7. The Congressional Budget Office, the JCT, and the PWBM use the OLG model, either in part or in full, as their main model. 
Figure 1. Projected Effects of the 2017 Tax Law on Macroeconomic Factors, 2016-40

GDP

Percent change

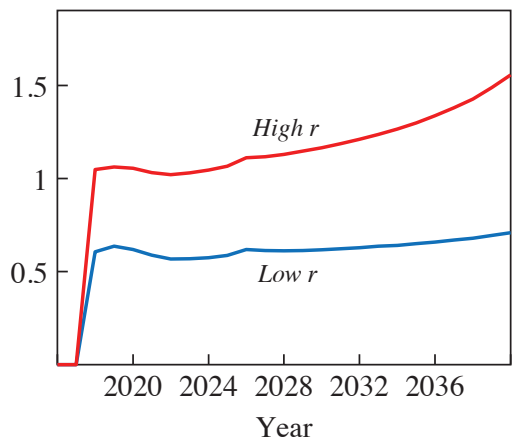

Hours worked

Percent change

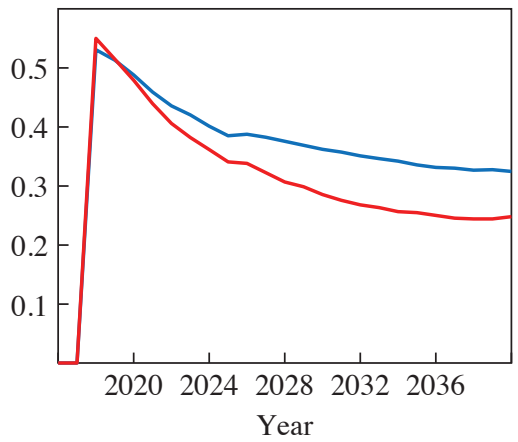

Capital services

Percent change

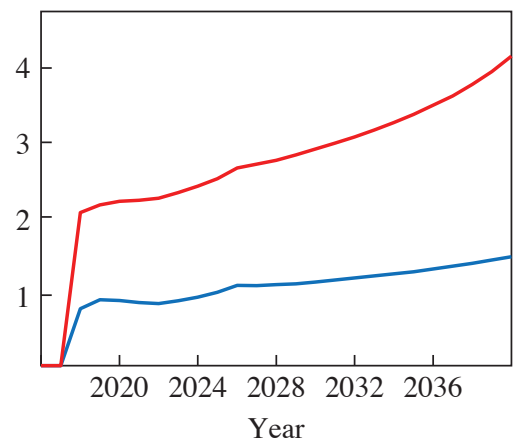

Federal tax revenue

Percent change

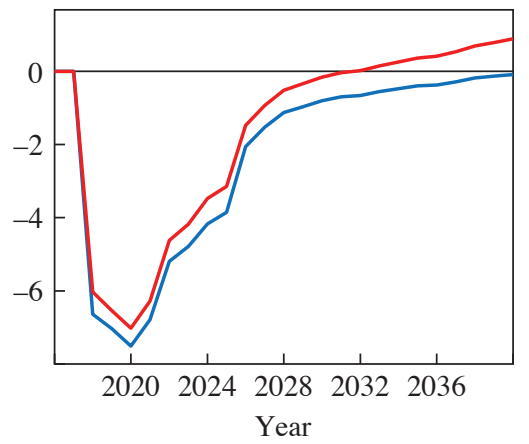

Federal debt

Percent change

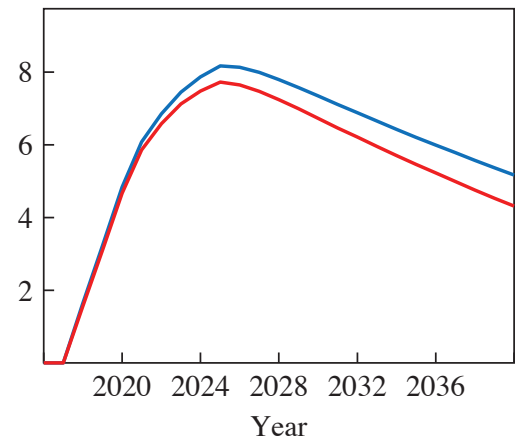

Source: PWBM. 
The combination of capital flows and household labor supply response produces short-run supply-side GDP results similar to Barro and Furman's reduced-form Barro-Redlick model. ${ }^{8}$ The Barro-Redlick model predicts that the individual-side tax provisions will raise GDP by 1.15 percent by 2019 , with no effect thereafter. If we then stack the individual-side effect onto the business-side effects that they report in their table 1, total GDP increases by 1.55 percent by 2027 without debt effects, and by 1.35 percent with debt effects. Using a similar initial interest rate assumption (the high- $r$ case), the PWBM's model value (with debt effects) is 1.06 percent by 2019 and 1.2 percent by 2027. Over the longer run, these values begin to diverge (1.6 percent for the PWBM by 2040, and 2.5 percent for Barro and Furman), mostly due to nonlinear debt effects in the OLG framework.

The OLG model also allows one to consider the short- and longrun effects of both individual-side and business-side tax reform within a single integrated model, thereby avoiding ad hoc model blending. The tighter integration of the individual and business sides naturally also supports income reclassification. And the OLG life cycle model can also capture intra- and intergenerational dynamic distributional analysis within the same framework, with more accuracy than simple distributional models. For example, Auerbach, Kotlikoff, and Darryl Koehler (2018) have recently shown that the 2017 tax law produces very little distributional impact once life cycle considerations are incorporated, in sharp contrast to the popular press's coverage of the law.

MODELING EXPECTATIONS As Barro and Furman note, dealing with expectations with the 2017 tax law is a bit tricky due to sunsets. Of course, an equilibrium with fully rational expectations would solve the political economy problem within the macroeconomic problem, thereby producing a single simulation. But taking a position on the political economy model (for example, a representative democracy or median voter) is challenging, so I agree with the authors' approach to consider two different options. Still, I think they cheat themselves a little bit in the law-as-written scenario by assuming consistent expectations.

To be sure, if the purpose of this exercise is to help government agencies dynamically score the 2017 tax law, then the simulations should correspond to the actual law, as written —otherwise, the budgeters are playing policymakers. However, it is still legitimate to ask whether economic

8. The 2017 tax law produces small Keynesian effects in the PWBM. Most of the shortrun effects were supply-driven. 
actors, when forming their expectations, will assume that the 2017 tax law will be extended, given the policy rhetoric. Toward this end, in my figure 1, the PWBM calculated two simulations where, when combined, sunsets arrived as a surprise on their sunset dates. This approach typically sets an upper bound of the possible macroeconomic gains relative to fully anticipated sunsets. Yet this approach incorporates arguably plausible expectations about tax extenders while still being consistent with the actual law. ${ }^{9}$ Consistently, the PWBM's analysis of the 2017 tax law generally falls between Barro and Furman's law-as-written and provisions-permanent scenarios.

STATIC IS STILL KING One of the main goals of dynamic scoring is to estimate the net amount of revenue losses from a tax cut that must be covered, potentially, by future generations. Economists enjoy dynamic models. However, for this purpose, static analysis is the key input into dynamic analysis, and is still king. During the process leading to the passage of the 2017 tax reform law, the Tax Foundation and the PWBM provided independent static analyses of the JCT's official calculations. The Tax Foundation and the JCT both priced the law similarly, at slightly less than $\$ 1.5$ trillion over the first decade. In contrast, the PWBM (2017a) priced it almost $\$ 500$ billion more. More recently, the Congressional Budget Office (2018) adjusted the JCT's static estimate upward by $\$ 400$ billion. In their analysis, Barro and Furman, however, start with the JCT's original static estimate and adjust it downward for dynamic effects, producing an ultimate dynamic score of just $\$ 1.2$ trillion.

The PWBM's (2017a) more pessimistic analysis stems, in part, from its different modeling of income-shifting and reclassification. Still, knowing what I know now (for example, about the growing ability of states to bypass state and local tax deduction limitations, and some new international tax reduction techniques), I believe that the PWBM's estimates are probably not pessimistic enough. Any dynamic score below $\$ 1.8$ trillion is, in my opinion, very unlikely to materialize over the next decade.

FUTURE WORK The choice of the initial interest rate in the standard neoclassical model without aggregate uncertainty plays a big role in predicting GDP gains, yet its correct calibration is theoretically ambiguous. I agree with Barro that discounting future risky corporate cash flows at the

9. At very high levels of depreciation with no convex adjustment costs, you could get a reversal in gains between the two cases due to intertemporal substitution. But that scenario is unlikely. 
risk-free rate makes little sense. At the same time, investors in the neoclassical model face no price risk (that is, there are no risky cash flows), so the usual justification for the presence of an equity premium in the model's initial interest rate is not present. Still, other parts of tax calibration are based on average values from a risky world. The core problem is that the real-world model generating the data includes aggregate uncertainty, which is necessary to generate risky cash flows, whereas the stylized neoclassical model does not. In other words, the real-world model has a higher dimension than the neoclassical model, making the calibration mapping challenging. Toward this end, the PWBM reported its results using a higher initial interest rate assumption (high $r$ ), similar to that of Barro and Furman, as well as using a lower interest rate assumption (low $r$ ). However, future research must tackle this problem directly by incorporating aggregate uncertainty into the model, thereby dealing with the well-known "curse of dimensionality" challenge for general equilibrium models.

The role of entrepreneurship, however, probably remains the biggest black hole in tax modeling. Entrepreneurs often risk substantially more personal wealth than could ever be recovered with future tax loss offsets, and entrepreneurs typically lose. Yet entrepreneurship is a primary driver of growth (and apparently of income inequality) in the United States. A successful entrepreneur generates economic rents, so the corporate tax rate now matters, even with full expensing. To the extent that these rents mostly reflect inefficient market power (for example, network effects), taxing these rents is likely efficient. But to the extent that these rents are required to induce risky investment (for example, patent protection for successful new drug development), taxing them is likely inefficient. To date, tax economists do not have many insights into this important topic.

\section{REFERENCES FOR THE SMETTERS COMMENT}

Altonji, Joseph G., Fumio Hayashi, and Laurence J. Kotlikoff. 1997. "Parental Altruism and Inter Vivos Transfers: Theory and Evidence." Journal of Political Economy 105, no. 6: 1121-66.

Auerbach, Alan J., Jagadeesh Gokhale, and Laurence J. Kotlikoff. 1994. "Generational Accounting: A Meaningful Way to Evaluate Fiscal Policy." Journal of Economic Perspectives 8, no. 1: 73-94.

Auerbach, Alan J., Laurence J. Kotlikoff, and Darryl Koehler. 2018. "The New Tax Bill: Winners and Losers." Working paper. https://www.kotlikoff.net/node/633

Auerbach, Alan J., and Kent Smetters, editors. 2017. The Economics of Tax Policy. Oxford University Press. 
Barro, Robert J., and Charles J. Redlick. 2011. "Macroeconomic Effects from Government Purchases and Taxes." Quarterly Journal of Economics 126, no. 1: 51-102.

Cardia, Emanuela. 1997. "Replicating Ricardian Equivalence Tests with Simulated Series." American Economic Review 87, no. 1: 65-79.

Congressional Budget Office. 2018. "The Budget and Economic Outlook: 2018 to 2028." Washington. https://www.cbo.gov/publication/53651

Diamond, Peter A. 1965. "National Debt in a Neoclassical Growth Model." American Economic Review 55, no. 5: 1126-50.

Feldstein, Martin, and Charles Horioka. 1980. "Domestic Saving and International Capital Flows.” Economic Journal 90, no. 358: 314-29.

Gale, William G., and John Karl Scholz. 1994. "Intergenerational Transfers and the Accumulation of Wealth." Journal of Economic Perspectives 8, no. 4: 145-60.

Gokhale, Jagadeesh, and Kent Smetters. 2003. "Fiscal and Generational Imbalances: New Budget Measures for New Budget Priorities.” Policy Discussion Paper no. 5. Federal Reserve Bank of Cleveland.

Kotlikoff, Laurence J., and Lawrence H. Summers. 1981. "The Role of Intergenerational Transfers in Aggregate Capital Accumulation." Journal of Political Economy 89, no. 4: 706-32.

- 1988. "The Contribution of Intergenerational Transfers to Total Wealth: A Reply." In Modelling the Accumulation and Distribution of Wealth, edited by Denis Kessler and André Masson. Clarendon Press.

Laitner, John. 1992. "Random Earnings Differences, Lifetime Liquidity Constraints, and Altruistic Intergenerational Transfers." Journal of Economic Theory 58, no. 2: 135-70.

Mertens, Karel, and José Luis Montiel Olea. 2018. "Marginal Tax Rates and Income: New Time Series Evidence." Quarterly Journal of Economics 133, no. 4.

Modigliani, Franco. 1988. "The Role of Intergenerational Transfers and Life Cycle Saving in the Accumulation of Wealth." Journal of Economic Perspectives 2, no. 2: 52-40.

Nishiyama, Shinichi, and Kent Smetters. 2005. "Consumption Taxes and Economic Efficiency with Idiosyncratic Wage Shocks.” Journal of Political Economy 113, no. 5: 1088-115.

Obstfeld, Maurice, and Kenneth Rogoff. 2001. "The Six Major Puzzles in International Macroeconomics: Is There a Common Cause?" NBER Macroeconomics Annual 15: 339-412.

PWBM (Penn Wharton Budget Model). 2016. "Setting Behavioral Responses in PWBM's Dynamic Simulations." Philadelphia: University of Pennsylvania, Wharton School.

. 2017a. "The Tax Cuts and Jobs Act, as Reported by Conference Committee (12/15/17): Static and Dynamic Effects on the Budget and the Economy." Philadelphia: University of Pennsylvania, Wharton School. 
. 2017b. "The Tax Cuts and Jobs Act, as Reported by Conference Committee (12/15/17): Tax Effects by Industry.” Philadelphia: University of Pennsylvania, Wharton School.

Reinhart, Carmen M., and Kenneth S. Rogoff. 2015. "Financial and Sovereign Debt Crises: Some Lessons Learned and Those Forgotten." Journal of Banking and Financial Economics 2, no. 4: 5-17.

Samuelson, Paul A. 1958. "An Exact Consumption-Loan Model of Interest with or without the Social Contrivance of Money." Journal of Political Economy 66, no. 6: 467-82.

Uzawa, Hirofumi. 1968. "Time Preference, the Consumption Function, and Optimum Asset Holdings." In Value, Capital and Growth: Papers in Honour of Sir John Hicks. Edinburgh University Press.

GENERAL DISCUSSION Alan Blinder had three comments related to the authors' assumptions. The first was the assumption that the net deficit effect will be financed with lump sum taxes. How the net deficit effect will ultimately be financed is uncertain; but according to Blinder, we know with absolute certainty that it will not be financed with lump sum taxes. Instead, it will be financed with something distortionary. He suggested a cleaner assumption would be to finance the net deficit effect with something akin to the average amount of distortion in the tax system. But the assumption of no distortions, he argued, is "absolutely wrong."

Second, Blinder was concerned about the Ramsey framework's assumption that the long-run real interest rate is constant, equal to the timepreference rate. Under this assumption, the long run is in essence the "infinity run," which in turn is subject to a whole host of its own assumptions-for instance, that everyone's behavior is essentially the same. He argued that under any policy-relevant time horizon-such as a decade or two - there is an upward-sloping supply curve of capital. Thus, the real interest rate likely moves above the time-preference rate, all things remaining equal, implying a smaller effect on capital formation. Echoing discussant Kent Smetters, Blinder argued that the basic real rate for federal borrowing should be thought of as the risk-free rate; and because the risk-free rate has been falling for decades, he concluded that the authors' interest rate assumptions are biased.

Third, Blinder echoed the point made by Furman that when there is full expensing, the corporate tax rate is irrelevant; lowering it only creates windfall benefits. Although coupling full expensing with cutting the corporate tax rate does not create a bias regarding the magnitudes of the effect 
on the growth rate, in a way it creates a bias toward the attractiveness of the policies.

William Gale applauded the authors for a heroic effort on a difficult issue and thanked them for producing a helpful paper. He noted that the paper reinforces the notion that the tax cut does not pay for itself. "This paper is just another nail in that coffin, but a very sophisticated, wellresearched nail," he stated. However, Gale expressed concern that the authors may have overestimated the effects of the new tax law in the provisions-permanent scenario because of their choice for the prereform baseline, which assumes the temporary provisions in place before the 2017 tax law would have expired. To more accurately isolate the effects of the 2017 tax law in the provisions-permanent scenario, Gale argued that the authors should instead assume that expiring provisions are also made permanent in the baseline. This comparison would standardize assumptions about policymakers' behavior-namely, that they tend to extend temporary tax cuts-and would allow for a cleaner estimate of the impact of the 2017 tax law per se. In table 11, the authors estimate that extending prereform bonus depreciation rules would raise GDP by 0.3 percent after 10 years. Using this as the baseline, a more accurate estimate for the effect of the 2017 tax law on GDP in the provisions-permanent scenario would be 0.7 percent-from table 13 , the authors' estimate of a 1.0 percent increase in GDP after 10 years with crowding out, less the 0.3 percent that would have occurred if the prereform temporary provisions had been extended.

Olivier Blanchard expressed two points. First, he wondered if one should be worried about a fall in research and development, which is presumably linked to total factor productivity. But perhaps the magnitude of the effect is small enough that it can be ignored. Second, he questioned the validity of the Cobb-Douglas functional form assumption, which implies unit elasticity of the capital-output ratio with respect to the user cost. ${ }^{1}$ Blanchard noted that there is very little direct evidence on the long-run elasticity of capital with respect to the user cost. "We're taking on faith a fairly big part of the mechanism, and we might want to see whether there is any evidence that would support the assumption," he concluded.

John Haltiwanger turned the discussion toward the role of endogenous innovation and productivity, and in turn the role of entrepreneurs in that

1. The Cobb-Douglas functional form assumption dates back to a seminal paper by Dale Jorgenson. See Dale W. Jorgenson, "Capital Theory and Investment Behavior," American Economic Review 53, no. 2 (1963): 247-59. 
process. He noted that there is increasing empirical evidence among innovation-intensive sectors of the economy that start-ups and high-growth young businesses play a disproportionate role in accounting for productivity growth, innovation, and job creation, and that entrepreneurs at that stage are overwhelmingly pass-through entities. Therefore, it is not clear whether the tax cuts will have a large effect on innovation and productivity in that respect. A paper by Daron Acemoglu and others shows that subsidies to large, mature incumbents can have significant negative effects on innovation and productivity growth. ${ }^{2} \mathrm{He}$ suggested that the authors evaluate the new tax law in light of this finding.

Donald Marron endorsed the style of the paper and encouraged more authors to write in a way that brings people with different perspectives together. He criticized the type of policy analysis that happens "at the level of op-eds," which, he noted, tend not to be as precise or informed, and are not often collaborative. He asked the authors what indicators we should track in, say, five years' time to know which author's predictions are more correct. Most economists are comfortable with expectations of about 2 percent annual GDP growth, but the uncertainties are large compared to the differences in the present paper; so looking at top-level GDP growth is not likely to be what determines the most accurate estimates.

Robert Hall noted that the conversation thus far seemed to neglect a fact "embodied in the Bible of corporate finance": that the cost of capital is not the cost of funding. ${ }^{3}$ Rather, the cost of capital incorporates the risk of the investment, and thus should not be used as a funding rate. This may explain why so-called hurdle rates are much higher than interest rates. Therefore, it would seem that the authors implicitly do not consider the personal taxation of $\mathrm{C}$ corporations in their model. Furman responded that the model's assumption of an infinite supply of capital implies that the personal taxation of $\mathrm{C}$ corporations does not change and that marginal finance is tax-free. Hall dissented, but agreed to talk more with the authors at a later time. "You're taking a strong stand on a controversial issue in public finance," he stated.

Next, Hall believes that a point missing from the tax reform discussion, in general, is that the introduction of expensing of business taxation

2. Daron Acemoglu, Ufuk Akcigit, Harun Alp, Nicholas Bloom, and William R. Kerr, "Innovation, Reallocation and Growth," Working Paper no. 18993 (Cambridge, Mass.: National Bureau of Economic Research, 2017).

3. Richard A. Brealey, Stewart C. Myers, and Franklin Allen, Principles of Corporate Finance, 12th ed. (New York: McGraw-Hill Education, 2017). 
of investment creates a consumption tax. Additionally, there has been a movement toward a consumption tax at the individual level, in the form of tax deferral. To avoid providing an inefficient subsidy of capital formation, there should be either a consumption tax administered at the personal level - that is, no tax on saving — or a first-year tax right off, but not both. There seems to be equal enthusiasm for both movements, he noted.

Finally, on the assumption of an infinite elasticity of the supply of capital (advocated by Barro), Hall pointed to research by Greg Kaplan and Giovanni Violante that thoroughly examines the issues of heterogeneity. ${ }^{4}$ According to Hall, this work implies that Barro is "about two-thirds correct"; that is, about two-thirds of wealth is held under the conditions approximated by Barro's model. Therefore, he concluded, "We ought to take two-thirds of Barro's number, and one-third of Furman's number to get the truth."

Robert Gordon wondered if the authors' estimated growth rate for 2018 and 2019 of 0.9 percent was too high, a priori, given that the tax cuts amount to 0.75 percent of GDP. The implied tax multiplier of $0.9 \div 0.75=1.2$ seemed counterintuitive to him, given that research by Valerie Ramey, among others, implies that government spending multipliers are barely above $1 .{ }^{5}$ Alan Blinder and Mark Zandi estimated the corporate tax cut multiplier resulting from the American Recovery and Reinvestment Act to be roughly 0.3. ${ }^{6}$ Nonetheless, supposing that the stimulus from the tax reform will be 0.9 percent growth, as Barro and Furman suggest, the Bipartisan Budget Act of 2018 adds another $\$ 300$ billion of government spending, which is expected to add another 0.75 percent to growth, and also add to that an "unknown spillover" due to the one-third increase in the value of the stock market over the last two years, which is expected to raise consumption. Adding these stimuli to the steady observed GDP growth rate of 2 percent a year yields an implied demandside GDP growth rate of about 4 percent a year for 2018 and 2019.

4. Greg Kaplan and Giovanni L. Violante, "A Model of the Consumption Response to Fiscal Stimulus Payments," Econometrica 82, no. 4 (2014): 1199-239; Greg Kaplan, Giovanni L. Violante, and Justin Weidner, "The Wealthy Hand-to-Mouth," Brookings Papers on Economic Activity, Spring 2014: 77-138.

5. For a review of the literature, see Valerie A. Ramey, "Can Government Purchases Stimulate the Economy?" Journal of Economic Literature 49, no. 3 (2011): 673-85; see also Valerie A. Ramey and Sarah Zubairy, "Government Spending Multipliers in Good Times and in Bad: Evidence from US Historical Data," Journal of Political Economy 126, no. 2 (2018): 850-901.

6. Alan S. Blinder and Mark Zandi, "How the Great Recession Was Brought to an End," July 27, 2010, https://www.princeton.edu/ blinder/End-of-Great-Recession.pdf. 
Gordon wondered, with all this demand-side growth, from where will the counterbalancing supply-side growth come? He noted that hours of work have been growing at around 1.6 percent a year for the past seven years, but this growth of hours required a reduction in the unemployment rate of 0.8 per year. A continuing reduction in the unemployment rate of 0.8 per year implies an unemployment rate in early 2020 of 2.5 percent, which would be unprecedented. By definition, the remainder of supplyside growth must come from productivity. Although modest productivity growth is expected, due to the extra investment generated by the tax cuts, he wondered whether it was even remotely plausible to imagine a jump in productivity growth in the total economy from the 0.6 percent achieved in the last 7 years to above 2 percent a year in 2018-19, which would be required to balance the demand-side stimulus. If supply-side growth does not occur, inflation may rise and cut off some of the demand-side stimulus on real activity, he concluded.

Mark Mazur liked the paper, and thinks it reflects a growing consensus on the way to look at the effects of the 2017 tax reform. He expressed two minor quibbles. The first was related to the supposed efficiency gains due to businesses reorganizing as $\mathrm{C}$ corporations. The majority of the shift will involve S corporations and limited liability companies converting to C corporations, which effectively comes down to corporations "checking a box" to indicate they want to be taxed at the entity level, which Mazur argued should have no effect on efficiency. Second, he explained that, though international provisions are often portrayed as raising revenues over the 10-year budget period, most of the revenue is raised all at once, after a lump sum tax is levied on unrepatriated foreign earnings. Therefore, he thinks it is incorrect to treat the international provisions as having a revenue effect over an extended period.

Richard Cooper was reminded of the unfavorable comparison of U.S. corporate taxes with those of foreign countries during the debate leading up to the tax reform. He argued that the authors' model was sufficiently general, in that it should apply to the European countries as well as the United States. Thus, the effects of similar reforms in Europe should apply in the same way as in the authors' model. He hypothesized that this was not actually true, and suggested more testing was needed. Although European investment has been increasing, he suggested that this is because world demand is increasing, not because of European tax changes.

George Perry appreciated the paper's demonstration that the tax cuts will not pay for themselves. But while he understood the paper's attempt to avoid political judgments, he believes the analysis would be more useful 
if it addressed the fiscal gap that will undoubtedly emerge as a result of the new tax law. Without making predictions or judgments about the future political climate, such an analysis would add realism to the paper to point out that maintaining the present tax package would require large cuts in spending, and to note that the cuts would have to fall heavily on the middle and lower income groups that now benefit from federal transfer, health, and retirement programs.

Robert Barro was absent from the discussion due to illness, so N. Gregory Mankiw, "having been Robert's colleague for 30 years," took the opportunity to respond to some of the points raised on his behalf. On Blinder's point about future increases in distortionary taxes, Barro might have responded that government spending could be cut in the future to reduce the distortions. That is, there are two sides to the issuespending and taxes-and Barro likely views the lump sum assumption as a moderate compromise. On Gordon's point about the corporate tax multiplier, Barro might have argued that Gordon was relying on the textbook Keynesian model, in which tax multipliers have to be smaller than spending multipliers. Although Mankiw, the author of several of the most widely used economics textbooks, "may love the Keynesian textbook model," there is evidence that tax multipliers are actually bigger than spending multipliers. He pointed to research by Christina Romer and David Romer that suggests tax multipliers are much larger than spending multipliers, which does not fit the textbook Keynesian model. ${ }^{7}$ If anything, this speaks poorly of the Keynesian model, and suggests that incentives may play a more significant role.

Furman briefly responded to several of the questions raised. He agreed with Mankiw's rebuttal of Blinder's point about the efficiency cost of financing and distortionary taxes. Furman believes it does not make sense to assume that the efficiency cost of the financing will be the same as in the previous system; discretionary spending could be cut to offset the tax distortions. Further, a value-added tax would be a more efficient way to collect revenue.

The most significant misimpression Furman heard during the discussion involved the relative size of tax changes for businesses and individuals. He argued that it is appropriate to include pass-throughs with corporations,

7. Christina D. Romer and David H. Romer, "The Macroeconomic Effects of Tax Changes: Estimates Based on a New Measure of Fiscal Shocks," American Economic Review 100, no. 3 (2010): 763-801. 
as the authors modeled; it is also important to disregard issues of timing. In the case of the law as written, there is in essence no change to the individual side in the long run because the provisions expire after 2025, so the individual side is not that important in the grand scheme of things. Further, as a result of these expiring provisions and other complications arising from the use of the chained consumer price index, it is very difficult to precisely analyze the individual income tax changes.

Furman was enthused by Haltiwanger's points about the role of endogenous innovation and productivity. In looking at the advantages of corporate form, Furman admitted that he and Barro had considered only one side of the issue, and thought it would be interesting to look at the other side. On Marron's point about the medium-run indicators of the model's predictive success, Furman believes nothing in the macroeconomic data is going to confirm one way or the other which of the authors is correct in his predictions, because the predicted effects are very small compared with the amount of variation. Micro data may be useful to show which corporations were affected. He also agreed with Cooper that it would be interesting to apply the model to Europe.

On Blinder's point about the infinity run, Furman joked that "infinity is a long time from now, and we are quite explicit that we only get 40 percent of the way there in 10 years." He believes this assumption should allay some of the concerns about the issues inherent in assuming a long run of infinity.

Finally, Furman was intrigued by Smetters's comments about the discount rate, acknowledging that he and Barro did not thoroughly explore this issue in the paper. The authors treat depreciation allowances like a corporate bond, in which a certain payment is promised every year, implying a risk-free rate. However, it is conceivable that the discount rate could be a function of the tax system. For example, the final tax bill removed net operating loss carrybacks. Most economists would have preferred an improvement of net operating loss carrybacks - as was proposed in the House of Representatives' version. Perhaps, then, the removal of net operating loss carrybacks should be modeled as increasing the discount rate that one should use for depreciation allowances. It may be important to think about not just when write-offs will occur but also how to change the discount rate that is used for the write-offs. 